\title{
EXPLORING THE ROLE OF DEFORESTATION ON REGIONAL HYDROCLIMATE IN SOUTHEAST AFRICA: AN APPROACH FUSING MODELS AND DATA
}

by

Megan Maksimowicz

\author{
A thesis \\ submitted in partial fulfillment \\ of the requirements for the degree of \\ Master of Science in Hydrologic Sciences \\ Boise State University
}

August 2018 


\section{Megan Maksimowicz SOME RIGHTS RESERVED

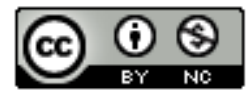

This work is licensed under a Creative Commons Attribution-Noncommercial 4.0 International License. 


\title{
BOISE STATE UNIVERSITY GRADUATE COLLEGE
}

\section{DEFENSE COMMITTEE AND FINAL READING APPROVALS}

\author{
of the thesis submitted by
}

Megan Maksimowicz

Thesis Title: Exploring the Role of Deforestation on Regional Hydroclimate in Southeast Africa: An Approach Fusing Models and Data

Date of Final Oral Examination: $\quad 03$ May 2018

The following individuals read and discussed the thesis submitted by student Megan Maksimowicz, and they evaluated her presentation and response to questions during the final oral examination. They found that the student passed the final oral examination.
Alejandro N. Flores, Ph.D.
Chair, Supervisory Committee
Jodi Brandt, Ph.D.
Member, Supervisory Committee
Nancy Glenn, Ph.D.
Member, Supervisory Committee
Matthew T. Masarik, Ph.D.
Member, Supervisory Committee

The final reading approval of the thesis was granted by Alejandro N. Flores, Ph.D., Chair of the Supervisory Committee. The thesis was approved by the Graduate College. 
To little Ruby and Grandma Josephine. 


\section{ACKNOWLEDGEMENTS}

This work would not have been possible without the collaboration of the Gorongosa National Park science team, Greg Carr, the National Center for Atmospheric Research- particularly for the use of the Yellowstone Supercomputer, the LEAF group, and of course my advisor and committee members. Special thanks are in order for the help from the Geoscience Department and all of my fellow graduate students that I received during this graduate school while brain injured journey. And last but not least, thanks to my family, my Peace Corps friends, and all of my closest friends- I could not have done it without your love and support. 


\begin{abstract}
Land cover acts as the gatekeeper to incoming and outgoing energy and water fluxes at the land surface, partitioning energy and water in accordance with the vegetation type and in response to atmospheric forcings. As Land Surface Models become more complex and more capable of simulating the coupled dynamics of the land-atmosphere system in greater spatial detail, the need for accurate representation of spatial distribution of vegetation types and their dynamics through time grows.

As humans modify land cover, there are complex dynamics at play between the vegetation, the surface energy balance and the cycling of water. The resultant hydroclimatic impacts of land cover change is dependent on local factors such as the local atmospheric forcings and the type of vegetation and land cover in question. Central Mozambique is a particularly useful setting to explore the impacts of changing land cover on climate because, since 2000 , the country's forests have been exploited by international corporations for timber extraction and conversion to agriculture. The region is of particular interest in the context of global climate dynamics and understanding landatmosphere exchange because the monsoonal seasonality ties the incoming oceanic moisture to the land cover. As such, Mozambique has a relatively high recycling rate, with up to $20 \%$ of the precipitation resulting from evapotranspiration from the same area. More locally, as Mozambicans rely heavily on dryland crops without the use of irrigation, the amount and distribution of local rainfall can have a much greater impact on local people than in an area where water is redistributed through mechanical means.
\end{abstract}


In order to examine the role of these vegetation changes in the redistribution of energy fluxes and resultant rainfall redistribution, we have conducted a suite of numerical experiments to investigate the impact of deforestation on regional land-atmosphere interactions. In particular, we represented deforestation in Central Mozambique by merging data gleaned from the Global Forest Cover Change dataset with the USGS land cover dataset used within the Weather Research and Forecasting (WRF) model.

In this study, we created a quasi-State and Transition model to alter the WRF model land cover input map. We used both numerical and spatial information from a regridded version of the Global Forest Cover Change Dataset. We then applied a combination of random selection and heuristic rules to these statistical information to determine how each pixel of the WRF land cover should be altered for our deforestation scenario. We then ran simulations with both the control WRF land cover and modified land cover within the WRF model to determine the difference in hydroclimatic variables. We selected the time periods of 2001 and 2015 (a wet and dry year, respectively), and the months of March - May (the dry down period after the rainy season) to show a spectrum of atmospheric conditions for forcing of the model runs.

Our results indicate that our methodology underestimates deforestation, though even these underestimates of deforestation result in impacts on the local hydroclimate within the WRF model scenarios. The overall impact is a general increase in temperature and a redistribution and decrease in rainfall due to changes in the energy and water balances. All of these outcomes are variable, though, due to spatial patterns of deforestation, topography, and weather patterns. These results demonstrate the need for better representation of deforestation within land-atmosphere modeling. 
TABLE OF CONTENTS

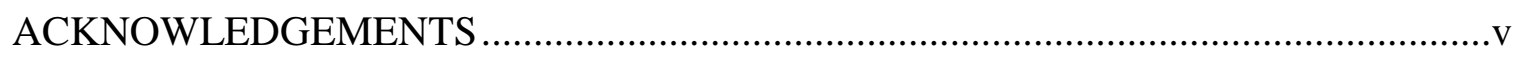

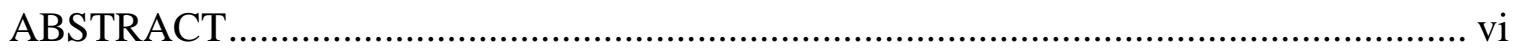

TABLE OF CONTENTS ..................................................................................... vii

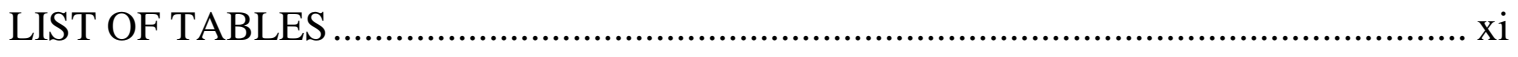

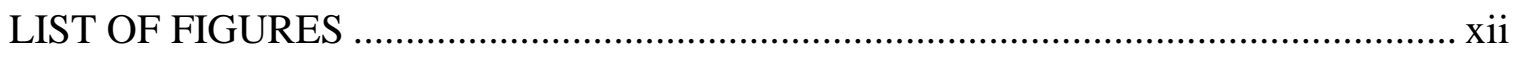

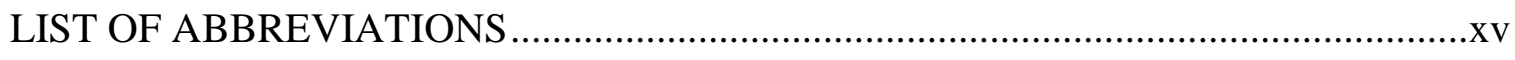

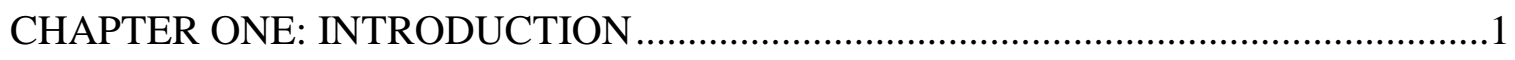

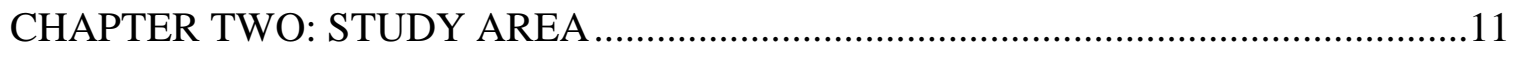

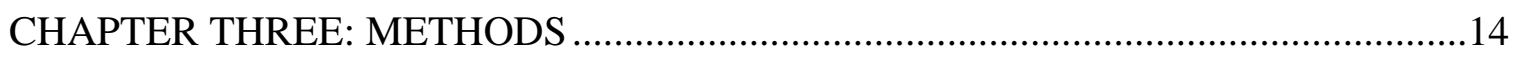

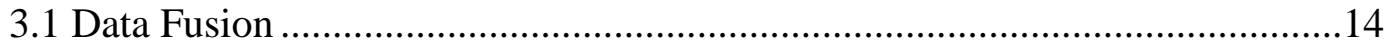

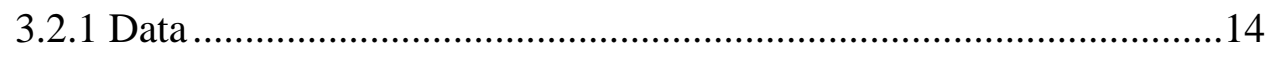

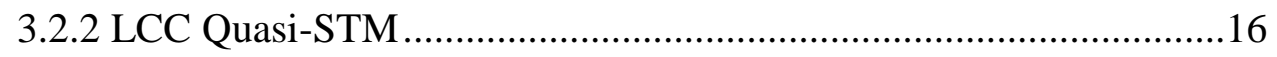

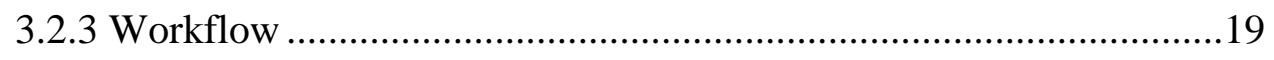

3.2.4 Areal Averaging .........................................................................19

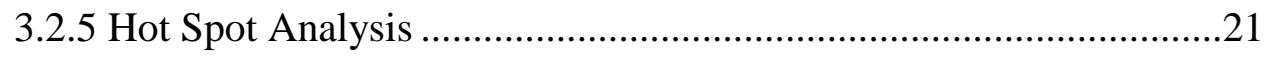

3.2.6 Statistics of Quartile Thresholds .....................................................22

3.2.7 Creating the Model Rules ..............................................................24

3.2.8 Random Selection of Land Cover Change Pixels ..............................27

3.2.9 Modified Land Cover Map .............................................................28 
3.2 Modeling Framework............................................................................. 31

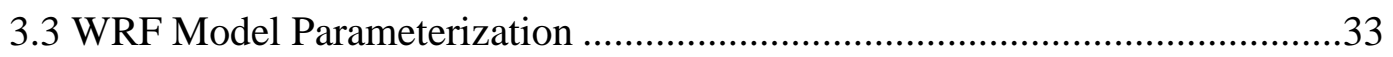

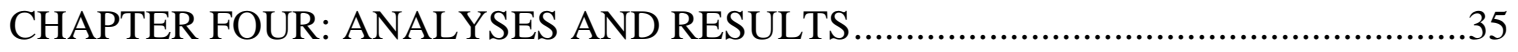

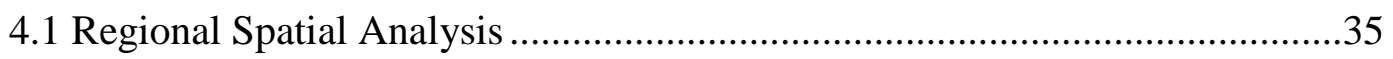

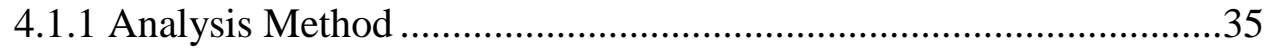

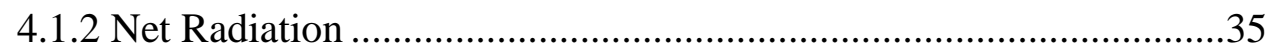

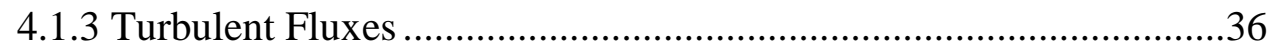

4.1.4 Cloud Cover ............................................................................. 38

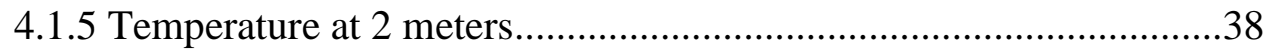

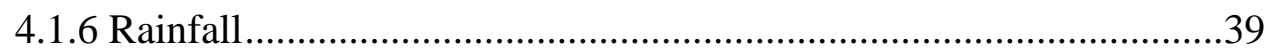

4.1.7 Table Summaries of Regional Analysis.....................................40

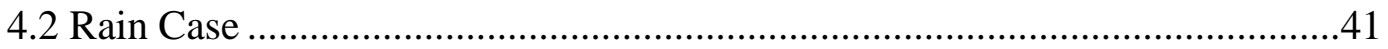

4.2.1 Spatial Patterns of Event .....................................................42

4.2.2 Locational Analysis Method ....................................................43

4.2.3 Locational Analysis Results.................................................45

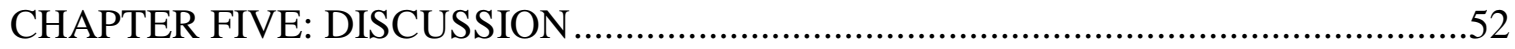

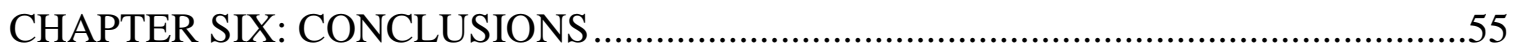

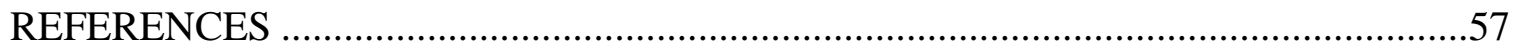

APPENDIX A: LOCATIONS OF MODEL OUTPUT AND PROCESSING SCRIPTS .63

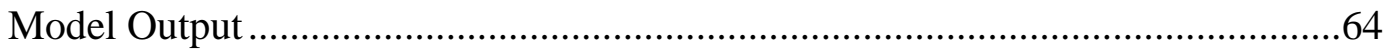

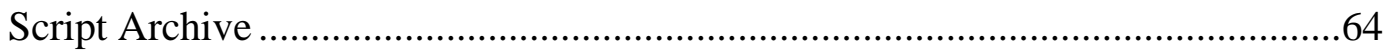

APPENDIX B: SUPPLEMENTAL FIGURES .....................................................65 


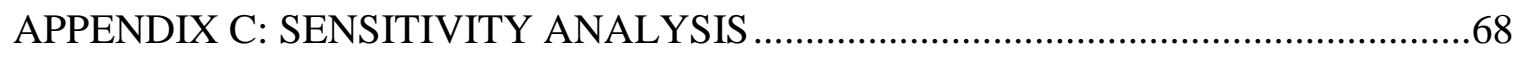

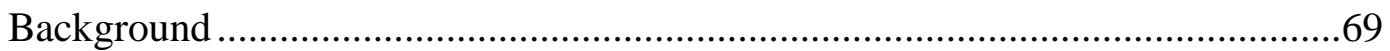

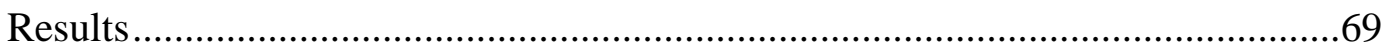

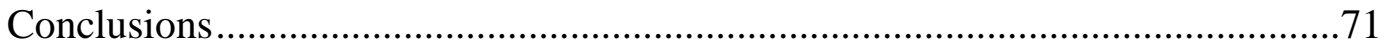




\section{LIST OF TABLES}

Table 1. Statistics determined from overlaying the regridded Hansen dataset on the WRF land cover. ............................................................................... 20

Table 2. Statistics applied to the WRF Land Cover within our model, after subtracting gain pixels from loss pixels........................................... 24

Table 3. Rules for defining "First State" of vegetation cover............................. 25

Table 4. $\quad$ Rules for transitioning each "First State" to its "New State." ................... 27

Table 5. Coverage for each land cover class in the WRF land cover. Each pixel is 1

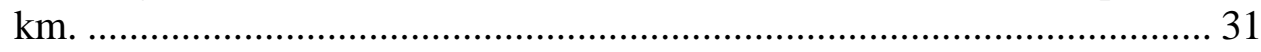

Table 6. Parameterizations selected to use in all WRF model scearnios................ 34

Table 7. Percent difference in each modeled parameter due to LCC. .................. 41

Table 8. Domain-wide accumulated rainfall depth for each month, in mm......... 41

Table 9. Monthly change in modeled accumulated rainfall due to LCC, in mm.... 41 


\section{LIST OF FIGURES}

Figure 1. Conceptual diagram of a precipitationshed, from Keys et al. (2012) ........ 8

Figure 2. Modified from Trenberth (1999). The recycling rate, $\rho$, for annual mean conditions for a length scale of $1000 \mathrm{~km}$ over land.

Figure 3. Model domains used in all analyses, with the African continent shown for reference.

Figure 4. Topographic map of analysis domain with boundaries of Gorongosa National Park shown.

Figure 5. WRF Land Cover for the study domain, with Gorongosa National Park outlined in black.

Figure 6. Hansen Forest Cover Dataset- tree cover percentage in green, loss in red, and gain in blue (Hansen et al., 2013).

Figure 7. Potential scenarios in examining a categegorical dataset along with a binary dataset. Here, an evergreen needleleaf forest pixel is classified as $>60 \%$ canopy cover. The same amount of loss in scenarios A and B could lead to different outcomes.

Figure 8. Workflow diagram of the steps for fusing the WRF and Hansen datasets 19

Figure 9. Conceptual models of areal averaging the binary Hansen dataset to the WRF grid. There are two separate datasets, represented here in blue for gain and red for loss.

Figure 10. Regridded Hansen dataset on the WRF grid, now with values ranging from 0 - 1 for each pixel. 21

Figure 11. "Hot spot" locations of loss and gain in the analysis area. Loss shown in red and gain shown in blue.

Figure 12. Cities of interest located in the domain........................................... 26

Figure 13. Randomly selected pixels within the loss hotspot areas, shown in purple. 
Figure 14. Modified WRF Land Cover, after applying our quasi-State and Transition

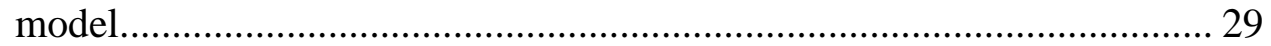

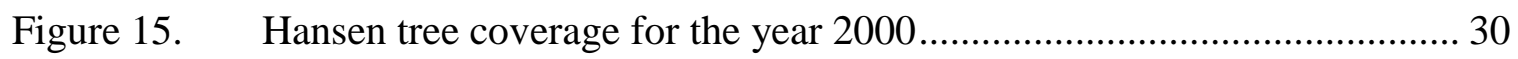

Figure 16. Percent of domain lost. Here, each tree coverage category from the year 2000 was considered individually, with all other tree coverage amounts masked.

Figure 17. Conceptual diagram of model input scenarios used in this study............ 32

Figure 18. Monthly change in modeled net radiation due to LCC, 2001.................. 36

Figure 19. Monthly change in modeled upward sensible heat flux at the surface (top panel) and upward latent heat flux at the surface (bottom panel), 2001, due to $\mathrm{LCC}$. 37

Figure 20. Monthly change in modeled cloud cover fraction due to LCC, 2001...... 38

Figure 21. Monthly change in modeled temperature due to LCC, 2001.................. 39

Figure 22. Monthly change in modeled accumulated rainfall, 2001, with LCC pixels shown in black. ............................................................................... 40

Figure 23. Difference in accumulated rainfall for the April 4 - 9 event, due to LCC.42

Figure 24. Difference in modeled cloud fraction for the April 4 - 9 rain event, due to

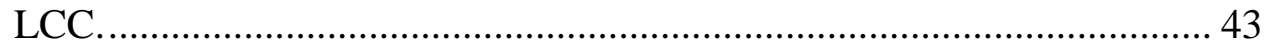

Figure 25. Here the domain and LCC pixels are shown. Surrounding the mountain are the boxes used for this analysis, expanding $10 \mathrm{~km}$ then $20 \mathrm{~km}$ on each side.

Figure 26. Probability density functions for outgoing longwave radiation. Control case in orange and modified case in indigo. $\tau$ values from left to right: $0.87,0.84,0.83$. All have a $p$-value of $<0.01$.

Figure 27. Probability density functions for incoming longwave radiation. Control case in orange and modified case in indigo. $\tau$ values from left to right: $0.93,0.96,0.95$. All have a $p$-value of $<0.01$.

Figure 28. Probability density functions for outgoing shortwave radiation. Control case in orange and modified case in indigo. $\tau$ values from left to right: $0.90,0.81,0.77$. All have a $\mathrm{p}$-value of $<0.01$. 
Figure 29. Probability density functions for incoming shortwave radiation. Control case in orange and modified case in indigo. $\tau$ values from left to right: $0.73,0.73,0.74$. All have a p-value of $<0.01$.

Figure 30. Probability density functions for upward sensible heat flux at the surface. Control case in orange and modified case in indigo. $\tau$ values from left to

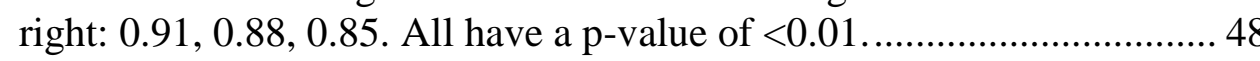

Figure 31. Probability density functions for upward sensible heat flux at the surface. Control case in orange and modified case in indigo. $\tau$ values from left to right: $0.94,0.93,0.93$. All have a p-value of $<0.01$.

Figure 32. Probability density functions for $2 \mathrm{~m}$ Temperature. Control case in orange and modified case in indigo. $\tau$ values from left to right: $0.96,0.94,0.93$. All have a $\mathrm{p}$-value of $<0.01$.

Figure 33. Probability density functions for accumulated rainfall. Control case in orange and modified case in indigo. $\tau$ values from left to right: $0.97,0.97$, 0.97. All have a p-value of $<0.01$. 51

Figure 34. Monthly change in modeled net radiation due to LCC, 2015................. 66

Figure 35. Monthly change in modeled upward sensible heat flux at the surface (top panel) and upward latent heat flux at the surface (bottom panel), 2015, due to LCC. 66

Figure 36. Monthly change in modeled cloud cover fraction due to LCC, 2015...... 67

Figure 37. Monthly change in modeled temperature at 2 meters due to LCC, 2015. 67

Figure 38. Monthly change in modeled accumulated rainfall, 2001, with LCC pixels shown in black.

Figure 39. Randomized land cover used in modified scenario for the sensitity analysis.

Figure 40. Time series data for specified variables for the whole domain. Control run in blue and randomized land cover run in green. 70

Figure 41. Domain-wide acumulated rainfall in $\mathrm{mm}$. Control run in blue and randomized land cover run in green. 


\section{LIST OF ABBREVIATIONS}

GCM

ITCZ

LCC

NRC

PDF

RCM

WRF
Global Climate Model

Intertropical Convergence Zone

Land Cover Change

National Research Council

Probability Density Function

Regional Climate Model

Weather Research and Forecasting 


\section{CHAPTER ONE: INTRODUCTION}

Land cover change (LCC) represents one piece of the climate change puzzle, and there are still uncertainties in how regional land cover change affects global climate, and vice versa. One issue that still remains for LCC in both regional and global climate modeling is the issue of scale. Empirical studies of tree cover and deforestation occur on the scale of meters and below, and can include detailed information such as leaf area index, height, exact locations of loss, number and types of species coexisting in one area, etc. Regional climate models (RCM), however, can exist on a scale from $\sim 30 \mathrm{~km}$ down to $1 \mathrm{~km}$, depending on computational resources available. While an RCM cannot incorporate all of the details from empirical studies, it has the advantage of being able to capture complexities of land-atmosphere interactions that allows the user to study larger scale relationships between LCC and resultant climatic changes. On the other end of the spectrum is a global climate model (GCM), with resolutions of down to $\sim 50$ to $25 \mathrm{~km}$. These GCMs, while having a simplistic representation of vegetation, can show global dynamics between vegetation and atmospheric patterns. Because of these differences in scale, examining the role of deforestation in land-atmosphere exchange becomes a balancing act between representing reality and being able to represent complex, largescale interactions. In our study area of Central Mozambique, Africa, there has been extensive deforestation due to an increase in demand for land rights for forest and agriculture. In the period of $2004-2009$, land use rights granted for these uses amounted to 2.5 million hectares, which is $3 \%$ of the land area (Hanlon, 2011). Extensive 
deforestation of this nature could potentially have large impacts on the hydrology and climate of a region. Therefore, our two objectives for this study were to:

1. Fuse a global forest cover dataset with the land cover in a regional model.

2. Run a suite of simulations in a regional climate model to examine the role of deforestation in land-atmosphere interactions.

In this way, we were able to update an existing land cover map within use in a regional climate model to more accurately represent spatial patterns of deforestation without creating a new land cover dataset from scratch. From these RCM model runs, we can determine both if LCC has an impact on local hydrology and climate, and at what scale these changes are important. In particular, in our study area of central Mozambique, Africa, the physical interactions between LCC, topography, and meteorology are all strongly connected. Therefore, we hypothesize that not only deforestation, but also the spatial patterns of deforestation (e.g., spatial contiguity) combined with local atmospheric patterns and topography are all key in determining hydroclimatic outcomes. To this end, we employed the Weather Research and Forecasting (WRF) model, a high-resolution (1 km scale) land-atmosphere model that resolves the physical interactions between LCC, topography, and meteorology. To update the WRF land cover, we utilized the Hansen Global Forest Cover Change Dataset (Hansen et al., 2013) to represent a more realistic deforestation scenario. This dataset, being global in scale, offers new opportunities to develop techniques to incorporate tree cover loss data into any land cover dataset that is already in use in regional and global climate models.

In the mid 2000s, scientists such as Pielke (2005) and Feddema et al. (2005) and the National Research Council (NRC) (2005) called for a better understanding in the role 
of land cover change within the context of climate modeling. In the intervening years, many scientists have performed sensitivity analyses to examine both the biophysical and biochemical effects of deforestation in GCMs. In a recent review paper by Perugini et al. (2017), the authors work to summarize the findings from these sensitivity analyses, along with a few observational studies. One key area that Perugini et al. (2017) notes as needing attention: the mismatch in scale and rates of deforestation and its representation within these GCM analyses. In this review, the majority of studies cited from the tropics rely on complete deforestation to determine general impacts of land cover change. While global climate model sensitivity analyses are able to capture the general regional effects of deforestation, there are still uncertainties in how these regional processes affect global circulation patterns. As Lee et al. (2011) point out, GCMs that use continentalscale land clearing show a feedback between land albedo and sea ice that is crucial in determining the global effects of land cover change. However, Lee et al. (2011) also state that we cannot be certain that this feedback would take place with a smaller scale of deforestation. As an NRC Report (2005) describes, regional energy balance perturbations can cause atmospheric teleconnections that affect the climate in region thousands of kilometers away. This NRC Report (2005) recommended understanding the magnitudes of regional energy balance change, which will in turn help us to understand the associated global climate responses. In 2010, Mahmood et al. specifically noted that LCC is a firstorder human climate forcing that must be assessed, particularly at the regional scale because it is these regional responses that produce droughts, floods, and other impacts that affect society the most. 
Furthermore, global land cover products typically used within both GCMs and RCMs show low accuracies when assessed (Broxton et al., 2014). Due to differences in class definitions, classification methods, satellite datasets used, etc., there are significant disagreements between global land cover products (Giri et al., 2005, Herold et al., 2008 and Broxton et al., 2014). Even when data from the same satellite sensor is used, there is significant interannual variability that is not consistent with the vegetation changes occurring on the ground (Friedl et al., 2010 and Broxton et al., 2014). For example, Broxton et al. (2014) found that within the MODIS Collection 5.1 Land Cover Type (MCD12Q1) data, 40\% of nonwater pixels undergo at least one change from 2001 to 2010, and that most of these are more than physically reasonable. Broxton et al. (2014) note that the reason for this high interannual variability is difficult to parse from the data itself, but is commonly attributed to the mixtures of vegetation classes within each pixel of satellite imagery (Latifovic and Olthof 2004, Smith et al., 2002, 2003, and Herold et al., 2008). Broxton et al. (2014) describe the problem with these mixtures of vegetation as satellite sensors being unable to unmix all of the spectral characteristics and phenologies located within each large pixel size.

In order to circumvent this variability between land cover datasets, we chose to select one land cover product already used within the WRF model, and to update it with deforestation patterns using the Global Forest Cover dataset from Hansen et al. (2013), referred to hereafter as the Hansen dataset. In this way, we were able to compare two internally consistent land cover datasets, where the only change occurring was deforestation. The Hansen dataset applies computational methods to global Landsat data at a resolution of $30 \mathrm{~m}$ to produce a comprehensive forest cover change dataset from the 
years 2000 to 2016. In this way, the Hansen dataset is created by uniformly processed Landsat data. By selecting this global dataset, applications of the methodologies presented here will be expandable all regions of the globe. The output of the Hansen dataset are percent forest cover from the year 2000, forest cover loss $(2000-2016)$ in binary ( 0 for no change, 1 for loss), and forest cover gain (2000 - 2012) in binary ( 0 for no change, 1 for gain), each available for every individual Landsat pixel over land. Hansen et al. (2010) define forest cover as at least $25 \%$ cover for trees of at least $5 \mathrm{~m}$ in height, citing the Australian Greenhouse Office report (2002) detailing the threshold of canopy density for accurate land cover change classification in Landsat. Forest cover loss is available at yearly time scales, whereas forest cover gain is only available for the whole time period of $2000-2012$. Therefore, net loss in forest cover must be considered in the aggregate scale, to incorporate both loss and gain together.

While there are advancements in both modeling and remote sensing, the resulting products from each of these fields are rarely built to be compatible. The input land cover into the WRF model relies on specific categories and their corresponding vegetation parameter tables, which must be updated by hand if other categories are to be added. As previously stated, Hansen loss and gain are available in binary values. Additionally, the grid spacing and resolution of land cover within WRF is much coarser than the Hansen dataset. Therefore, a methodology to combine these disparate datasets has the advantage of updating land cover maps within a land-atmosphere model without building a new land cover dataset. To address these challenges, we created a simplified version of a State and Transition Model (STM), which we refer to as a quasi-STM. According to Bestelmeyer et al. (2017), an STM can be viewed in the mode of Pulsford et al. (2014), as 
a specific theory about how ecosystems respond to disturbance, or in the mode of Westoby et al. (1989), as a way of categorizing ecosystem change, stemming from a wide array of ecosystem dynamics models. Here we apply the Westoby et al. (1989) view of ecosystem change to vegetation categories in the WRF model, using statistical knowledge of deforestation gleaned from the Hansen dataset. A complete STM will categorize discrete plant communities that can exist and coexist at a site, and will model the transitions between these communities to determine alternative states that can occur on the same site (Westoby et al., 1989). Our quasi-STM, however, diverges from this as it is applied much more broadly to determining the transition from one land cover category to a new land cover category due to deforestation.

The output from this quasi-STM is a new land cover map incorporating deforestation that can be directly inserted into the pre-processing step of the WRF model initialization. After creating a new version of the WRF land cover map, we then ran a suite of simulations that compares the control WRF map (circa 1992 - 1993) to the modified WRF map, which incorporates deforestation from the years $2000-2016$.

In this study, we utilize the high-resolution physically based model WRF model because it incorporates land-atmosphere interactions. By using this regional scale model, we are able to resolve the complexities of local meteorological patterns, local topography, and spatial patterns of deforestation. The WRF model consists of a dynamical core that solves several partial differential equations related to the dynamics of the atmosphere (Skamarock et al., 2008). Along with these general atmospheric movements, WRF is capable of solving physical processes including radiation budgeting, cloud microphysics, and land surface physics. Each of these parameters has multiple schemes from which to 
choose, each of differing complexity and computational efficiency (Skamarock et al., 2008). As well as within the remote sensing community, the modeling community has recognized the need for better representation of vegetation dynamics has been recognized. The Noah-MP (multiple parameterization) land surface model (Niu et al., 2011) is available for use in the WRF model. This land surface model is capable of representing complex interactions, including vegetation canopy energy balance, layered snowpacks, frozen soil infiltration, soil moisture-groundwater interaction, runoff, and vegetation phenology (Niu et al., 2011). Along with these intensive vegetation interactions, the WRF model is capable of modeling very fine resolutions (down to 1 $\mathrm{km}$ ), dependent on the computational resources available. We are focusing on the region of Southeast Africa, in central Mozambique. The climatology and topography of this area make it an interesting place to understand the interactions between meteorology and local topography.

Galvin (2008) describes the complex interactions between the Intertropical Convergence Zone (ITCZ) and the topography of the region. He notes that the normal "monsoonal" patterns associated with the ITCZ making landfall is complicated by the presence of higher topography along the coast and further inland, and by the convergence of air from the Indian and Atlantic Oceans. Galvin (2008) explains that air from the Indian Ocean is very moist, but shallow. This requires the aid of orographic lift to initiate rainfall. Another complicating factor in this region is the high-recycling rate. In the 2012 


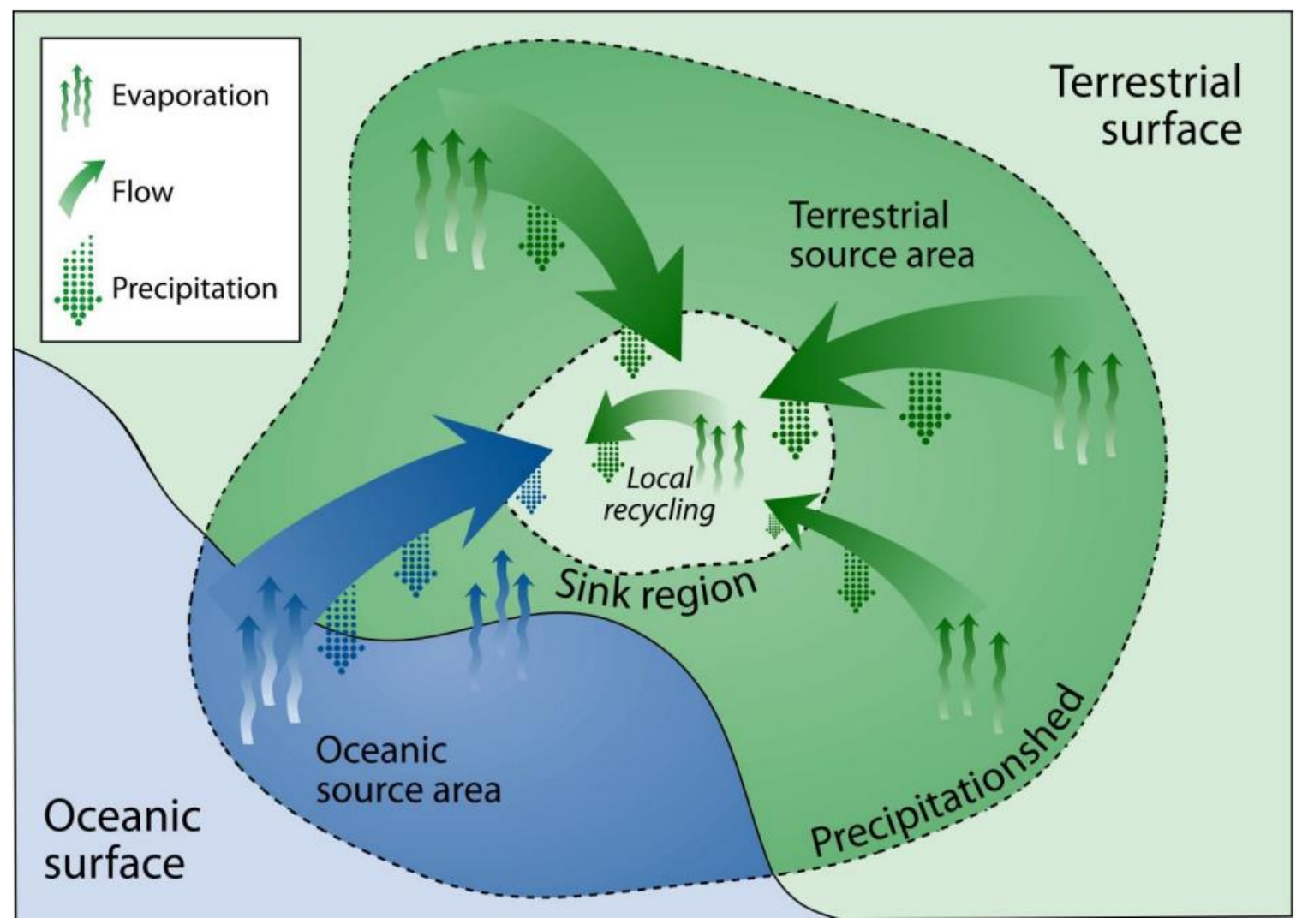

Figure 1. Conceptual diagram of a precipitationshed, from Keys et al. (2012).

study by Keys et al., the authors describe the concept of a precipitationshed, shown in

Figure 1. Much like a watershed describes where water flows depending on its origination, a precipitationshed describes the locus of points from which local precipitation likely originated as evapotranspiration.

Within much of the tropics, and indeed, within this study area, atmospheric recycling, or the contribution of local evapotranspiration to local precipitation (Trenberth, 1999), is relatively high. This can be seen in Figure 2 from Trenberth (1999). This indicates that any deforestation, and any changes to evapotranspiration, in this study area have the potential to highly impact rainfall in the area. 


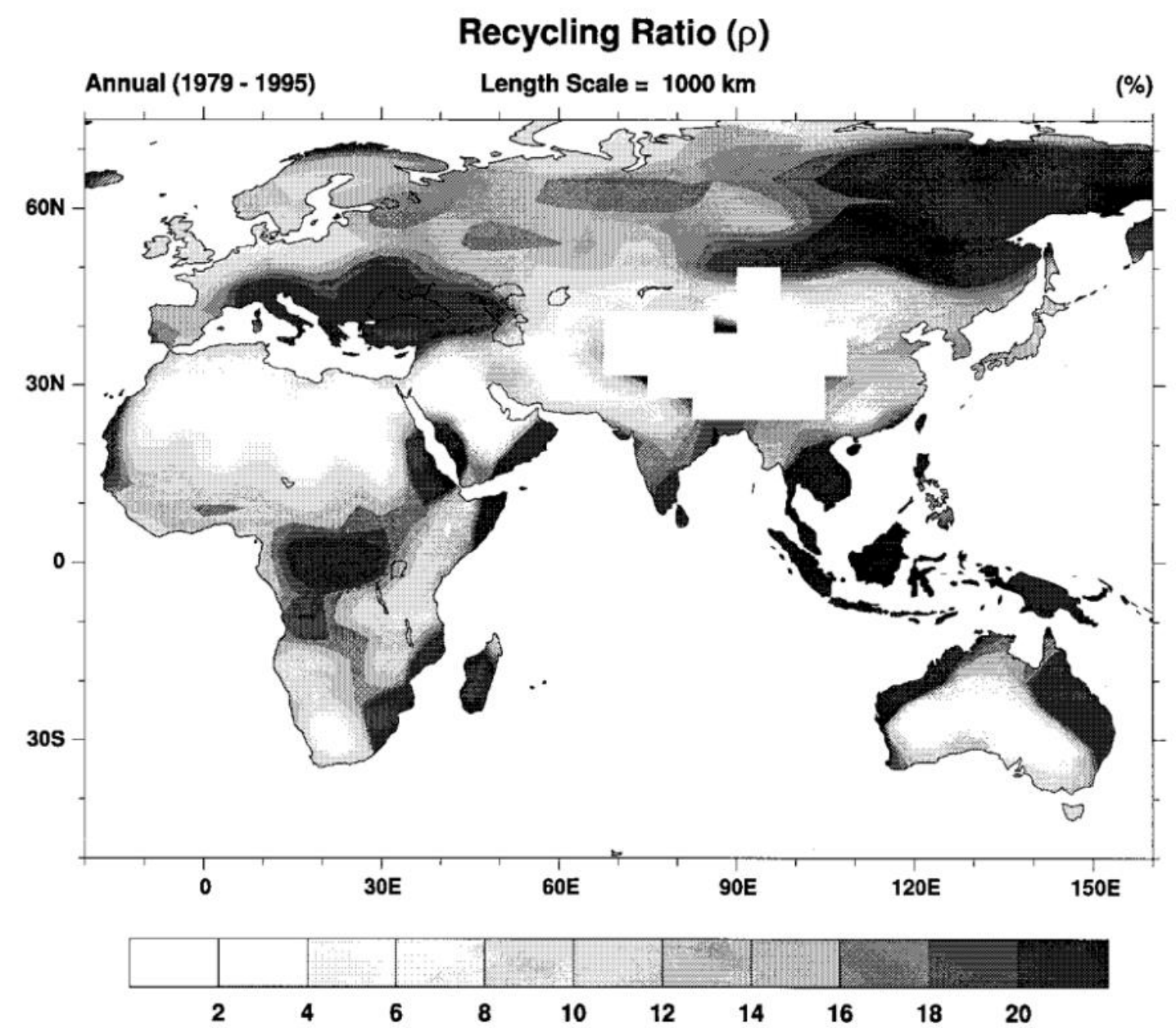

Figure 2. Modified from Trenberth (1999). The recycling rate, $\rho$, for annual mean conditions for a length scale of $1000 \mathrm{~km}$ over land.

To examine deforestation, meteorological and topographic patterns, in this study we focus on the biophysical effects of deforestation on a regional scale in the tropics. Biophysical effects from deforestation on climate are well documented: the albedo, roughness length, seasonal senescence, and leaf area index are all important parameters (Bonan, 2008). However, as shown in Perugini's review- not all deforestation is equal, with deforestation in boreal, temperate and tropical forests all having differing local and global effects on climate. This is due to the fact that in any location, climatic response to deforestation is due to not only first-order energy balance interactions (such as decreasing 
albedo and evapotranspiration), but also second-order effects due to more complex landatmosphere feedbacks (such as increasing incoming solar radiation due to a decrease in cloud cover) (Alkama \& Cescatti, 2016). Generally, in the tropics, the decrease in albedo due to removal of the dark forest canopy (which should cause a cooling), is offset by the decrease in evapotranspiration (leading to warming) (Perugini et al., 2017).

As we work to learn how our global climate will be changing in the future, it is imperative to determine the role of deforestation, and to apply realistic deforestation scenarios within regional and global climate models. From the novel methodologies created in this study, we were able to control for a realistic deforestation scenario, determining both the local and regional effects of tree cover removal on hydrology and climate. By utilizing a global forest cover change dataset, we provide a technique that can be applied in any region of the world. 


\section{CHAPTER TWO: STUDY AREA}

Our study centers near Gorongosa National Park in Central Mozambique, Africa, but the model domains have been extended outside of the park to capture regional weather patterns and to expand the applicability of this research.

Gorongosa National Park is located in the southern portion of the Great African Rift Valley and encompasses 1,456 $\mathrm{m}^{2}$ of land. The park spans a valley with the Barue platform on the west and the Cheringoma escarpment on the east. Just outside of the park to the west is Mount Gorongosa, an important geographical feature whose orthographic lift promotes rainfall from moist, warm air (Tinley, 1977). The area contains a combination of floodplain grasslands, savanna, Miombo forests, and a tropical rainforest on Mount Gorongosa. The climate in central Mozambique is tropical savanna in the Koppen classification system, typified by distinct wet and dry seasons. The rainy season corresponds to an annual southward shift in the ITCZ that brings humid air to the region, typically from December to April. The area experiences a pronounced dry season, with very little rain occurring from May through November (Beilfuss et al., 2007). At the southern edge of the valley floor is a permanent lake, Lake Urema, that is $10-15 \mathrm{~km}^{2}$ in size, but can grow to $200 \mathrm{~km}^{2}$ during wet years (Beilfuss et al, 2007). Gorongosa is part of the Urema Catchment, which is within the Pungwe River Basin in Central Mozambique (Steinbruch, 2010).

All of the modeled scenarios have the same model domains, as shown in Figure 3. All analysis takes place in the innermost domain (shown in Figure 4), which is centered 
on Central Mozambique, but also includes portions of the Indian Ocean and the border with Zimbabwe. The northern and southern borders of this domain are located at $17.522^{\circ}$ and $-20.506^{\circ}$ latitude, respectively.

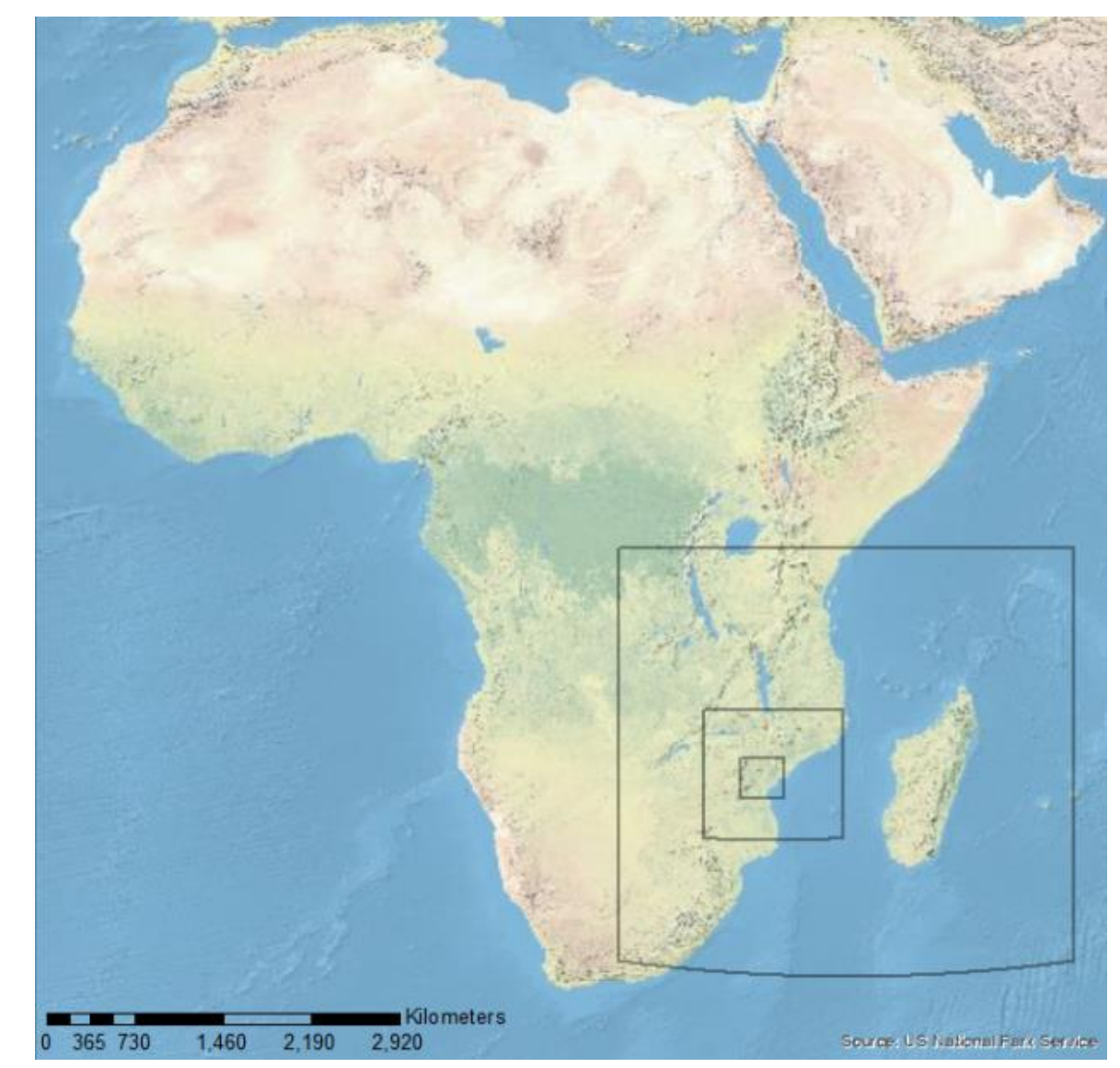

Figure 3. Model domains used in all analyses, with the African continent shown for reference.

The eastern and western borders of this domain fall on $35.9^{\circ}$ and $32.7^{\circ}$ longitude, respectively. The full modeling domain extends to include all of Zimbabwe, Malawi, Lesotho, Swaziland and Madagascar, as well as significant portions of Botswana, Zambia, Tanzania, and the Democratic Republic of the Congo, South Africa, and the Indian Ocean. 


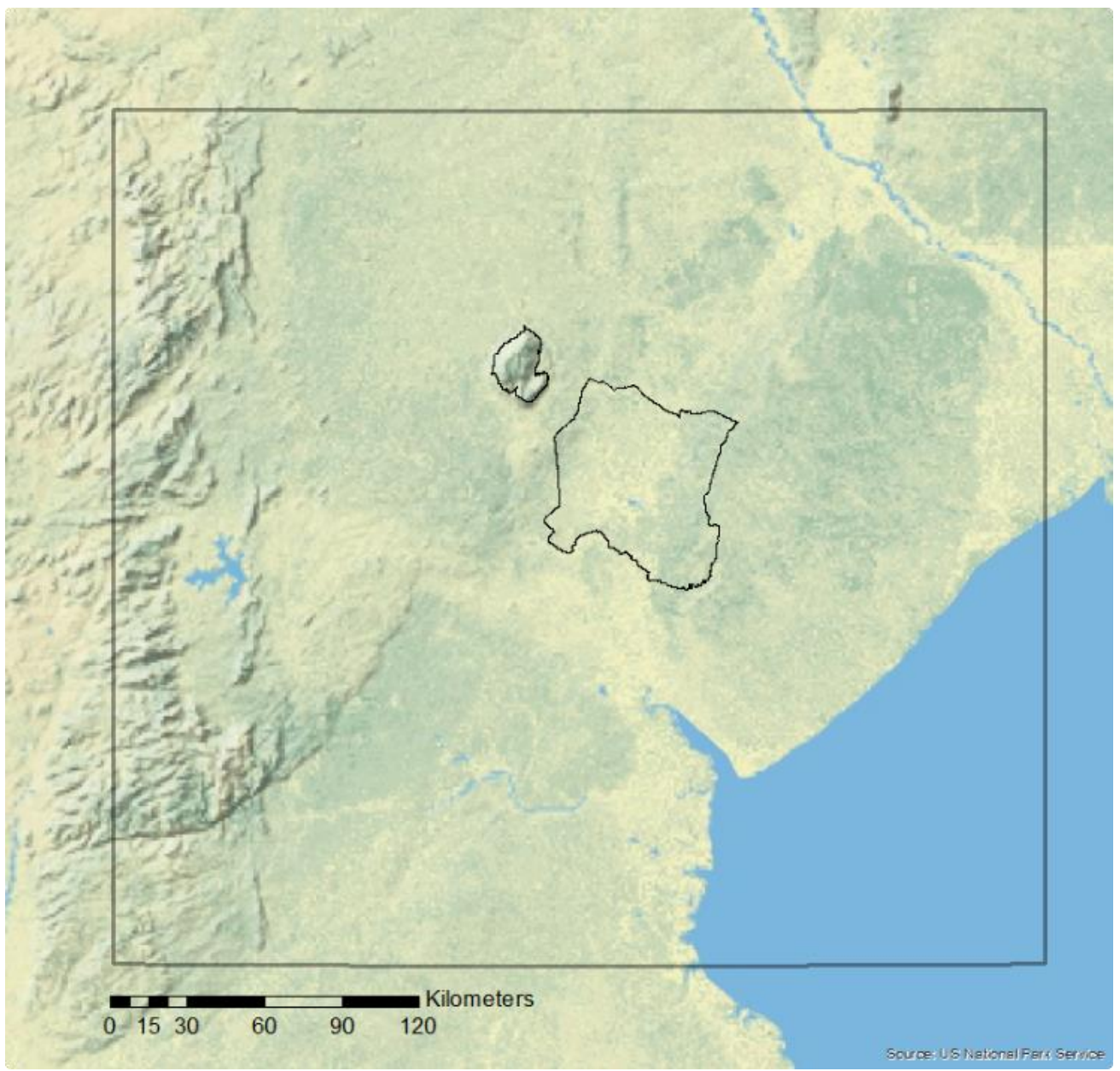

Figure 4. Topographic map of analysis domain with boundaries of Gorongosa National Park shown. 


\section{CHAPTER THREE: METHODS}

\subsection{Data Fusion}

In this section we present the methods we employed to achieve objective 1: Fuse a global forest cover dataset with the land cover in a regional model. In this methodology, the final product is a dataset that matches the input parameters to the WRF model, with the same land use categories and grid spacing from an unmodified land cover dataset.

\subsubsection{Data}

The WRF model has two land cover maps included in a baseline dataset distributed with the model, and are commonly used. We selected the USGS 30s map as it represents an older time period, with our modified map representing and updated version of the land cover, referred to hereafter as the WRF land cover dataset. The WRF land cover classification is built on AVHRR data from the year 1992 - 1993 at a resolution of $1 \mathrm{~km}$ (Loveland et al., 2000). This WRF land cover dataset not only utilizes global satellite data, but the creators also incorporated ancillary datasets of elevation and ecoregions to create a comprehensive global land cover dataset (Loveland et al., 2000). 


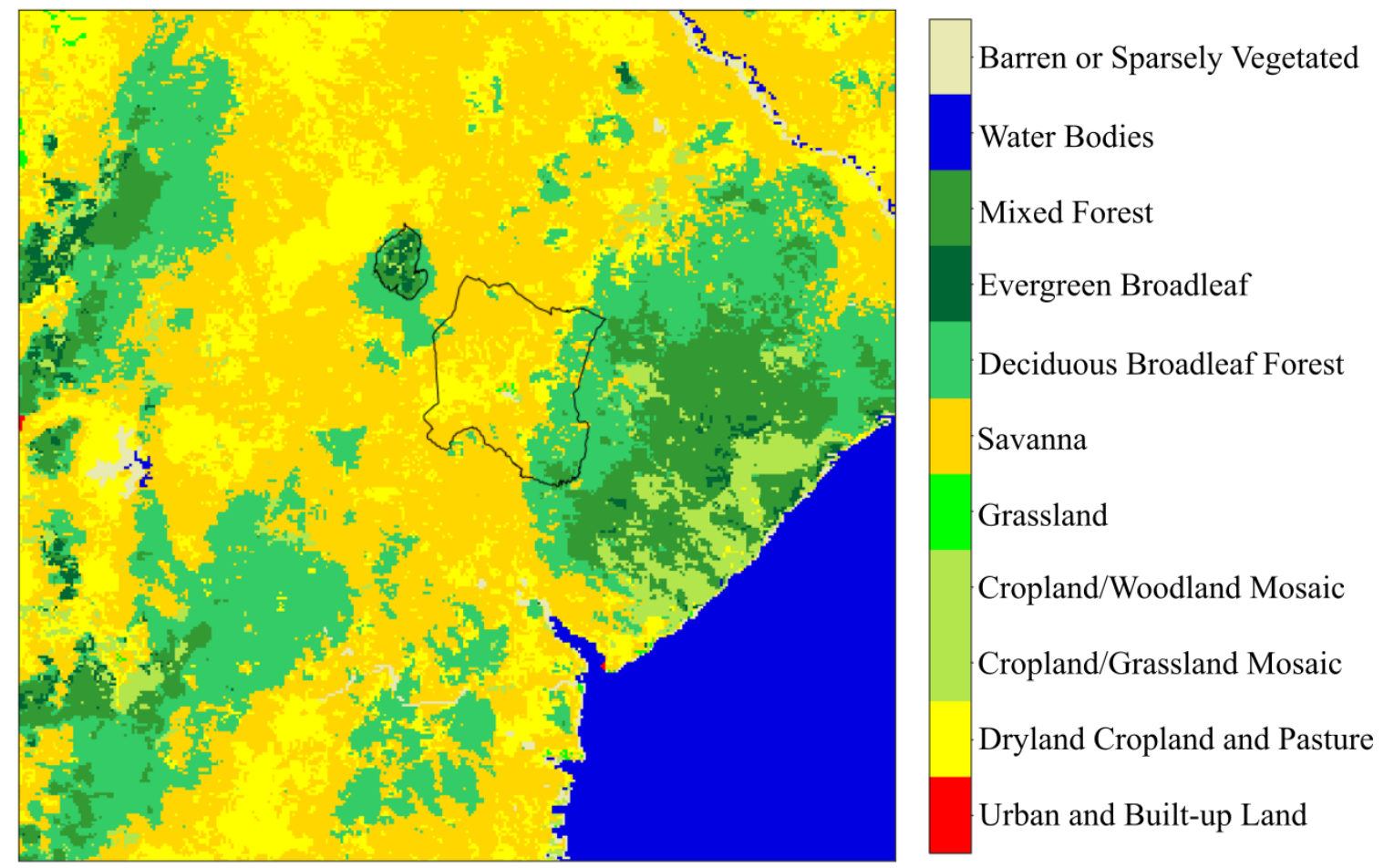

Figure 5. WRF Land Cover for the study domain, with Gorongosa National Park outlined in black.

The WRF land cover dataset was developed with the International GeosphereBiosphere Programme's (IGBP) unified land cover goals- to provide global land cover characteristics most often used in environmental research (Loveland et al, 2000). This dataset is categorical, based on characteristics identified by the IGBP as critical to vegetation studies. Each land use category is defined by a set of variables that describes its biophysical properties, such as albedo, moisture availability, emissivity, roughness length, and thermal inertia (Skamarock et al., 2008). There is also a component of seasonality built into the categories, with parameters for summer and spring seasons (Skamarock et al., 2008).

To represent forest cover change in our study area, we utilized the Global Forest Change dataset from Hansen et al. (2013), referred to hereafter as the Hansen dataset. The Hansen data for the analysis domain is shown in Figure 6. This global dataset is 
derived from $30 \mathrm{~m}$ Landsat data, with loss defined as stand-replacement disturbance or complete loss of canopy at the Landsat pixel scale (and gain defined as the opposite at the Landsat pixel scale) (Hansen et al., 2013). Version 1.4 spans years 2000 - 2016, with gain aggregated from 2000 - 2012, and loss available for the whole time period, and on a yearly basis. The data also contains forest cover for the year 2000, as a percent. All other data is binary, with ' 0 ' for no change and ' 1 ' for change.

\subsubsection{LCC Quasi-STM}

Compiling data from the Hansen dataset and synthesizing it with the WRF dataset presented several challenges. First, there is a significant difference in spatial resolution between datasets that needs to be reconciled in some way. Second, we needed to come up with a set of rules to compare binary and categorical data. Third, the Hansen dataset consists of two separate datasets for loss and gain data. The loss data are available yearly for the years 2000 - 2016, while the gain data is available from the whole time period of $2000-2012$. Therefore, a time series of net loss is not available, but an aggregate net loss can be calculated for the whole time period. 


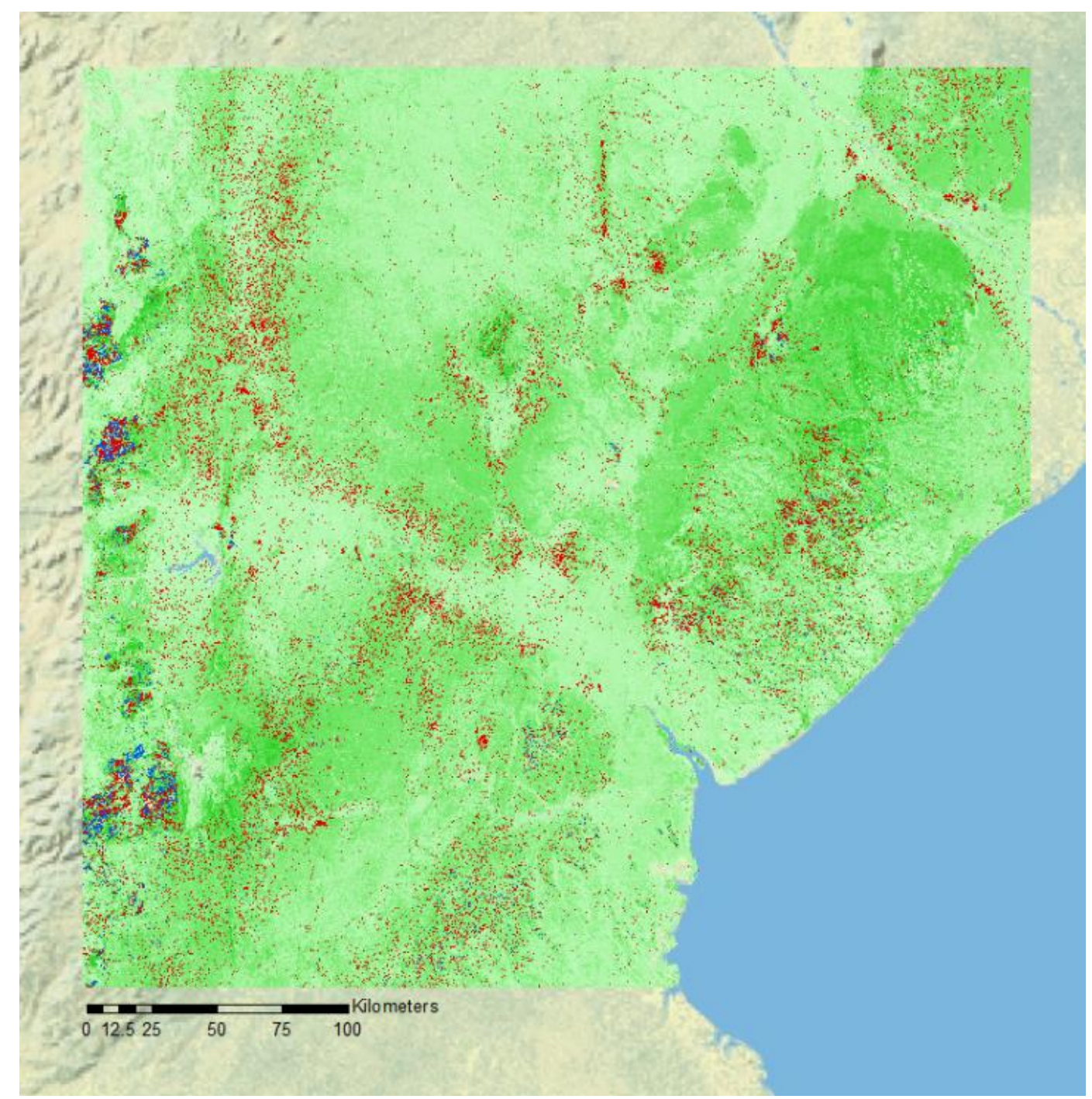

Figure 6. Hansen Forest Cover Dataset- tree cover percentage in green, loss in red, and gain in blue (Hansen et al., 2013).

Along with these challenges, we set out to develop a straightforward approach for applying these methods to different geographic areas, different scales, and potentially different land use products. Foremost, we sought to develop a method that specifically dealt with the land cover classes (e.g., plant functional types) already contained in the WRF dataset so as to make input into the model as simple as possible. We wanted to represent spatial patterns of deforestation, as one of our hypotheses is that not only deforestation, but also the patterns of deforestation (e.g., spatial contiguity) are key in 
determining the resulting hydroclimatic outcomes. Lastly, we wanted a process that was fairly simplistic so as to be applied in broad studies with little computing and few modifications that could correspondingly be applied to other land use/land cover datasets in a relatively straightforward manner.

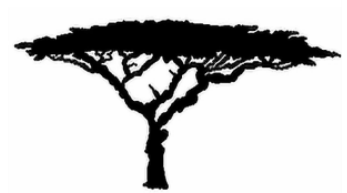

First State

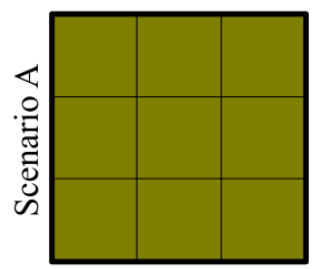

$61 \%$

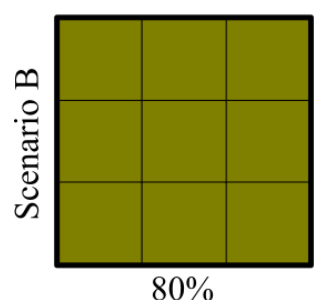

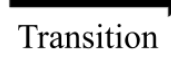

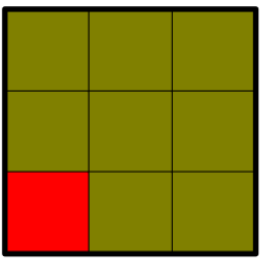

$11 \%$ Loss

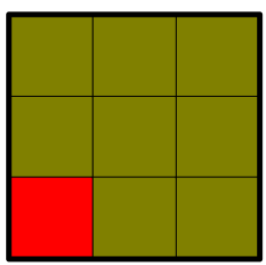

$11 \%$ Loss

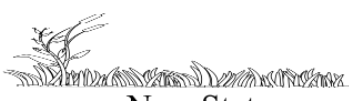

New State

Cropland/Woodland Mosaic?

Savanna?

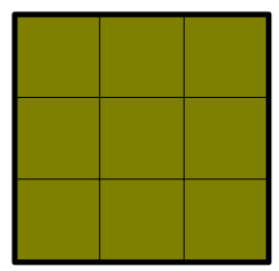

Figure 7. Potential scenarios in examining a categegorical dataset along with a binary dataset. Here, an evergreen needleleaf forest pixel is classified as $>60 \%$ canopy cover. The same amount of loss in scenarios A and B could lead to different outcomes.

To address these challenges and goals, we decided to create a quasi-State and Transition Model (STM) that considers the data on an aggregate scale instead of on a pixel-by-pixel scale. An STM uses a probability analysis to determine the likelihood of one state transitioning to another state. We took this approach in part due to scenarios such as those presented in Figure 7. For example, within the WRF land cover classification system, a pixel with tree canopy cover greater than $60 \%$ where the trees 
remain green all year is considered an evergreen forest. This can present us with a variety of options for the new state, depending on how we view the first state, and what types of conversion are most likely in our study area.

We also viewed it as imperative to maintain some of the spatial characteristics of the deforestation, as we hypothesize that spatial patterns are an important factor that controls the spatiotemporal patterns of land-atmosphere interaction and, therefore, the associated hydrologic response.

\subsubsection{Workflow}

To create this model, we applied the workflow shown in Figure 8, with descriptions of each step in the following sections.

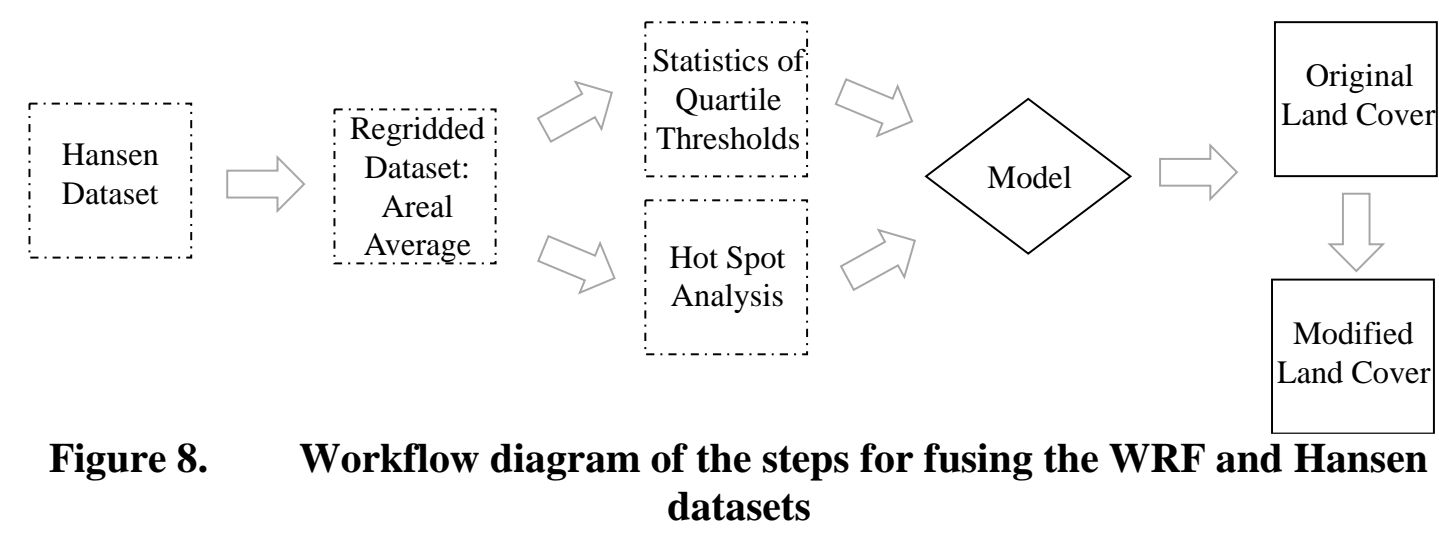

\subsubsection{Areal Averaging}

In this first step, we wanted to compare both datasets at the same resolution. As we wanted to alter the input WRF land cover map, we wanted to scale up the Hansen dataset to $1 \mathrm{~km}$, the same resolution as the WRF input land cover. We also needed to ensure that the resultant grids of each dataset matched, so we used the National Center for Atmospheric Research's command language function area_hi2lores (The NCAR 
Command Language, 2017). This script, along with all others utilized in this research were archived on GitHub, the details of which are located in Appendix A. With this function, we were able to find the average of each $30 \mathrm{~m}$ pixel in the Hansen dataset that fell within each $1 \mathrm{~km}$ pixel of the WRF dataset. This spatial average effectively corresponds to the percentage of pixels within the Hansen dataset that exhibit gain or loss at the scale of the WRF landcover dataset.

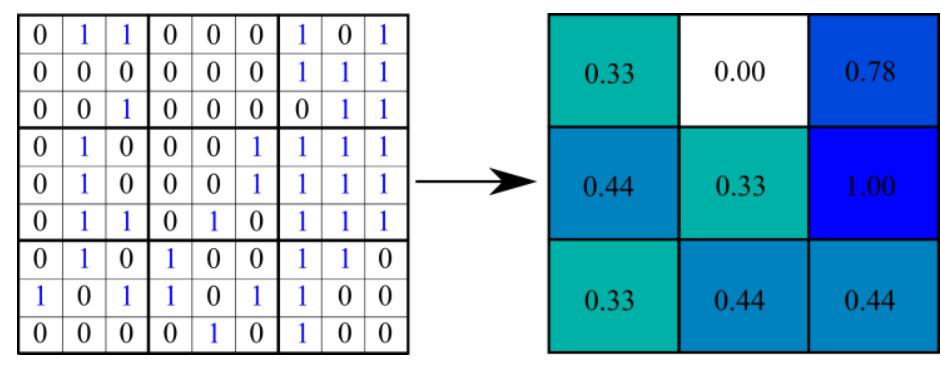

\begin{tabular}{|l|l|l|l|l|l|l|l|l|}
\hline 0 & 1 & 1 & 0 & 0 & 0 & 1 & 0 & 1 \\
0 & 0 & 0 & 0 & 0 & 0 & 1 & 1 & 1 \\
\hline 0 & 0 & 1 & 0 & 0 & 0 & 0 & 1 & 1 \\
\hline 0 & 1 & 0 & 0 & 0 & 1 & 1 & 1 & 1 \\
0 & 1 & 0 & 0 & 0 & 1 & 1 & 1 & 1 \\
0 & 1 & 1 & 0 & 1 & 0 & 1 & 1 & 1 \\
\hline 0 & 1 & 0 & 1 & 0 & 0 & 1 & 1 & 0 \\
\hline 1 & 0 & 1 & 1 & 0 & 1 & 1 & 0 & 0 \\
\hline 0 & 0 & 0 & 0 & 1 & 0 & 1 & 0 & 0 \\
\hline
\end{tabular}

Figure 9. Conceptual models of areal averaging the binary Hansen dataset to the WRF grid. There are two separate datasets, represented here in blue for gain and red for loss.

The output from this exercise is conceptualized in Figure 9, with $1 \mathrm{~km}$ pixels ranging from 0 to 1 created from the $30 \mathrm{~m}$ pixels of 0 or 1 . Output from the areal averaging regridding can be seen in Figure 10. The averaged loss values range from 0.0 to 0.99 , while the gain values range from 0.0 to 0.81 . Locations of greatest change correspond with visual analysis of Landsat in the region. 

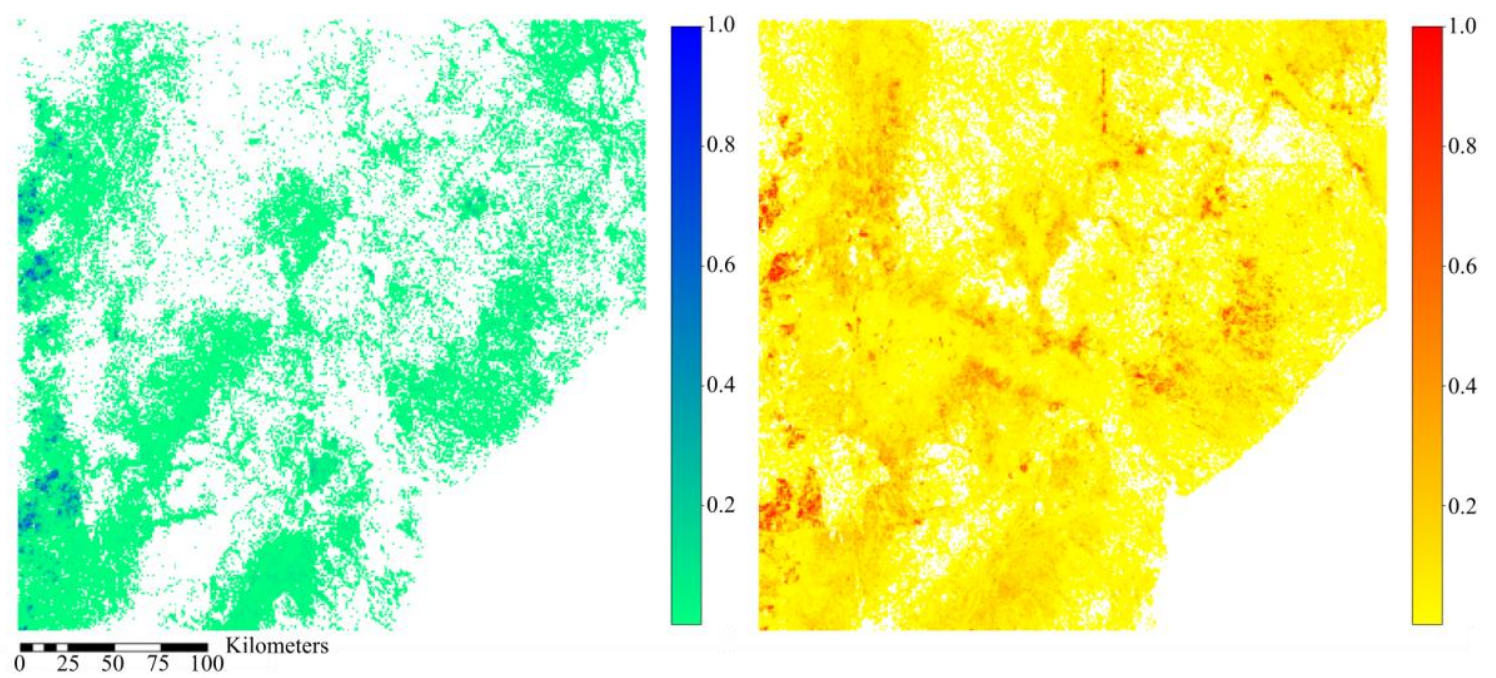

Figure 10. Regridded Hansen dataset on the WRF grid, now with values ranging from 0 - 1 for each pixel.

\subsubsection{Hot Spot Analysis}

From the regridded areal average, we located the areas of most loss and most gain. We used the Hot Spot Analysis (Getis-Ord Gi*) statistical tool within ArcGIS (Getis \& Ord,1992), which evaluates a pixel in relation to its surrounding pixels to determine where features not only have a high fraction of gain/loss, but are also surrounded by high fractions of gain/loss. We created spatial features of gain/loss by clustering values that fell within a $99 \%$ confidence interval of being a statistically significant "hot spot." Figure 11 shows the locations of most deforestation from our study site. 


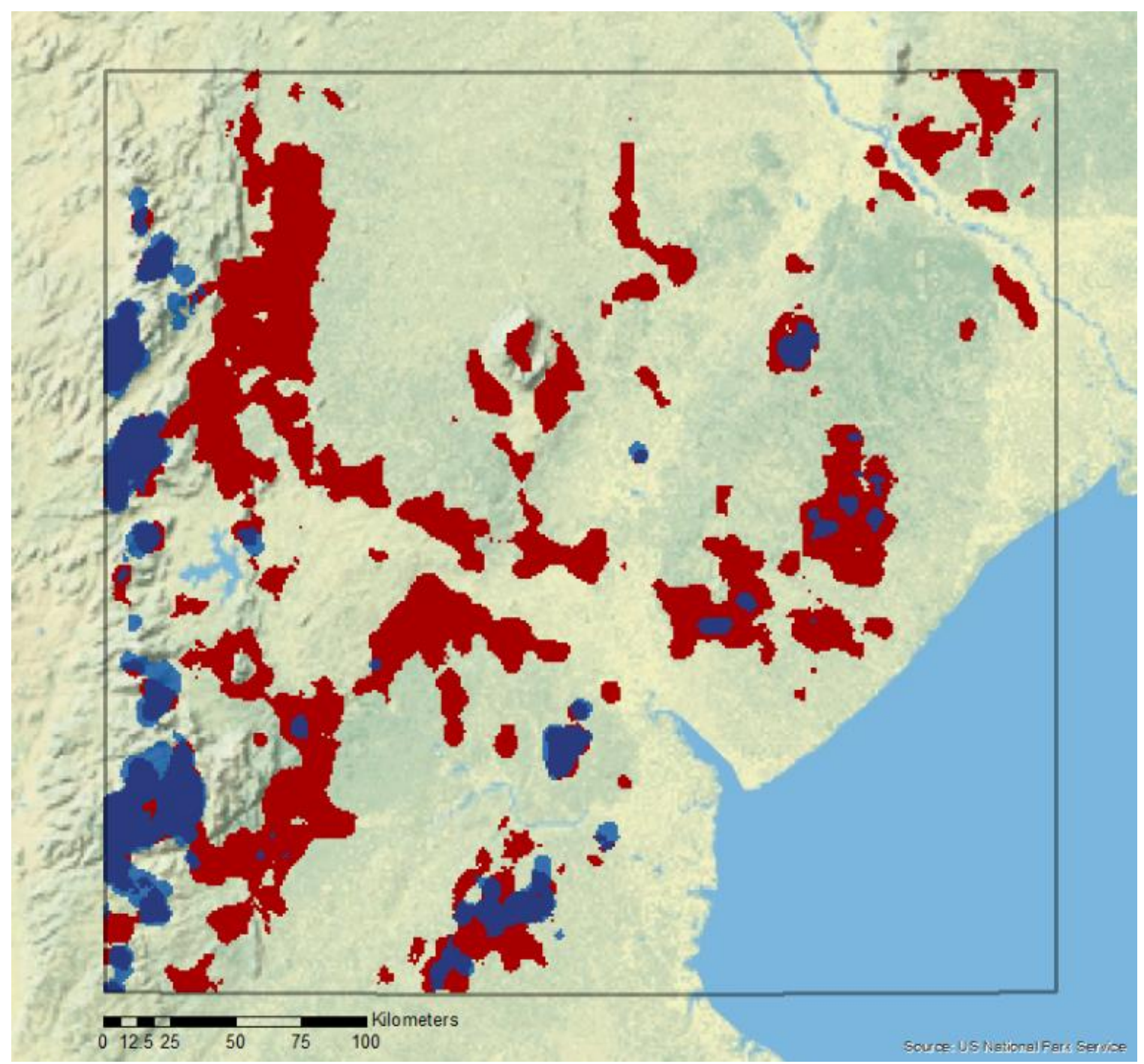

Figure 11. "Hot spot" locations of loss and gain in the analysis area. Loss shown in red and gain shown in blue.

\subsubsection{Statistics of Quartile Thresholds}

Besides a spatial analysis of the aggregated Hansen dataset, we also performed a statistical analysis, the statistics of which are found in Table 1. First, we determined from the hot spot analysis that the majority of gain in the study area occurred at the same locations as loss, and that loss far outpaced gain. Second, we overlaid the regridded areal 
Table 1. Statistics determined from overlaying the regridded Hansen dataset on the WRF land cover.

\begin{tabular}{l|c|c|c|c||}
\cline { 2 - 5 } \multicolumn{1}{c|}{} & \multicolumn{4}{c|}{$\begin{array}{c}\text { Threshold of } \\
0-0.25\end{array}$} \\
\cline { 2 - 6 } \multicolumn{1}{c|}{ Loss (2000 - 2016) } & $\begin{array}{c}\text { Pixels of } \\
\text { loss }\end{array}$ & $\begin{array}{c}\text { Percent of } \\
\text { loss }\end{array}$ & $\begin{array}{c}\text { Percent of } \\
\text { land cover } \\
\text { class }\end{array}$ & $\begin{array}{c}\text { Percent of } \\
\text { domain }\end{array}$ \\
\hline Urban & 18 & 0.02 & 100.00 & 0.02 \\
Dryland cropland & 17586 & 15.83 & 99.02 & 15.22 \\
Cropland/Grassland & 43 & 0.04 & 100.00 & 0.04 \\
Cropland/woodland & 4232 & 3.81 & 96.42 & 3.66 \\
Grassland & 143 & 0.13 & 100.00 & 0.12 \\
Savanna & 42645 & 38.39 & 97.22 & 36.90 \\
Deciduous Broadleaf & 21430 & 19.29 & 93.97 & 18.54 \\
Evergreen Broadleaf & 906 & 0.82 & 72.65 & 0.78 \\
Mixed Forest & 8033 & 7.23 & 86.88 & 6.95 \\
Water & 15112 & 13.60 & 100.00 & 13.08 \\
Barren & 944 & 0.85 & 99.58 & 0.82 \\
Total & 111092 & & & 96.12 \\
\hline
\end{tabular}

Regridded Hansen Dataset Statistics

\begin{tabular}{|c|c|c|c|}
\hline \multicolumn{5}{|c|}{$\begin{array}{c}\text { Threshold of } \\
0.26-0.50\end{array}$} \\
\hline $\begin{array}{c}\text { Pixels of } \\
\text { loss }\end{array}$ & $\begin{array}{c}\text { Percent of } \\
\text { loss }\end{array}$ & $\begin{array}{c}\text { Percent of } \\
\text { land cover } \\
\text { class }\end{array}$ & $\begin{array}{c}\text { Percent of } \\
\text { domain }\end{array}$ \\
\hline & & & \\
142 & 4.30 & 0.80 & 0.12 \\
110 & 3.33 & 2.51 & 0.10 \\
942 & 28.53 & 2.15 & 0.82 \\
1090 & 33.01 & 4.78 & 0.94 \\
201 & 6.09 & 16.12 & 0.17 \\
815 & 24.68 & 8.81 & 0.71 \\
2 & & & \\
3302 & 0.06 & 0.21 & 0.00 \\
\hline
\end{tabular}

\begin{tabular}{|c|c|c|c|}
\hline \multicolumn{5}{|c|}{$\begin{array}{c}\text { Threshold of } \\
0.51-0.75\end{array}$} \\
\hline $\begin{array}{c}\text { Pixels of } \\
\text { loss }\end{array}$ & $\begin{array}{c}\text { Percent of } \\
\text { loss }\end{array}$ & $\begin{array}{c}\text { Percent of } \\
\text { land cover } \\
\text { class }\end{array}$ & $\begin{array}{c}\text { Percent of } \\
\text { domain }\end{array}$ \\
\hline 17 & 2.61 & 0.10 & 0.01 \\
25 & 3.84 & 0.57 & 0.02 \\
136 & 20.89 & 0.31 & 0.12 \\
125 & 19.20 & 0.55 & 0.11 \\
95 & 14.59 & 7.62 & 0.08 \\
253 & 38.86 & 2.74 & 0.22 \\
& & & \\
651 & & & 0.56 \\
\hline
\end{tabular}

Threshold of $0-0.25$

\begin{tabular}{|c|c|c|c|c|}
\hline \multirow[b]{2}{*}{ Gain $(2000-2012)$} & \\
\hline & $\begin{array}{c}\text { Pixels of } \\
\text { gain }\end{array}$ & $\begin{array}{l}\text { Percent of } \\
\text { gain }\end{array}$ & $\begin{array}{l}\text { Percent of } \\
\text { land cover } \\
\text { class }\end{array}$ & $\begin{array}{c}\text { Percent of } \\
\text { domain }\end{array}$ \\
\hline Urban & 18 & 0.02 & 100.00 & 0.02 \\
\hline Dryland cropland & 17741 & 15.42 & 99.89 & 15.35 \\
\hline Cropland/Grassland & 43 & 0.04 & 100.00 & 0.04 \\
\hline Cropland/woodland & 4356 & 3.79 & 99.25 & 3.77 \\
\hline Grassland & 143 & 0.12 & 100.00 & 0.12 \\
\hline Savanna & 43788 & 38.07 & 99.82 & 37.89 \\
\hline Deciduous Broadleaf & 22765 & 19.79 & 99.83 & 19.70 \\
\hline Evergreen Broadleaf & 1100 & 0.96 & 88.21 & 0.95 \\
\hline Mixed Forest & 9013 & 7.84 & 97.48 & 7.80 \\
\hline Water & 15112 & 13.14 & 100.00 & 13.08 \\
\hline Barren & 948 & 0.82 & 100.00 & 0.82 \\
\hline Total & 115027 & & & 99.53 \\
\hline
\end{tabular}

\begin{tabular}{|c|c|c|c}
\hline \multicolumn{4}{c}{$\begin{array}{c}\text { Threshold of } \\
0.76-1\end{array}$} \\
\hline $\begin{array}{c}\text { Pixels of } \\
\text { loss }\end{array}$ & $\begin{array}{c}\text { Percent of } \\
\text { loss }\end{array}$ & $\begin{array}{c}\text { Percent of } \\
\text { land cover } \\
\text { class }\end{array}$ & $\begin{array}{c}\text { Percent of } \\
\text { domain }\end{array}$ \\
\hline & & & \\
2 & 1.44 & 0.01 & 0.00 \\
11 & 7.91 & 0.25 & 0.01 \\
19 & 13.67 & 0.04 & 0.02 \\
16 & 11.51 & 0.07 & 0.01 \\
23 & 16.55 & 1.84 & 0.02 \\
68 & 48.92 & 0.74 & 0.06 \\
& & & \\
139 & & & 0.12 \\
\hline
\end{tabular}

\begin{tabular}{|c|c|c|c|}
\hline \multicolumn{5}{|c|}{$\begin{array}{c}\text { Threshold of } \\
0.51-0.75\end{array}$} \\
\hline $\begin{array}{c}\text { Pixels of } \\
\text { gain }\end{array}$ & $\begin{array}{c}\text { Percent of } \\
\text { gain }\end{array}$ & $\begin{array}{c}\text { Percent of } \\
\text { land cover } \\
\text { class }\end{array}$ & $\begin{array}{c}\text { Percent of } \\
\text { domain }\end{array}$ \\
\hline 4 & 3.60 & 0.02 & 0.00 \\
4 & 3.60 & 0.09 & 0.00 \\
17 & 15.32 & 0.04 & 0.01 \\
7 & 6.31 & 0.03 & 0.01 \\
32 & 28.83 & 2.57 & 0.03 \\
47 & 42.34 & 0.51 & 0.04 \\
& & & \\
111 & & & 0.10 \\
\hline
\end{tabular}

\begin{tabular}{|c|c|c|c}
\hline \multicolumn{4}{c}{$\begin{array}{r}\text { Threshold of } \\
0.76-1\end{array}$} \\
\hline $\begin{array}{c}\text { Pixels of } \\
\text { gain }\end{array}$ & $\begin{array}{c}\text { Percent of } \\
\text { gain }\end{array}$ & $\begin{array}{c}\text { Percent of } \\
\text { land cover } \\
\text { class }\end{array}$ & $\begin{array}{c}\text { Percent of } \\
\text { domain }\end{array}$ \\
\hline & & & \\
& & & \\
\hline 1 & 25.00 & 0.02 & 0.00 \\
\hline 2 & 50.00 & 0.00 & 0.00 \\
\hline 1 & 25.00 & 0.01 & 0.00 \\
\hline 4 & & & \\
\hline
\end{tabular}


average datasets on the WRF dataset to determine the corresponding land cover class at each pixel. Third, we determined a thresholding system to simplify how to compare the two datasets. Each pixel of the aggregated Hansen dataset was categorized into 0 - 25\%, $26-50 \%, 51-75 \%$, and $76-100 \%$ loss or gain. We then took the total number of gain pixels from each threshold at each land cover class and subtracted them from the total number of loss pixels in each threshold/land cover class to determine an aggregate net loss per threshold, per land cover class. From these aggregate calculations, we had a defined number of pixels for each land cover class, and a level of loss that each land cover class was experiencing.

Table 2. Statistics applied to the WRF Land Cover within our model, after subtracting gain pixels from loss pixels.

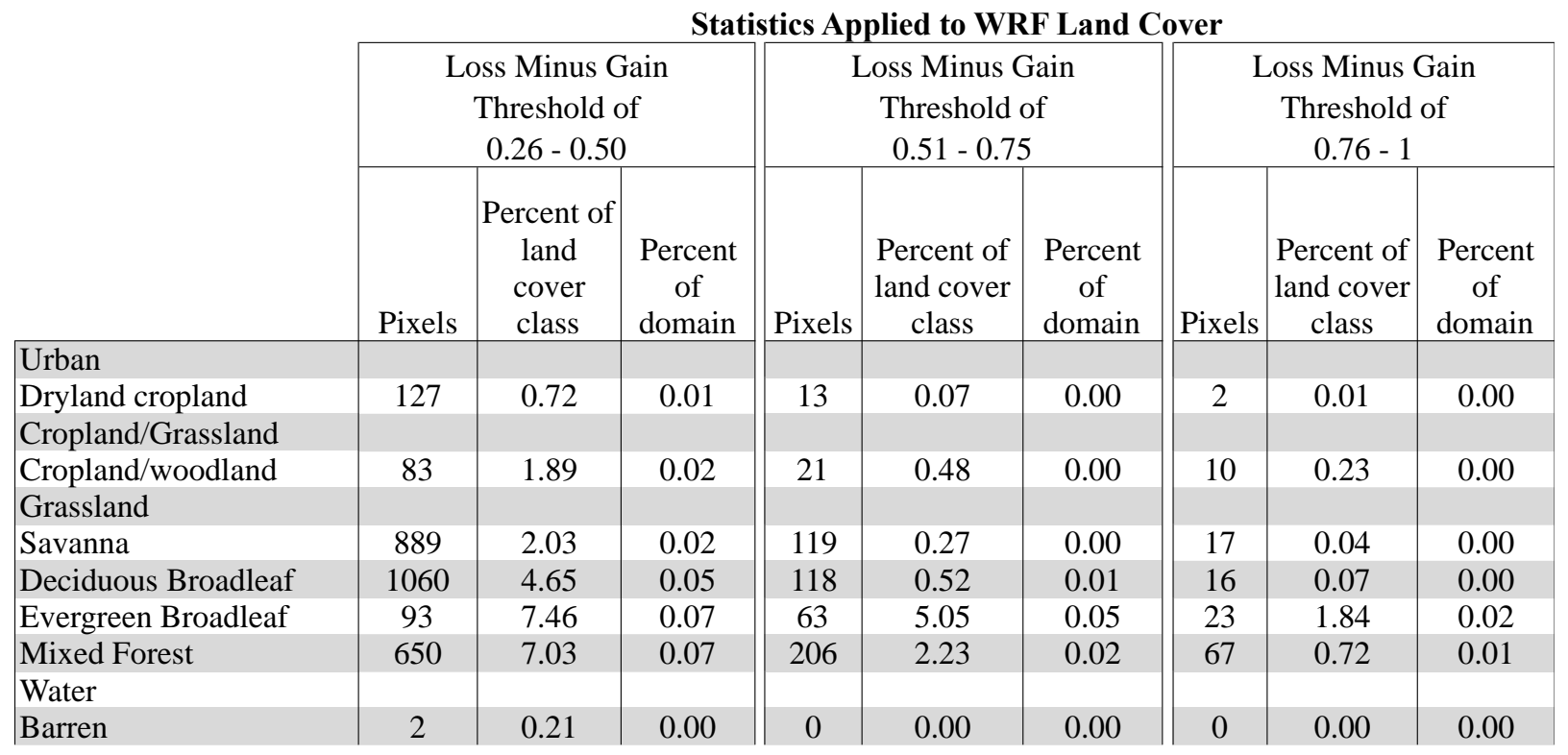

We used the statistics in Table 2 in our quasi-STM. This was based on two assumptions: gain and loss pixels were occurring in approximately the same area, and pixels experiencing less than $25 \%$ loss did not transition to a new state.

\subsubsection{Creating the Model Rules}

First, we categorized each land cover class in the WRF model as a "level of tree 
cover" as shown in Table 3.

Table 3. Rules for defining "First State" of vegetation cover.

\begin{tabular}{lc}
\hline WRF Land Cover Type & $\begin{array}{c}\text { Level of Tree } \\
\text { Cover }\end{array}$ \\
\hline \hline Barren & None \\
Dryland Cropland & Low \\
Cropland/Woodland Mosaic & Intermediate \\
Savanna & Intermediate \\
Deciduous Broadleaf Forest & High \\
Evergreen Broadleaf Forest & High \\
Mixed Forest & High \\
\hline
\end{tabular}

Second, we created a set of rules for changing each level of tree cover based on an amount of loss, shown in Table 4. We based the transition land cover on an examination of Landsat imagery and reports of the land use change in Mozambique. The majority of tree cover change in the area is conversion to agricultural lands, or for the sale of timber (Hanlon, 2011). However, there are some areas of Landsat imagery that are barren after tree cover loss. There is a small area of tree cover loss due to urbanization around the city of Inhaminga. This was not considered in this study as the majority of the study area is either not urbanized, or lightly urbanized. All major cities in the domain area can be seen in Figure 12. 


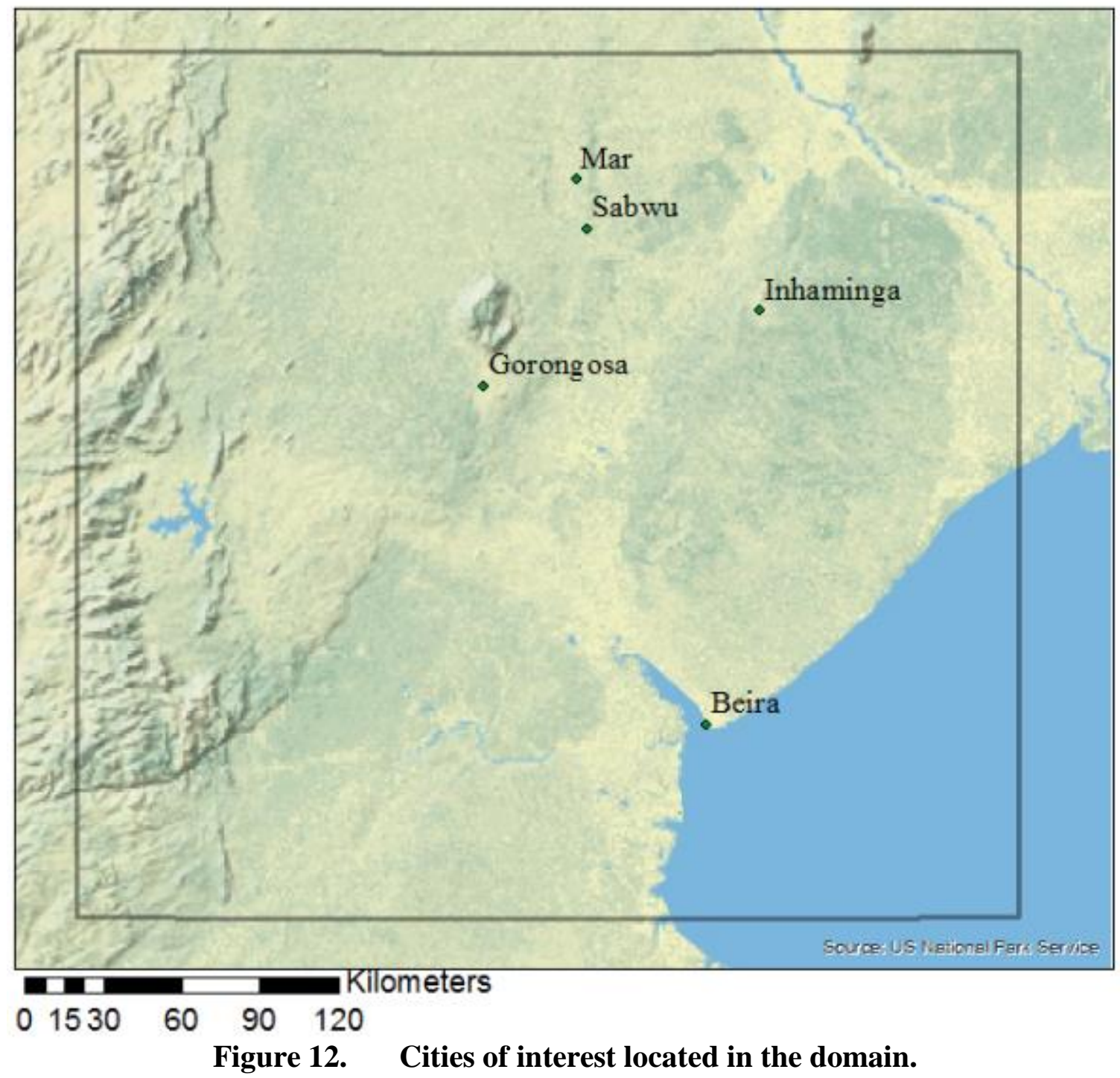


Table 4. Rules for transitioning each "First State" to its "New State."

\begin{tabular}{lccc}
\hline & $\begin{array}{c}\text { Land Cover } \\
\text { after } 25-50 \% \\
\text { Lriginal Land Use Type }\end{array}$ & $\begin{array}{c}\text { Land Cover } \\
\text { after 50-75\% } \\
\text { Loss }\end{array}$ & $\begin{array}{c}\text { Land Cover } \\
\text { after 75 - 100\% } \\
\text { Loss }\end{array}$ \\
\hline \hline Dryland Cropland & Barren & Barren & Barren \\
\hline Cropland/Woodland & Dryland & Dryland & \\
Savanna & Cropland & Cropland & Barren \\
\hline Deciduous Broadleaf & Cropland/ & & \\
Evergreen Broadleaf & Woodland & Dryland & \\
Mixed Forest & Mosaic & Cropland & Barren \\
\hline
\end{tabular}

\subsubsection{Random Selection of Land Cover Change Pixels}

We randomly selected pixels corresponding to each land cover class within the loss hotspot areas. This was part of our approach to calculating net loss on an aggregate scale as opposed to a cell-by-cell basis. In this way, we were able to maintain the spatial patterns of deforestation while evenly distributing pixels of loss across the hotspot area. The number of selected pixels was based on the numbers from each category of loss, and we then changed the land cover corresponding to the rules in Table 4. For example, we randomly selected 127 dryland cropland pixels within the loss hot spot areas to represent the pixels that underwent 26 - 50\% loss and converted them to the "Barren" land use class in the WRF land cover map. The locations of the random pixels that were selected for change are shown in Figure 13. 


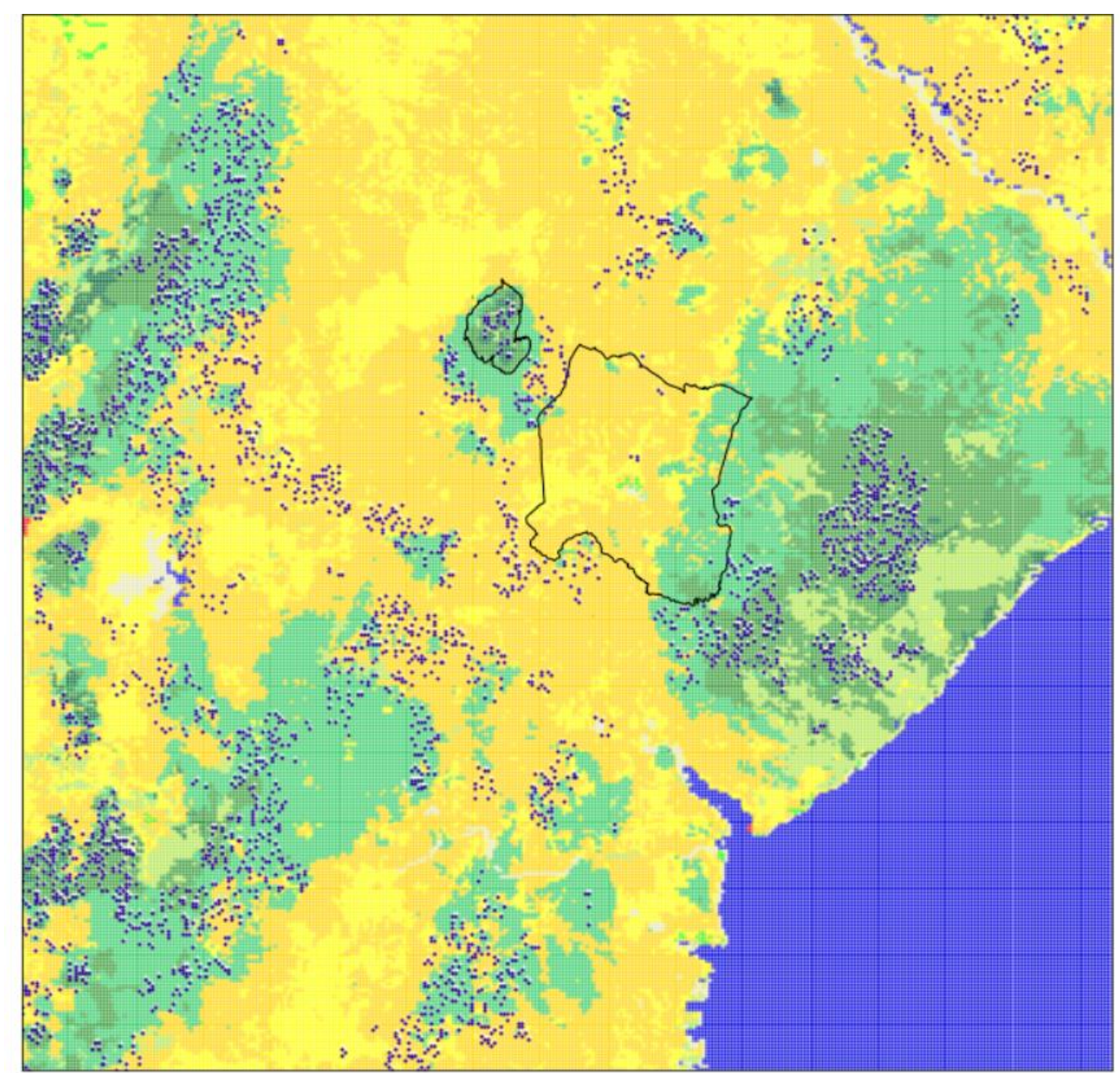

Figure 13. Randomly selected pixels within the loss hotspot areas, shown in purple.

\subsubsection{Modified Land Cover Map}

After applying the model to all of the changed pixels, the resultant land cover map in Figure 14 was produced. Only $4 \%$ of the pixels in the land portion of the study area were changed, and $3 \%$ of the of the pixels in the entire domain were changed. These changes led to some areas of increased heterogeneity in the land cover classes. Some of these areas correspond with areas of higher elevation, including Mount Gorongasa, the Barue Platform in the eastern central portion of the domain, and a ridge where the cities of Mar and Sabwu are located. 


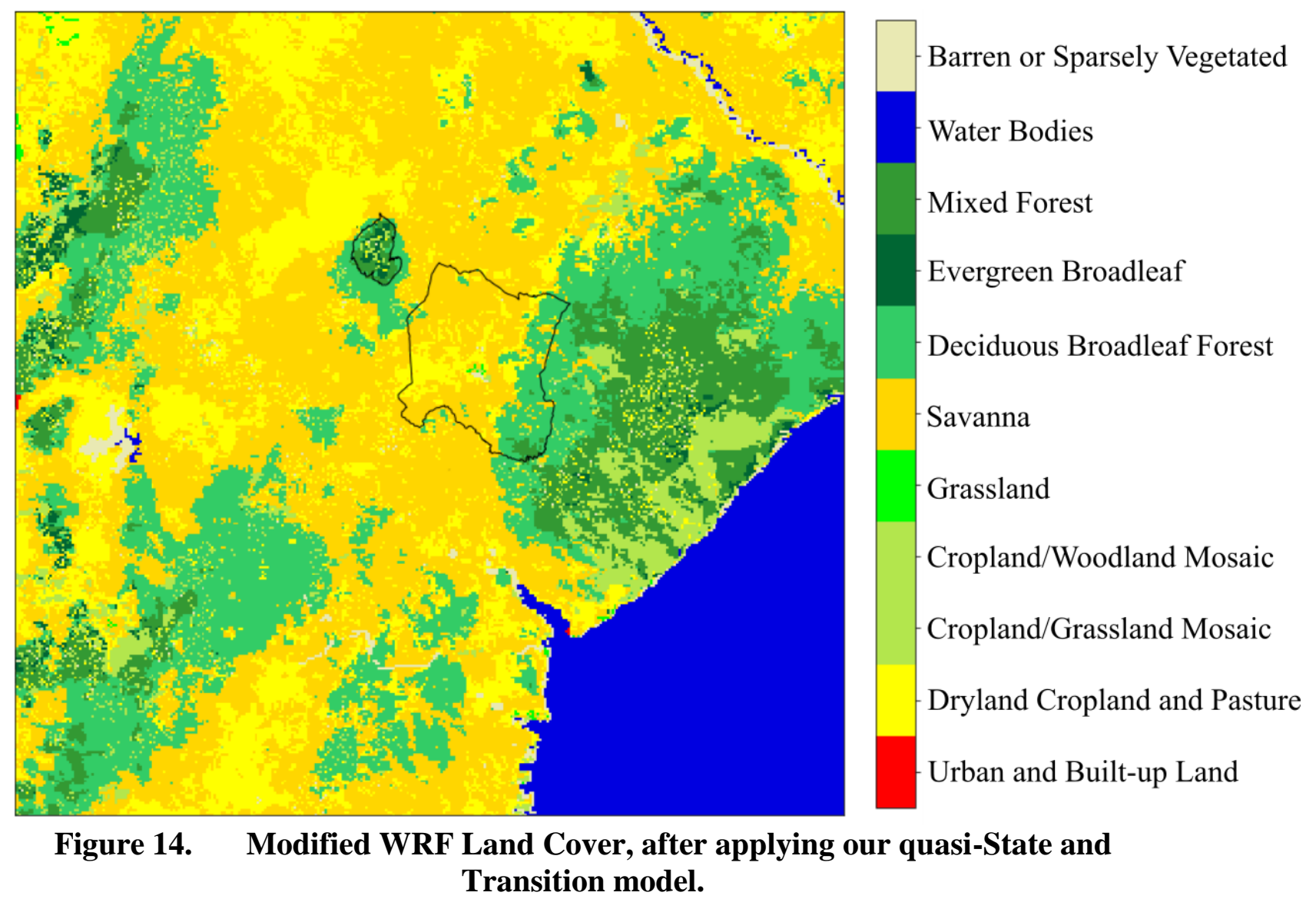

\section{$\underline{\text { 3.2.10 Comparison of Modified Map with Hansen Dataset }}$}

We calculated statistics of the Hansen dataset to see how the modified WRF land cover map compares. To achieve this, we extracted all pixels of the dataset within a certain threshold of tree coverage for the year 2000, and masked all other pixels. The percent of the full domain that each of these tree cover amounts is shown in Figure 15. We then calculated the total loss for each tree coverage amount for the time period, shown in Figure 16. We calculated the total gain without considering the percentage of tree coverage in 2000. The total gain for the time period is $699 \mathrm{~km}^{2}$, or $0.6 \%$ of the entire domain. 


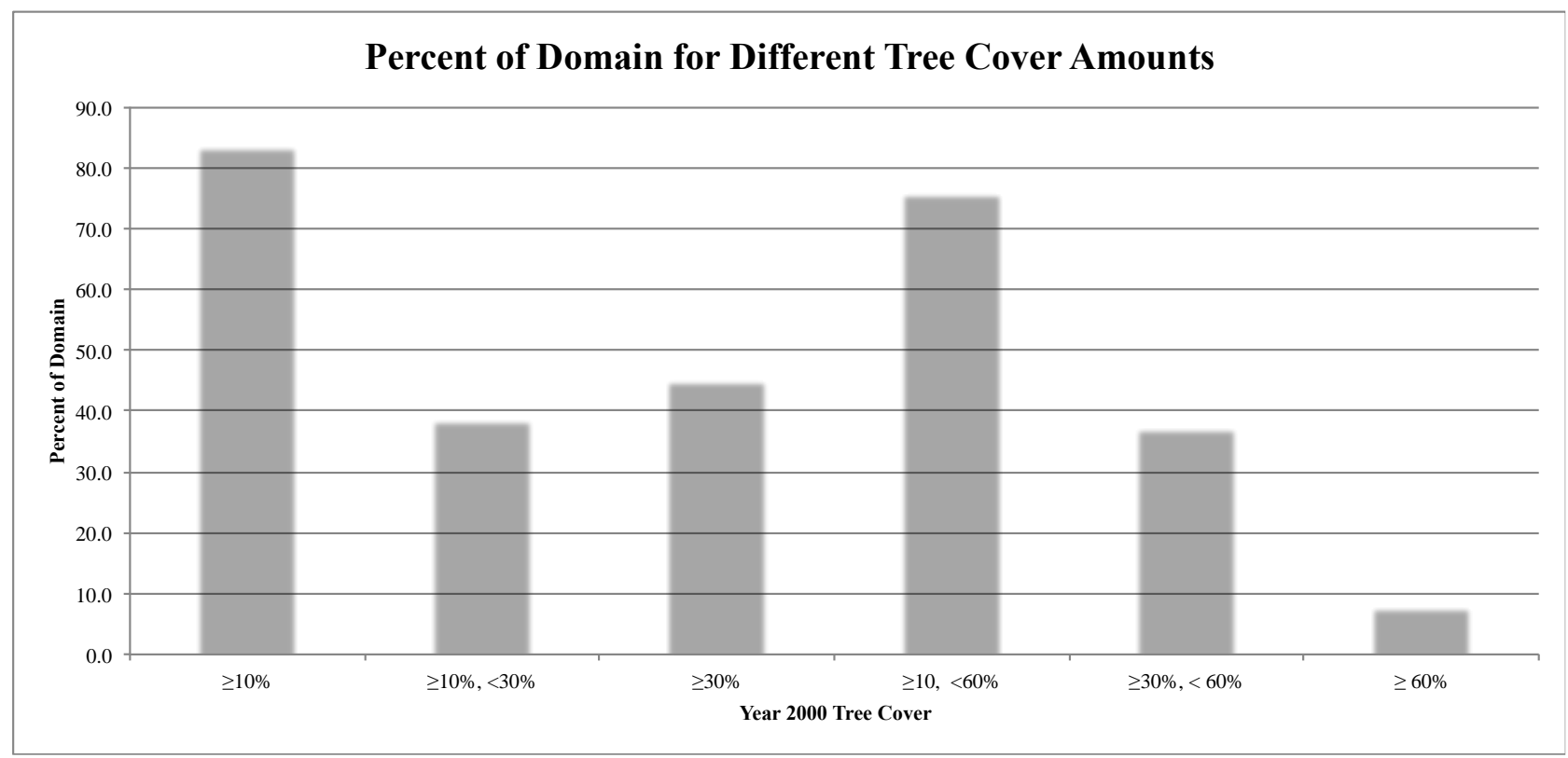

Figure 15. Hansen tree coverage for the year 2000

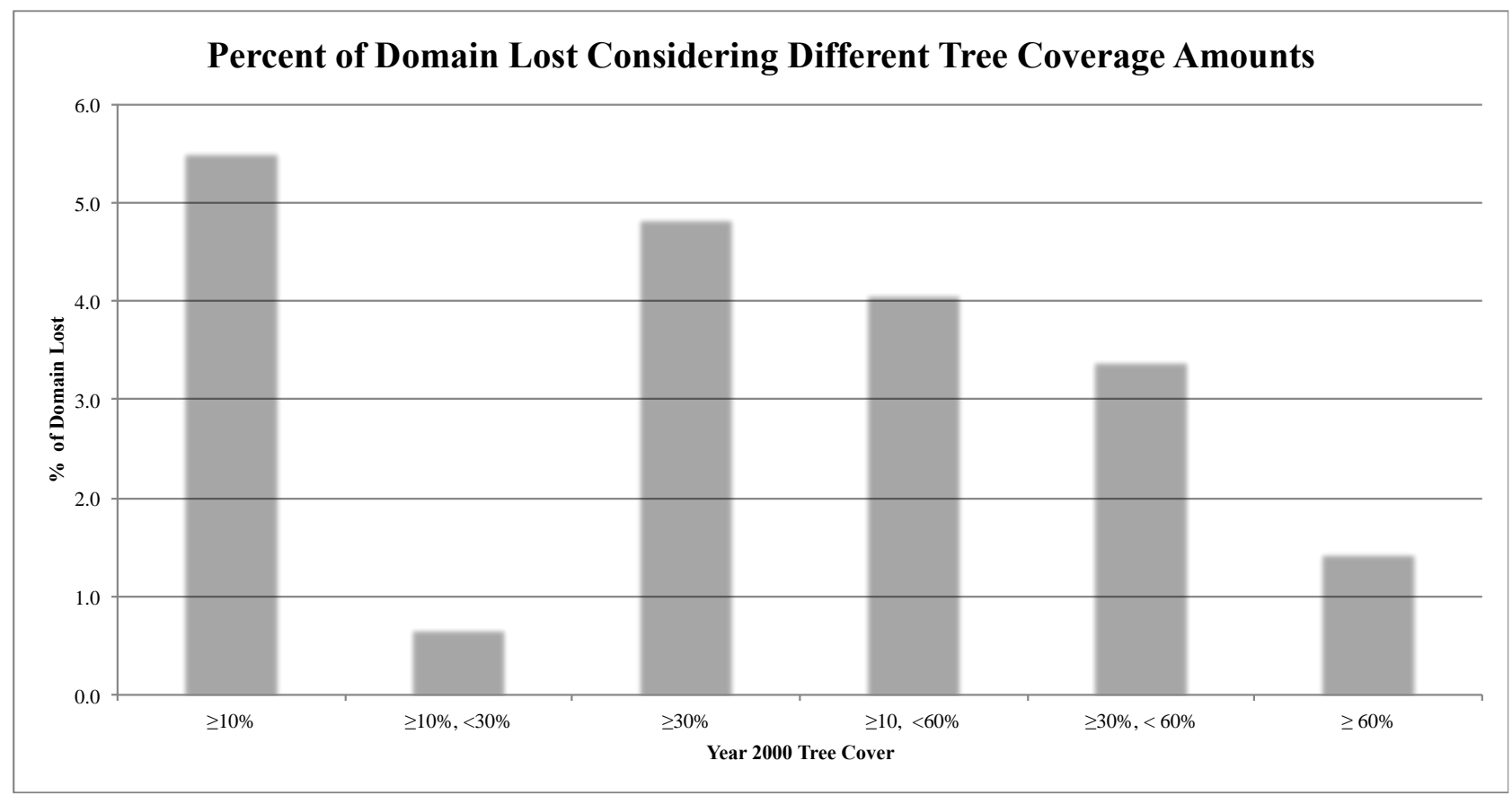

Figure 16. Percent of domain lost. Here, each tree coverage category from the year 2000 was considered individually, with all other tree coverage amounts masked. 
From these statistics, we can see that the modified land cover map underestimates tree cover loss, especially when we consider tree coverage ranging from savanna $(\geq 10 \%)$, to forested areas ( $\geq 60 \%$ ), which were both modified in our new land cover map.

According to these statistics, $5.5 \%$ of the domain was lost to deforestation, and another $0.6 \%$ was reforested for a net loss of $4.9 \%$ of the domain. In comparison, $3 \%$ of the entire domain was altered in the new land cover, with a difference of $1.9 \%$.

Table 5. Coverage for each land cover class in the WRF land cover. Each pixel is $\mathbf{1 ~} \mathbf{k m}$.

\begin{tabular}{lrr}
\hline \multicolumn{1}{c}{$\begin{array}{c}\text { WRF Land Cover } \\
\text { Class }\end{array}$} & $\begin{array}{c}\text { Pixels in } \\
\text { domain }\end{array}$ & $\begin{array}{c}\text { Percent of } \\
\text { Domain }\end{array}$ \\
\hline \hline Urban & 18 & 0.0 \\
Dryland Cropland & 17,760 & 15.4 \\
Cropland/Grassland & 43 & 0.0 \\
Cropland/Woodland & 4,389 & 3.8 \\
Grassland & 143 & 0.1 \\
Savanna & 43,865 & 38.0 \\
Deciduous Broadleaf & 22,804 & 19.7 \\
Evergreen Broadleaf & 1,247 & 1.1 \\
Mixed Forest & 9,246 & 8.0 \\
Water & 15,112 & 13.1 \\
Barren & 948 & 0.8 \\
Total & 115575 & \\
\hline
\end{tabular}

Also of note is the apparent mismatch between the 2000 tree cover and the forest cover classes within WRF, as seen in Table 5. Forest classes account for $28.8 \%$ of the model domain, while only $7.7 \%$ of the Hansen dataset shows a forest cover of above $60 \%$ in the year 2000 .

\subsection{Modeling Framework}

We approached this study as a sensitivity analysis; comparing two land cover datasets within the same modeling parameters. We selected the WRF model for its high resolution and its physical representation of land-atmosphere interactions. The WRF 
model works by dynamically downscaling climate data by simulating coupled landatmosphere dynamics in response to input atmospheric conditions at the domain boundaries and land surface vegetation and soil characteristics (Skamarock et al., 2008). In this way, we can achieve much finer resolution results than a global climate model, with information pertaining to the whole atmospheric column. To capture the modeled differences due to land cover change we implemented two scenarios. In one scenario, we used the original WRF land cover, and in the other we used WRF land cover modified to incorporate deforestation. All other boundary conditions are maintained in both scenarios. The methodology for creating this modified land cover dataset is described in the following section. We followed the methodology in Figure 17 to create different model input scenarios with different land cover forcing.

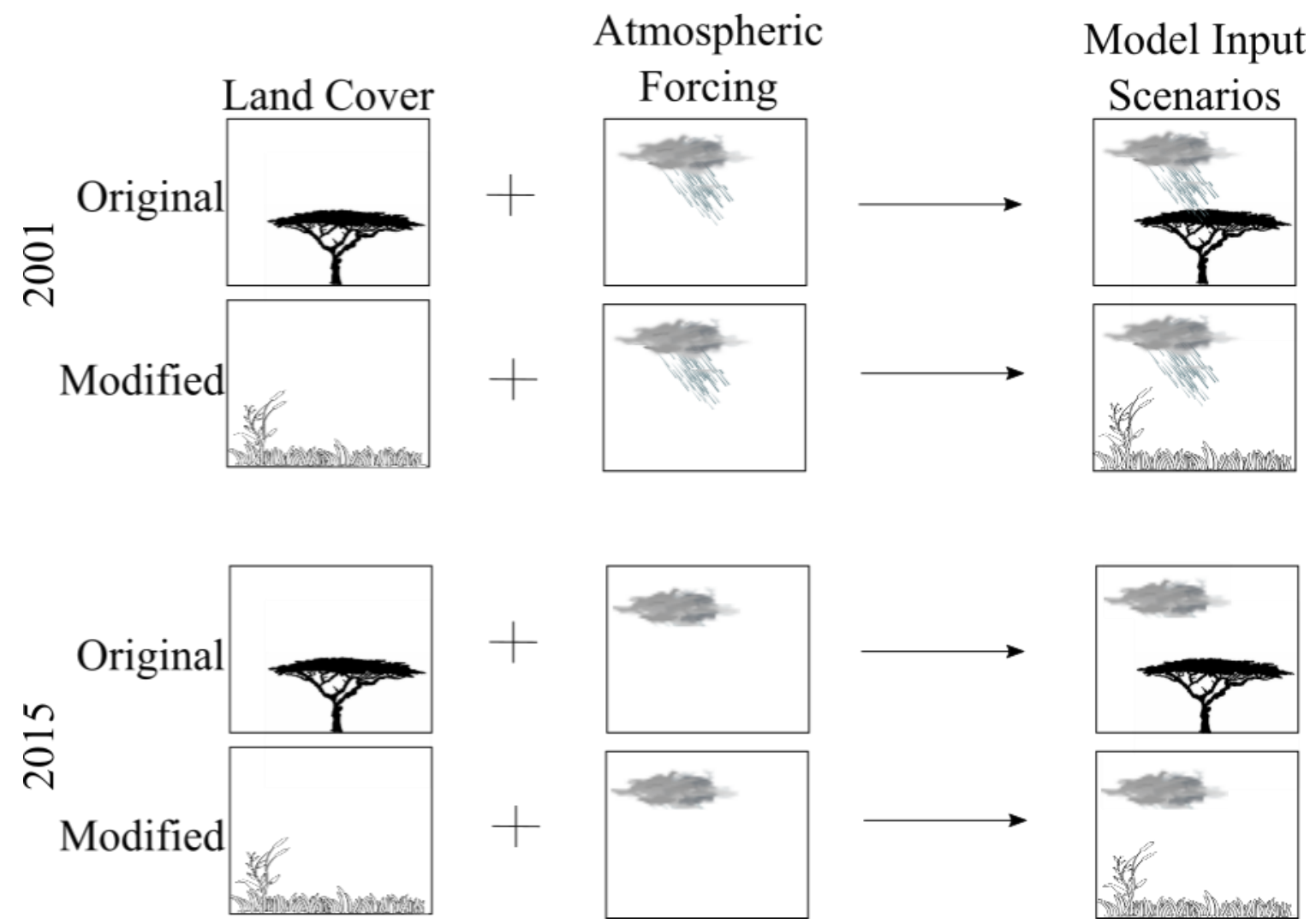

Figure 17. Conceptual diagram of model input scenarios used in this study. 


\subsection{WRF Model Parameterization}

All model runs were performed on the National Center for Atmospheric Research's Wyoming Super Computing Center on the Yellowstone supercomputer, with WRF Version 3.8.1, built with an Intel compiler. We selected European Reanalysis (ERA-Interim) as the atmospheric forcing for WRF as it has been shown to perform better than other reanalysis data in representing the weather patterns in Africa (Siam et al., 2013). Reanalysis data are particularly useful for atmospheric forcing for their long period of record that assimilates historical data. All data resulting from a reanalysis project were formed from consistent methods of data assimilation and modeling, allowing for uniformly updated methodology that spans long time periods of analysis. From the ERA-Interim analysis, we chose two time periods of atmospheric forcing: a wet year (2001), and a dry year (2015). We chose a time period of March - May (with a twomonth spin-up) to study. This period of time corresponds to a shoulder season, moving from the rainy season to the dry season. In this way, we were able to examine both the extremities in rainfall, as well as an intermediate time period for each. We selected a domain size for the innermost domain that is small enough to resolve convective scale circulations $(<4 \mathrm{~km})$, but large enough to capture potential regional-scale biophysical effects of deforestation on hydroclimate. 
Table 6. Parameterizations selected to use in all WRF model scearnios.

\begin{tabular}{|c|}
\hline WRF Parameterization \\
\hline Scheme \\
\hline f................... WDM 6 Class \\
\hline Longwave Radiation .......................... CAM3 \\
\hline Shortwave Radiation.......................... CAM3 \\
\hline Surface Layer ..................................... Monin-Obukhov \\
\hline Land Surface Physics......................... Noah-MP \\
\hline Planetary Boundary Layer Physics........... Mellor-Yamada-Janjic \\
\hline Cumulus Scheme (outermost domain)........ Betts-Miller-Janjic \\
\hline Domain Resolutions...................... 25 km, 5 km, 1 km \\
\hline
\end{tabular}

Table 6 shows the parameterizations within WRF that were selected for our simulations. We selected the Noah-MP land-atmosphere model for its complex vegetation representation, canopy layer radiation transfer with shaded fraction, soil moisture and heat fluxes, runoff, evaporation from open water, and interaction with an aquifer layer (Niu et al., 20011). We selected the WRF Double Moment 6-Class microphysics scheme for precipitation convection (Hong et al., 2010) and the BettsMiller-Janjic cumulus scheme by Betts (1989), Betts and Miller (1986), and Janjic (1994). The cumulus scheme was only active in the outer two domains of the simulation because the innermost, highest resolution domain is capable of resolving convective motions. These microphysics and cumulus scheme selections were based on a study by Surussavadee and Aonchart (2013) that showed that these schemes performed well in the tropics. 


\section{CHAPTER FOUR: ANALYSES AND RESULTS}

In our analyses, we first focused on overall regional trends of the energy and water balance. We then focused on topography and its role in affecting the hydroclimatic changes from deforestation. Here we focus on results from the year 2001. Additional Results from 2015 can be seen in Appendix B, "Supplemental Figures." According to the African Flood and Drought Monitor (Sheffield et al., 2013), for the time period of 2000 2017, 2001 was the wettest year for the study domain, and 2015 was the driest year.

\subsection{Regional Spatial Analysis}

\subsubsection{Analysis Method}

In analyzing the regional trends in the water and energy balance, we took the monthly average at each cell in the model output. We then subtracted the monthly averaged spatial fields from the simulation with the WRF land cover case (hereafter referred to as the control case) from the modified values. Resulting maps, therefore, show the modeled change due to deforestation.

\subsubsection{Net Radiation}

For net radiation, for each hourly output we subtracted the outgoing shortwave and longwave from the incoming shortwave and longwave, then found the average monthly values at each cell. In this instance, we found the percent difference in net radiation to show the magnitude of change. The largest driver of incoming net radiation 

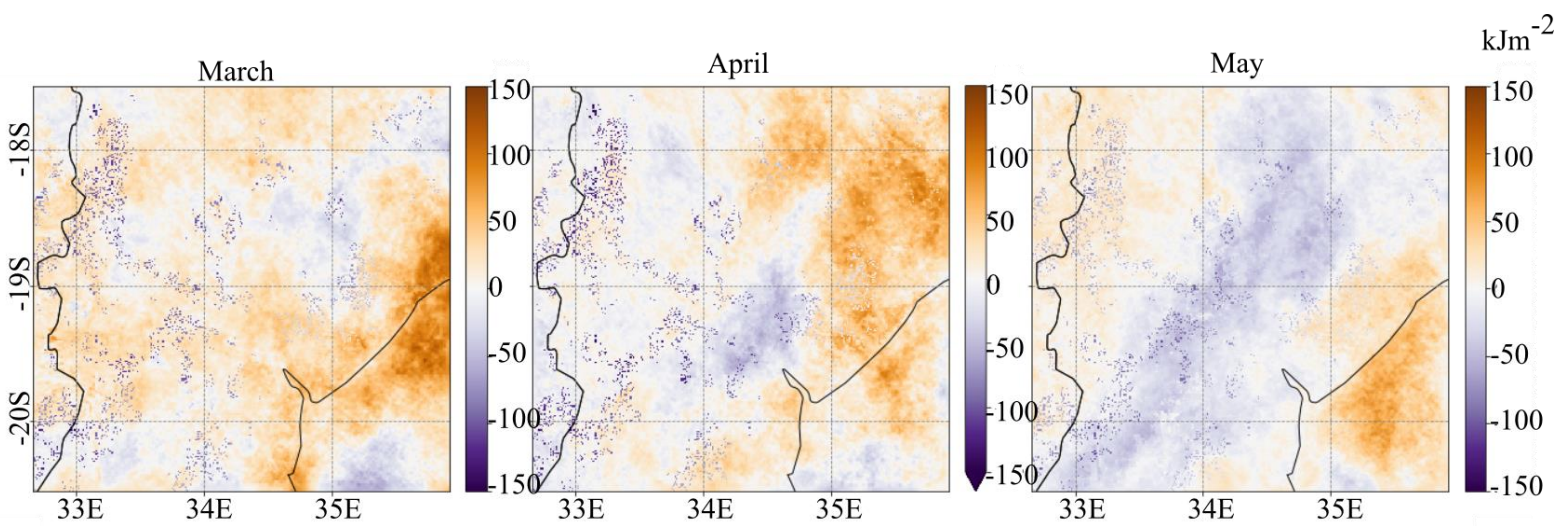

Figure 18. Monthly change in modeled net radiation due to LCC, 2001.

at the microclimatic scale is albedo. Removal of the darker forest cover leads to an increase in albedo. This decreases net radiation at the location of deforestation as more incoming shortwave radiation is reflected. The largest driver of incoming net radiation at the regional scale is cloud cover, a conclusion for which we provide additional justification in the following sections. Regional net radiation due to cloud cover is much more variable than the albedo change, but covers a larger scale. Incoming longwave radiation and reflected shortwave radiation have opposite effects, as less cloud cover during the day leads to more incoming shortwave and more cloud cover reflects outgoing long wave back to surface, increasing longwave down. The change in net radiation is driven by changes in incoming shortwave, leading to an average net increase in incoming radiation.

\subsubsection{Turbulent Fluxes}

To examine the turbulent fluxes, we show both the upward latent heat flux and upward sensible heat flux in Figure 19. 


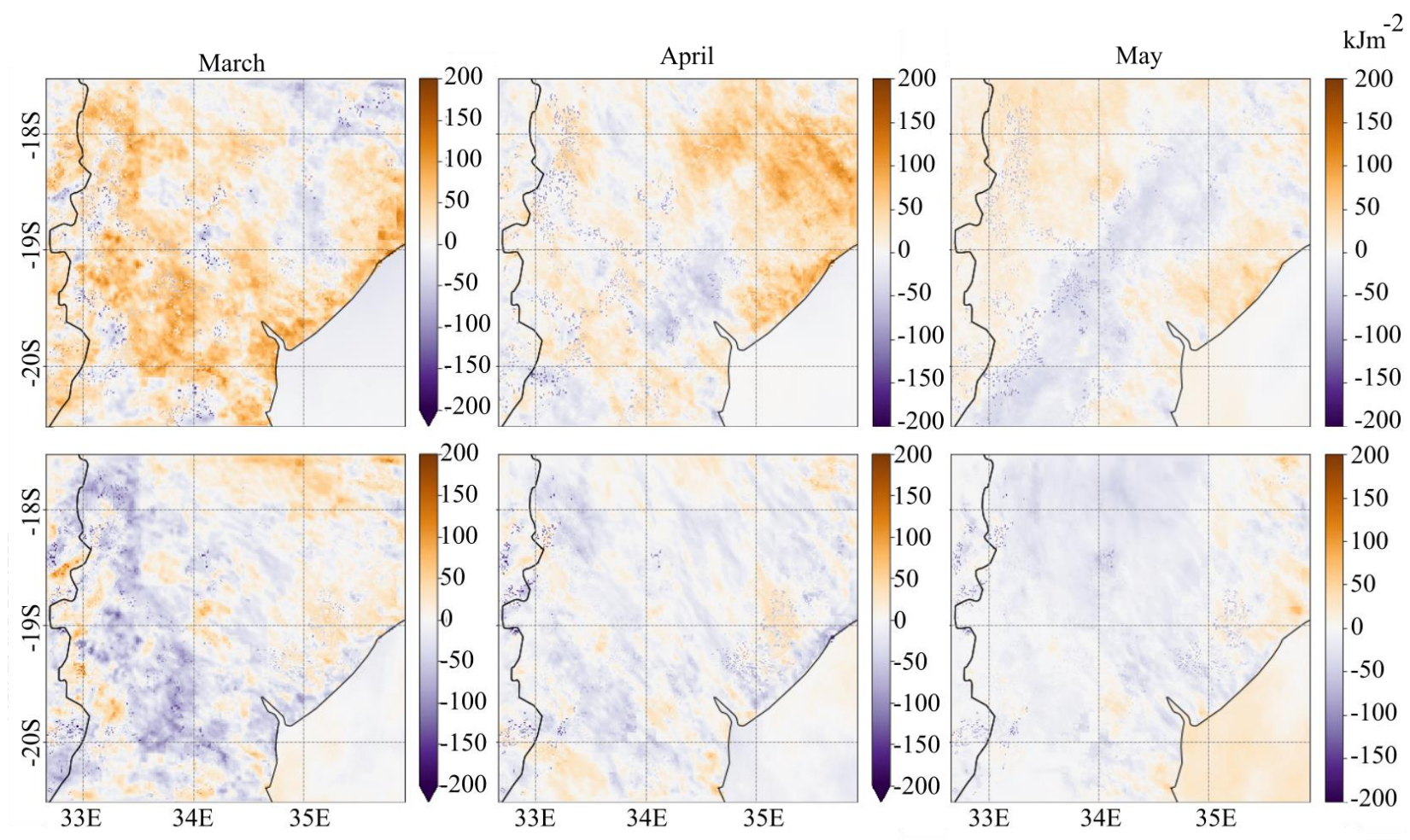

Figure 19. Monthly change in modeled upward sensible heat flux at the surface (top panel) and upward latent heat flux at the surface (bottom panel), 2001, due to LCC.

In viewing the patterns of these turbulent fluxes along with the patterns of net radiation, several observations emerge. First, some of the patterns from net radiation changes are the largest driver of change within the turbulent fluxes as well. This can be seen in the May panel for sensible heat change. When there is less net radiation available, there is a corresponding decrease in energy partitioned to sensible heat (and vice versa). Second, there are other times where the latent heat portion of the energy balance is a larger driver in change in the sensible heat flux. This can be seen in the March panel for latent heat flux change. Here, along the western edge of the domain we can see a large decrease in latent heat from the control case to the modified case. This matches the same area in the sensible heat change panel, with a decrease in latent heat flux resulting in a corresponding increase in sensible heat. From March to May, our study site becomes 
increasingly drier, so whether latent heat flux or net radiation drives changes in partitioning of energy may be determined by the amount of moisture available for evapotranspiration. Further evidence for this can be seen in Appendix B, "Supplemental Figures.”

\subsubsection{Cloud Cover}

Here we show the difference in cloud cover in the lower portion of the atmosphere. To solve for these changes, we found the difference between the modified and control runs for the cloud fraction from a representative model layer in the lower atmosphere.
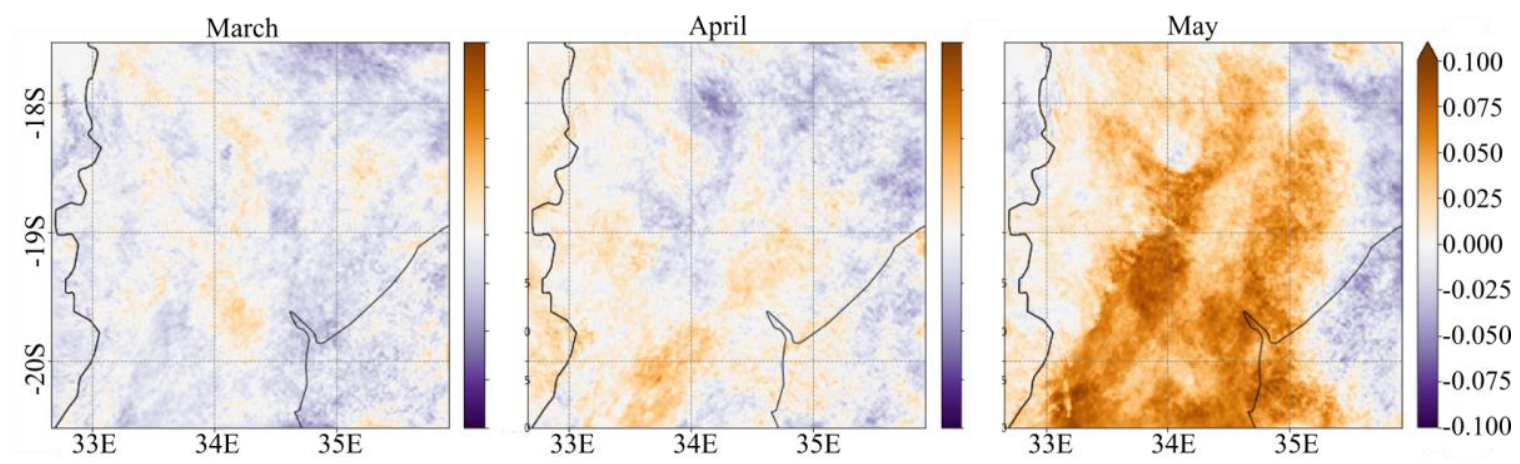

Figure 20. Monthly change in modeled cloud cover fraction due to LCC, 2001.

Cloud cover in the upper atmosphere did not change between the different model scenarios. Cloud cover change in the lower atmosphere matches the patterns of change in net radiation, as shown in Figure 18. Here we can see the cloud cover transitioning farther south due to LCC, particularly in the April and May cases.

\subsubsection{Temperature at 2 meters}

The general trend in temperature change is an increase in temperature, with the loss of evaporative cooling and the gain in incoming solar radiation being the main forcing. However, there is some variability, as the shifting cloud cover in May decreases 
incoming solar radiation in the southwestern portion of the domain. This leads to an average decrease in temperature in these areas. Here we see the sum of all of the effects from each energy balance parameter together. As we move from a wetter month to a drier month, warming due to a decrease in latent heat flux becomes less important and an increase in cloud cover drives cooling in some areas.
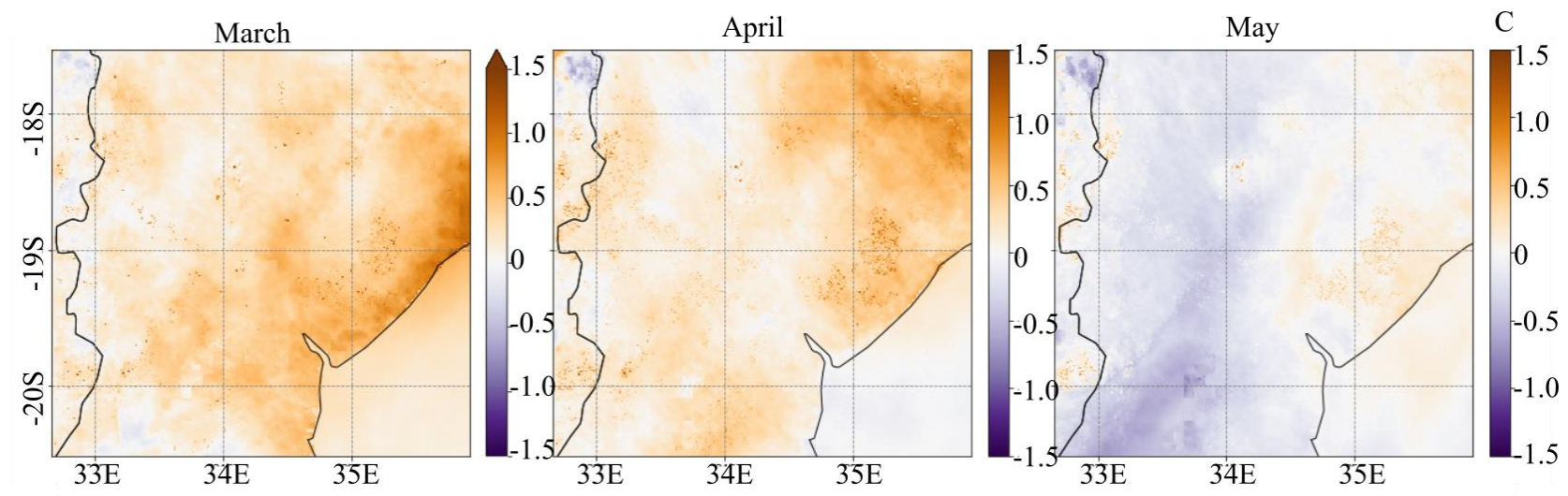

Figure 21. Monthly change in modeled temperature due to LCC, 2001.

\subsubsection{Rainfall}

Here we show the difference in the total rainfall amounts at each cell. Here there are patterns indicating a shift in rainfall due to LCC. For example, in the March case, rainfall shifts from an increased amount in the south during the control case to an increased amount in the north during the modified case. Along with this redistribution of 
rainfall, there is a net decrease in the total amount of rainfall from the control case to the modified case. Total depth amounts will be discussed in the next section.
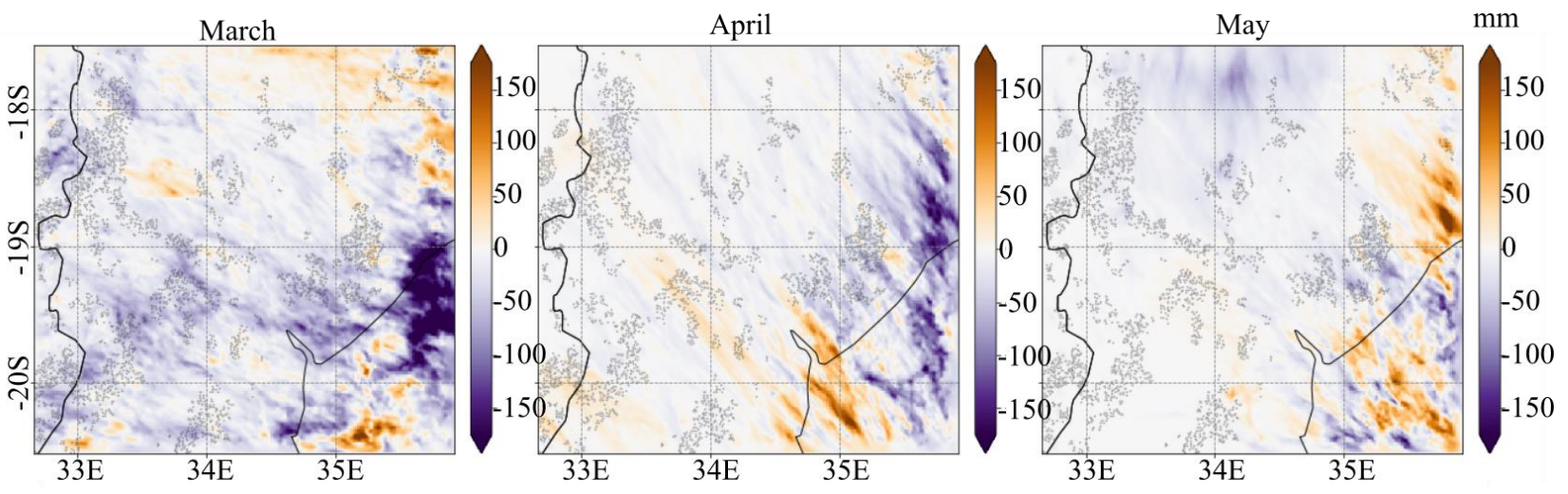

Figure 22. Monthly change in modeled accumulated rainfall, 2001, with LCC pixels shown in black.

\subsubsection{Table Summaries of Regional Analysis}

Here we show statistics of the percent change in domain-wide average values for the region for key components of the surface energy balance. It should be noted that there is no change in energy storage in the ground in the LCC scenario. Also, there is no net change in the average temperature between the two runs for the three-month time period. The net average values for all parameters in the energy balance show very little change, indicating that the majority of changes are at the microclimatological scale. This also indicates that the majority of the change results from a redistribution of the energy balance. 
Table 7. Percent difference in each modeled parameter due to LCC.

\begin{tabular}{lcccc}
\hline & Mean & Max & Min & Std Dev \\
\hline \hline Latent Heat Flux & 1.1 & 0.1 & 0.0 & 2.0 \\
Sensible Heat Flux & 0.3 & 0.2 & 1.0 & 1.5 \\
Longwave Up & 0.1 & 0.1 & 0.1 & 2.0 \\
Longwave Down & 0.1 & 0.1 & 0.1 & 1.0 \\
Shortwave Up & 0.9 & 0.4 & 1.9 & 2.8 \\
Shortwave Down & 0.1 & 0.1 & 0.2 & 0.8 \\
\hline
\end{tabular}

However, in the case of rainfall, even the aggregated values of accumulated rain for the whole domain show notable differences between the control and modified scenarios.

LCC results in a net loss of average rainfall depth for the whole time period, though we can see that the greatest differences occur in months where rainfall is greatest.

Table 8. Domain-wide accumulated rainfall depth for each month, in $\mathbf{m m}$.

\begin{tabular}{ccc}
\hline & Original & Modified \\
\hline \hline March & 34 & 17 \\
April & 24 & 19 \\
May & 16 & 13 \\
Total & 73 & 49 \\
\hline
\end{tabular}

Table 9. Monthly change in modeled accumulated rainfall due to LCC, in $\mathbf{m m}$.

\begin{tabular}{ccccc}
\hline & Mean & Stdev & Max & Min \\
\hline \hline March & -17 & 31 & 162 & -353 \\
April & -5 & 23 & 142 & -196 \\
May & -3 & 19 & 250 & -102 \\
Total & -25 & 39 & 186 & -381 \\
\hline
\end{tabular}

\subsection{Rain Case}

Here we investigate one rainfall event to examine the role of weather patterns and terrain further. By looking at one rainfall event, we can see how the local weather patterns at the time of the event interact with the topography of the domain area. This rainfall event takes place from April 4-9, 2001. The total rainfall in the domain from this event is $21 \mathrm{~mm}$ in the control run, and $16 \mathrm{~mm}$ in the modified scenario. For this 
analysis, we used the same WRF model output from the previous analyses, but subset the output to the time and areas of concern.

\subsubsection{Spatial Patterns of Event}

Here we show accumulated rainfall and cloud cover changes during the rain event for the whole domain, using the same analyses methods described previously.

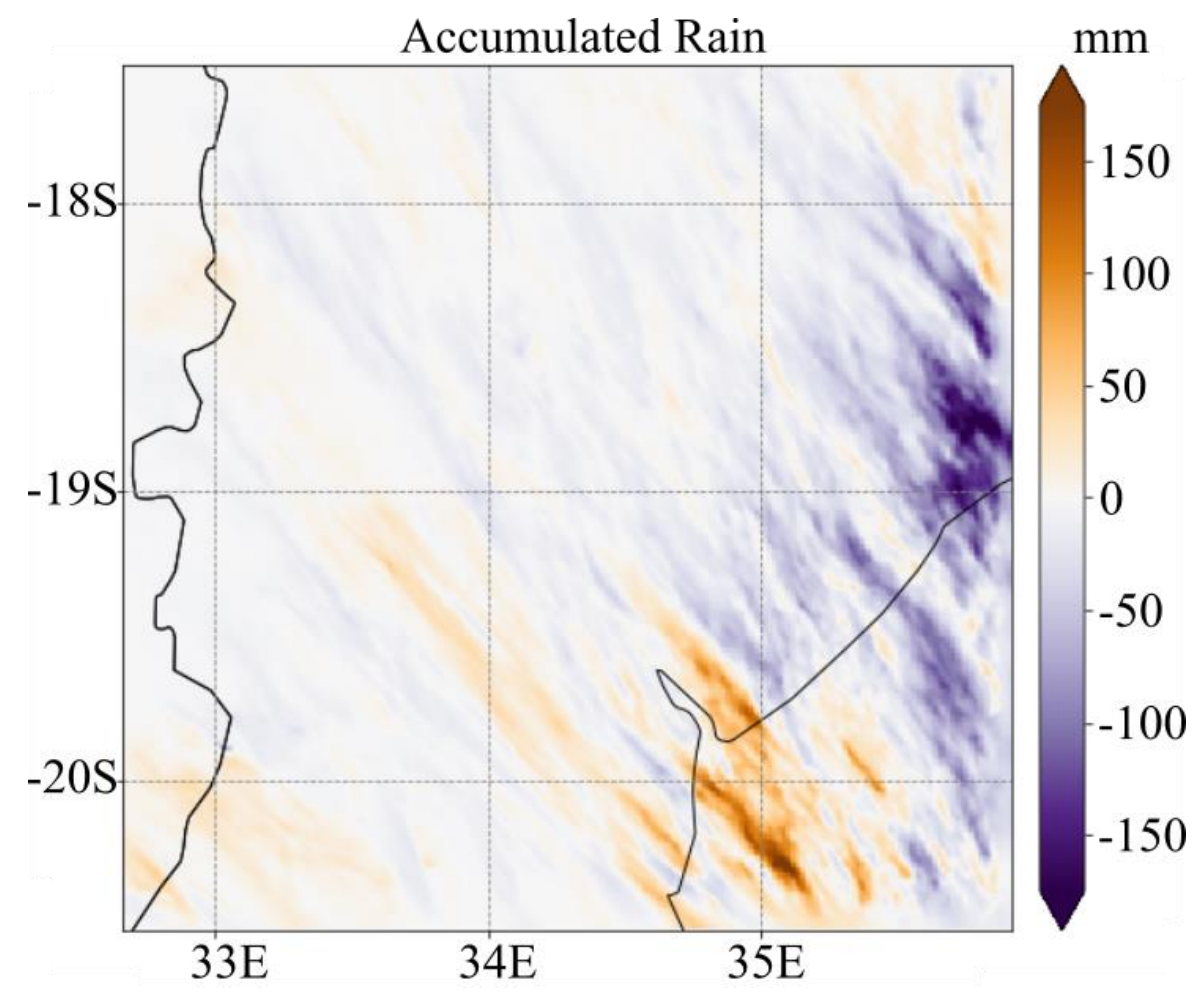

Figure 23. Difference in accumulated rainfall for the April 4 - 9 event, due to LCC.

In Figure 23, rainfall fell in the central part of the domain in the control case, but the rainfall fell in the southern portion of the domain in the modified case. 


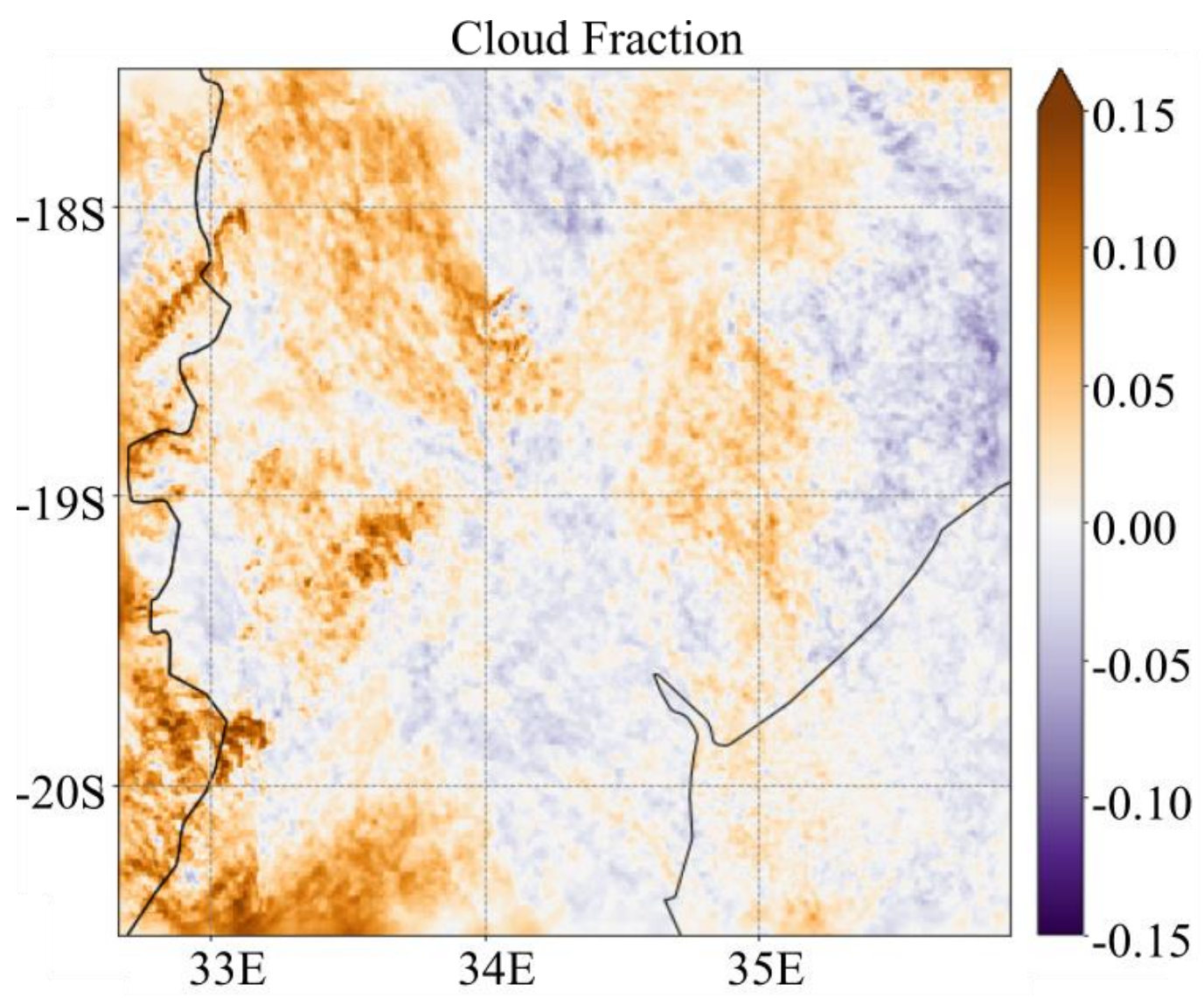

Figure 24. Difference in modeled cloud fraction for the April 4 - 9 rain event, due to $\mathbf{L C C}$.

In Figure 24, the differences in cloud fraction show interaction with terrain such as Mount Gorongosa in the north central portion of the domain, or the mountain range in Zimbabwe just to the west of Mozambique. To explore the impact of these changes in rainfall and cloud cover in combination with the topography of Mount Gorongsa on the energy and water balance, we used the methods detailed in the next section.

\subsubsection{Locational Analysis Method}

In order to examine the role of mountainous terrain in our study area during a rainfall event, we examined differences between the modified land cover and control cases in a successively increasingly large window surrounding Mount Gorongosa (Figure 25). 


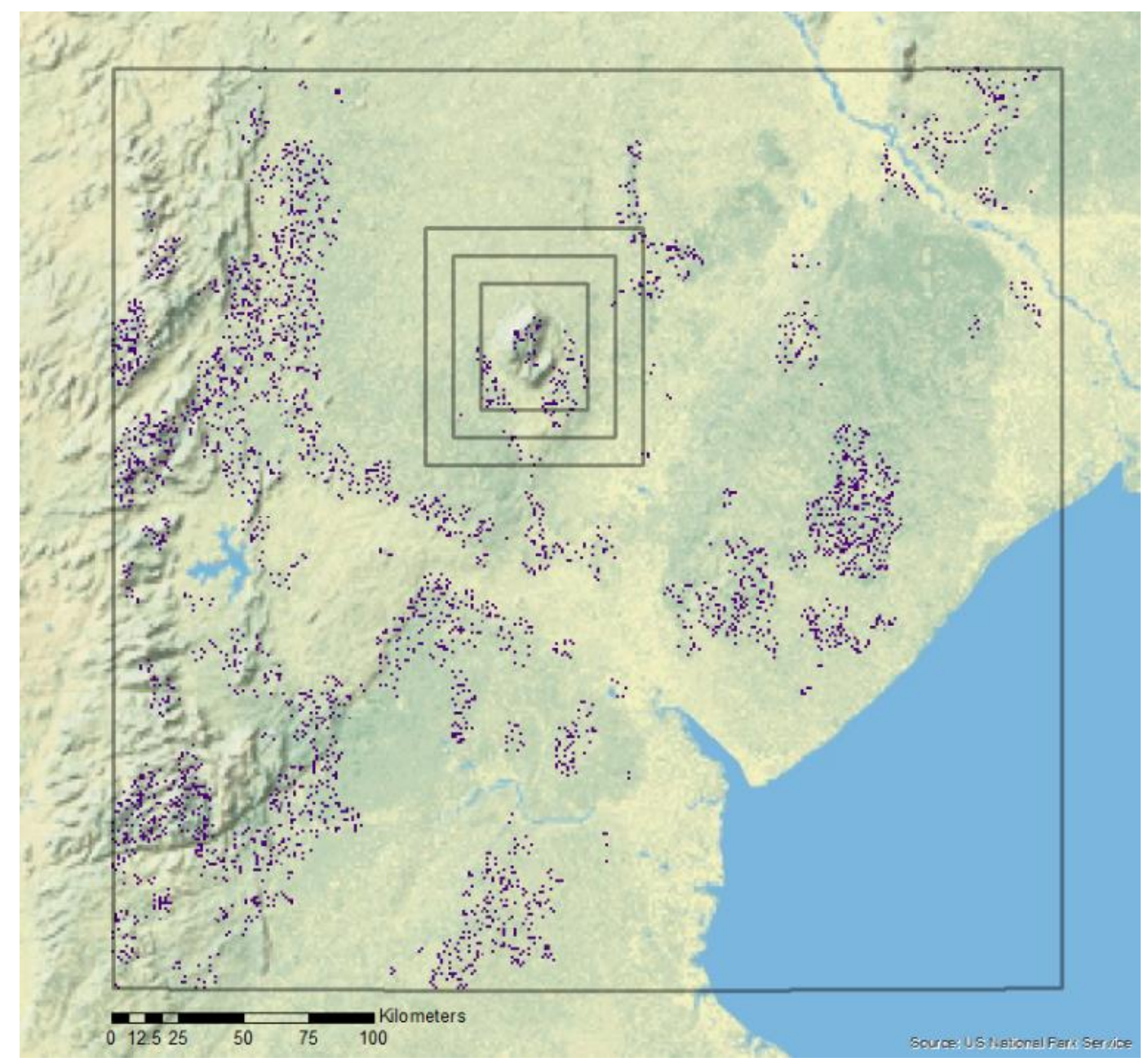

Figure 25. Here the domain and LCC pixels are shown. Surrounding the mountain are the boxes used for this analysis, expanding $10 \mathrm{~km}$ then $20 \mathrm{~km}$ on each side.

First, we selected several boxes around the mountain area: the first surrounding Mount Gorongosa and contains the majority of the tree cover loss area according to the Hansen dataset. Each successive box after expands the analysis area by $10 \mathrm{~km}$ on each side of the box. In this way, we are able to examine how each variable interacts with the topography, particularly in a case where the local meteorological patterns are changing in one scenario to another. Then, for analysis of each variable, we used the kernel density estimation function within Matlab, ksdensity (Hill, 1985, Silverman, 1986, Jones, 1993, and Bowman and Azzalini, 1997), to estimate a probability density function (PDF) for 
each variable of interest in both the control run and modified model simulations. We utilized the non-parametric measure of rank correlation by Kendall (Kendall, 1938) to determine the agreement between the PDFs in each scenario, given by $\tau$. The values of $\tau$ range from -1 to 1 , with a positive $\tau$ indicating concordance between each pair of variables (Kendall, 1938). A small p-value (less than 0.05) indicates that the PDFs are significantly non-correlated (Kendall, 1938).

\subsubsection{Locational Analysis Results}

\subsubsection{Longwave Radiation}

Outgoing longwave radiation will indicate how the area emits absorbed radiation, and incoming longwave radiation will indicate how it receives this emitted radiation, reflected back from the cloud cover. In our rainfall event, we see very little change between the control and modified runs in the longwave radiation variables.
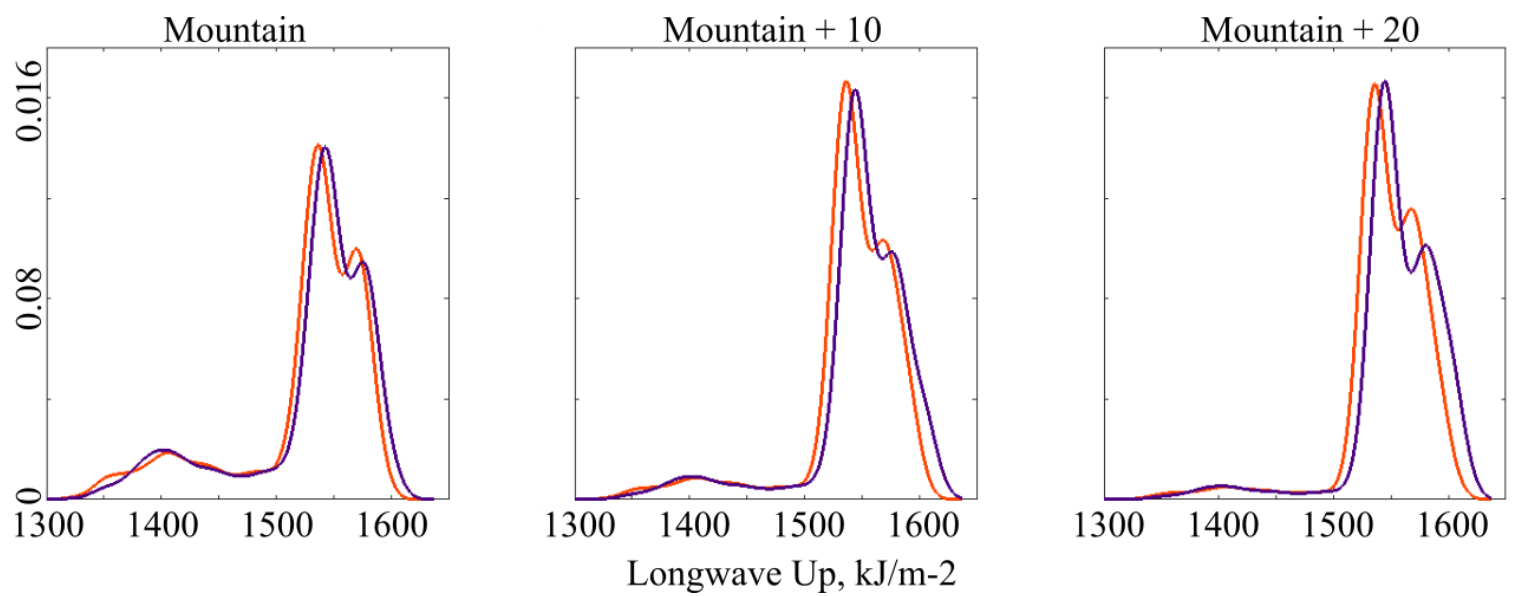

Figure 26. Probability density functions for outgoing longwave radiation. Control case in orange and modified case in indigo. $\tau$ values from left to right: $0.87,0.84,0.83$. All have a p-value of $<0.01$. 

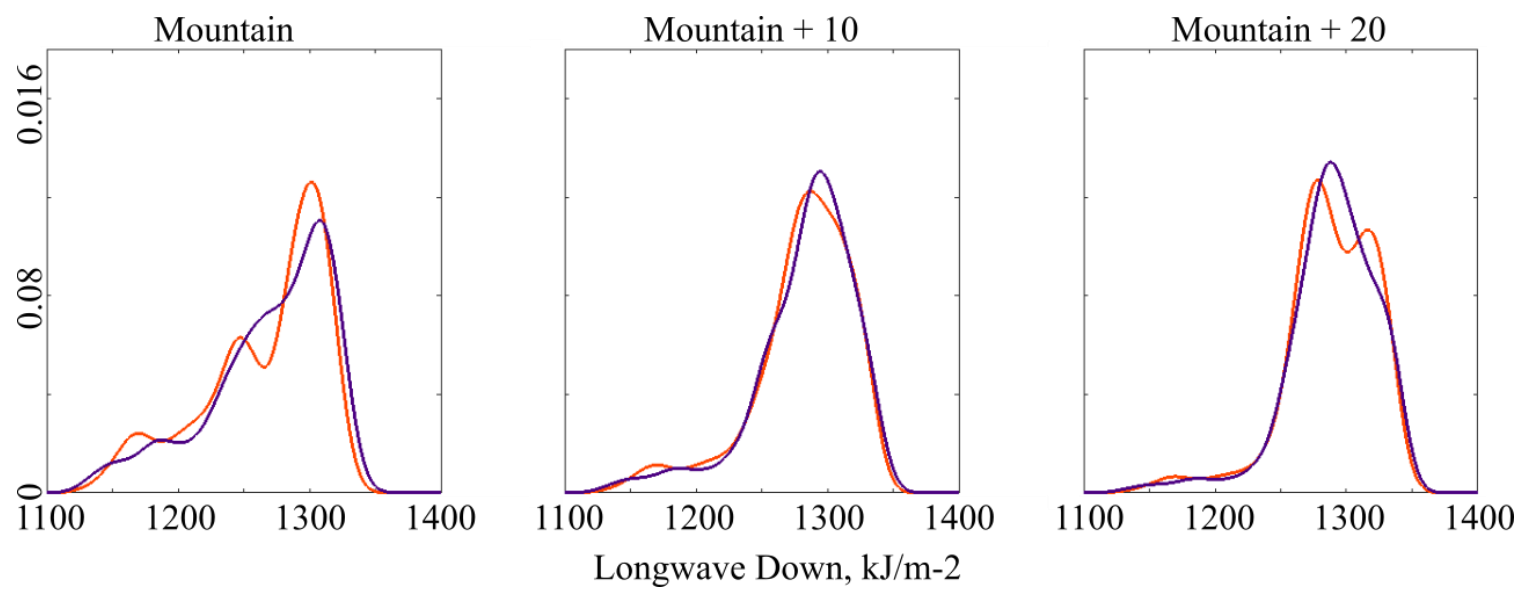

Figure 27. Probability density functions for incoming longwave radiation. Control case in orange and modified case in indigo. $\tau$ values from left to right: $0.93,0.96,0.95$. All have a p-value of $<0.01$.

In Figure 27, incoming longwave at the location directly around the mountain has the most change. In this plot (Figure 27, left panel), there are three major modalities within the control case, with three different types of vegetation interacting with the longwave radiation. In the modified scenario, the three modalities still exist, but there is smoothing between these groups, most likely due to the added interaction with increased cloud cover in this particular rainfall event.

\subsubsection{Shortwave Radiation}

Differences in incoming solar radiation will indicate how much of the radiation from the sun was intercepted or reflected by cloud cover. Outgoing solar radiation will indicate how the land cover reflects the solar radiation. Shortwave radiation is also most impacted at the location surrounding the mountain. These effects are shown in Figure 28 and Figure 29. 

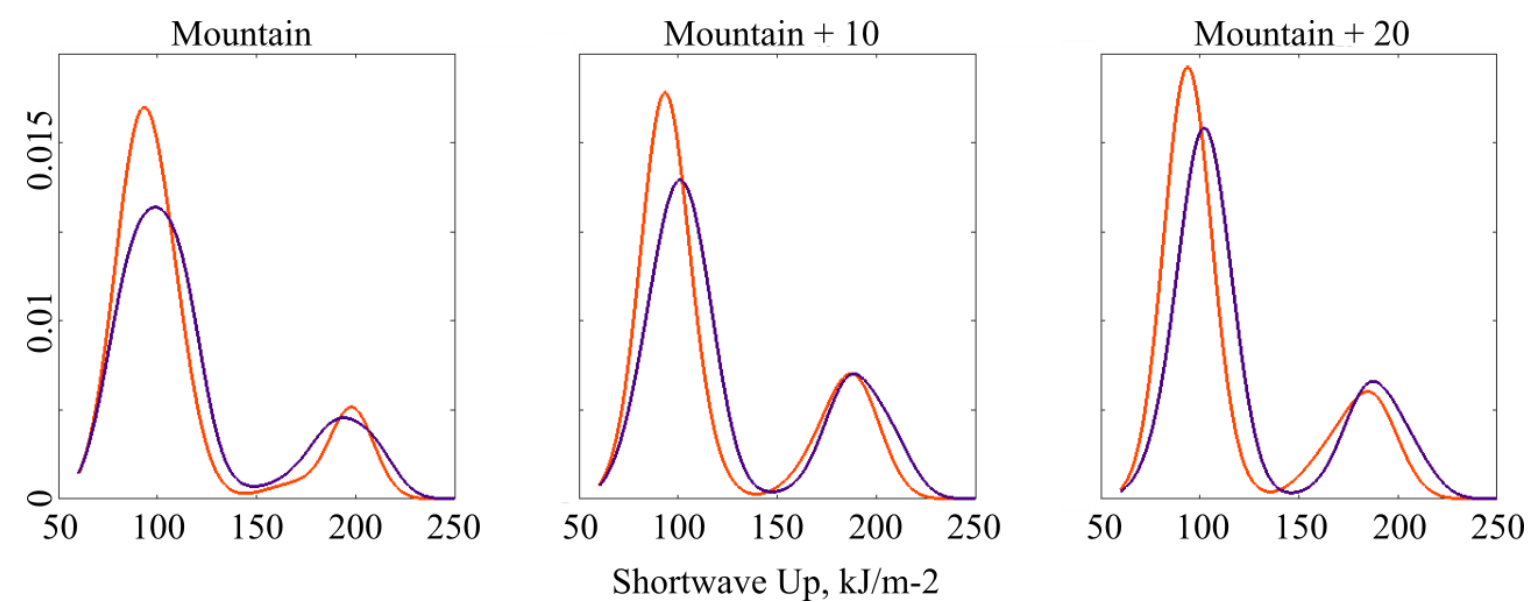

Figure 28. Probability density functions for outgoing shortwave radiation. Control case in orange and modified case in indigo. $\tau$ values from left to right: 0.90 , $0.81,0.77$. All have a p-value of $<0.01$.
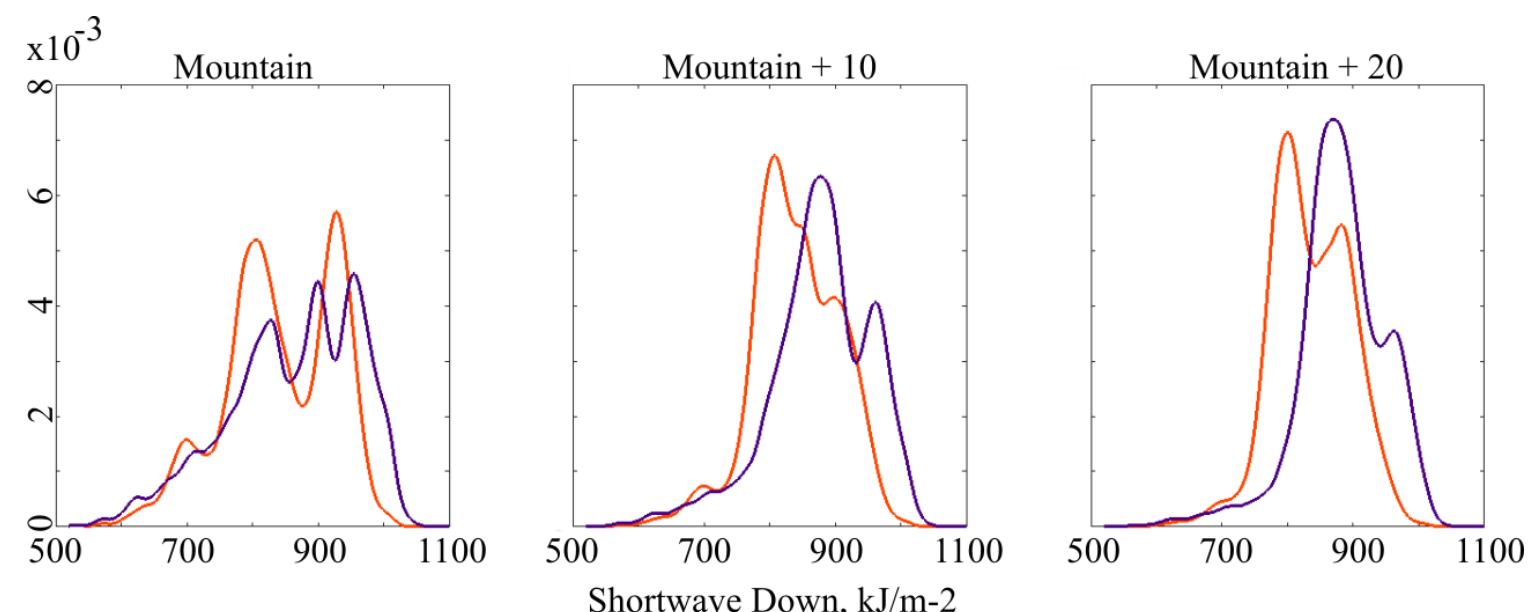

Figure 29. Probability density functions for incoming shortwave radiation. Control case in orange and modified case in indigo. $\tau$ values from left to right: 0.73 , $0.73,0.74$. All have a p-value of $<0.01$.

In Figure 28, the largest effects on reflected shortwave occurs exactly at the location of the vegetation change. The difference between PDFs of upward shortwave radiation between the modified and control runs show smaller differences when examining the larger surrounding areas. In Figure 29 there are significant differences in the PDFs between the control and modified runs, which we attribute to the changes in cloud cover between the runs. Specifically, an increase in cloud cover in the modified 
scenario shifts the modes of the incoming shortwave radiation values lower. Again, these effects become smaller the more area we include around the mountain.

\subsubsection{Upward Sensible Heat Flux}

The sensible heat flux indicates the amount of energy related to changes in temperature. Here the sensible heat flux shows a secondary peak around $500 \mathrm{~kJ} / \mathrm{m}-2$ near the mountain in both the control and the modified scenarios, but the peak is larger for the modified scenario.
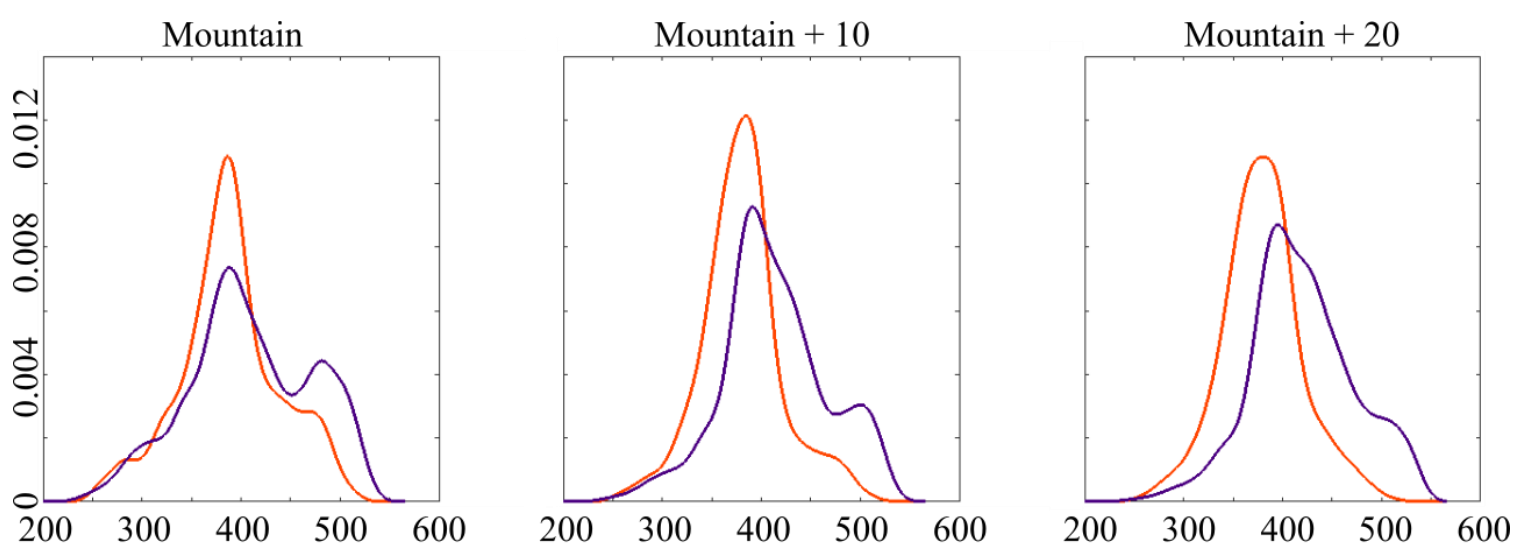

Upward Sensible Heat Flux, kJ/m-2

Figure 30. Probability density functions for upward sensible heat flux at the surface. Control case in orange and modified case in indigo. $\tau$ values from left to right: $0.91,0.88,0.85$. All have a p-value of $<0.01$.

As we move farther away from the mountain, the PDFs between the control and modified runs become more similar, but a smaller peak still remains at $500 \mathrm{~kJ} / \mathrm{m}-2$ in the modified scenario. The control scenario has much lower values of upward sensible heat flux, as more of the available net radiation is being partitioned to the latent heat portion of the energy balance.

\subsubsection{Upward Latent Heat Flux}

The latent heat flux indicates the amount of energy related to changes in phase. In the upward latent heat flux, we can see that the probability density estimate curves have 
the greatest divergence beyond the mountain itself. Latent heat flux is controlled by evapotranspiration, as well as the movement of moisture through turbulent mixing. As air moves over mountainous terrain, the air cools which can facilitate precipitation of moisture in the air. Additionally, as the air interacts with topography, local wind speeds and movement can become more variable.
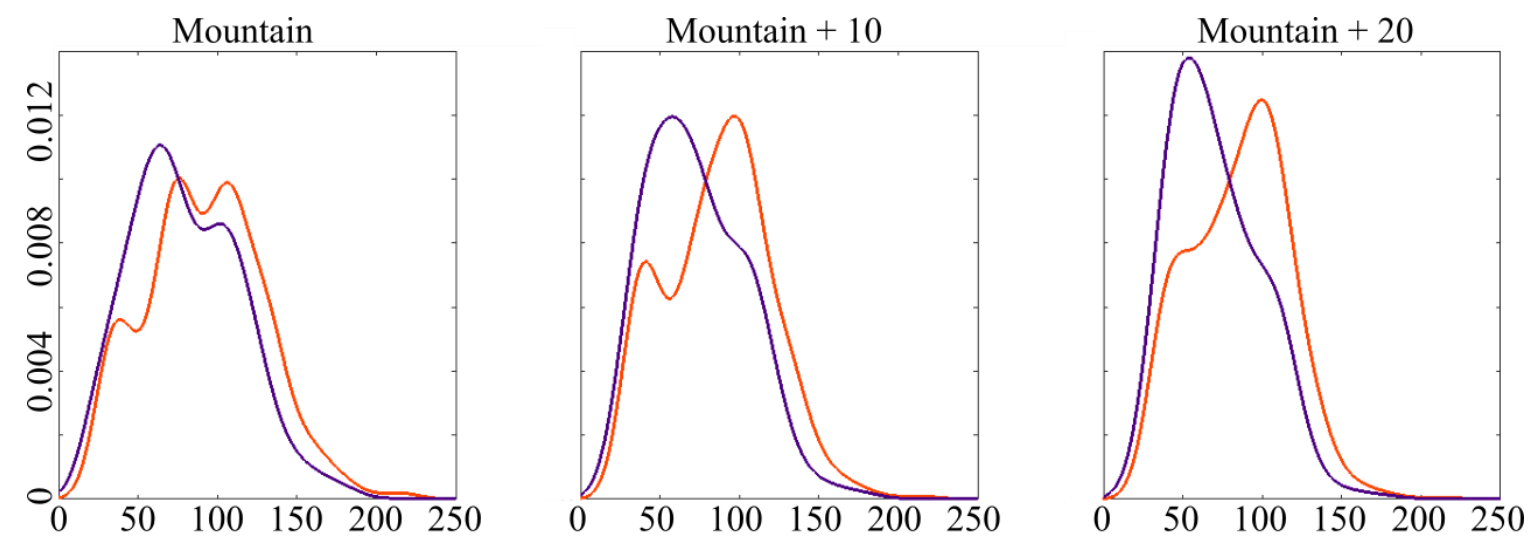

Upward Latent Heat Flux, kJ/m-2

Figure 31. Probability density functions for upward sensible heat flux at the surface. Control case in orange and modified case in indigo. $\tau$ values from left to right: 0.94, 0.93, 0.93. All have a p-value of $<0.01$.

Therefore, the turbulent fluxes are much more likely to be affected by the mountainous terrain than something like the reflectance of shortwave radiation which is mostly controlled by albedo. In Figure 31, as we move farther away from the mountain, the peak of the control PDF moves to higher values (closer to $100 \mathrm{kJm}^{-2}$ ), whereas the peak of the modified scenario remains near $50 \mathrm{kJm}^{-2}$. This indicates that more energy is redistributed to evaporative cooling in the control case, farther from the mountain. 


\subsubsection{Temperature at 2 meters}

When averaged over the space and time, the temperature differences are barely noticeable. There is a small shift to higher values in the modified scenario, but most variation is smoothed out in the averaging.
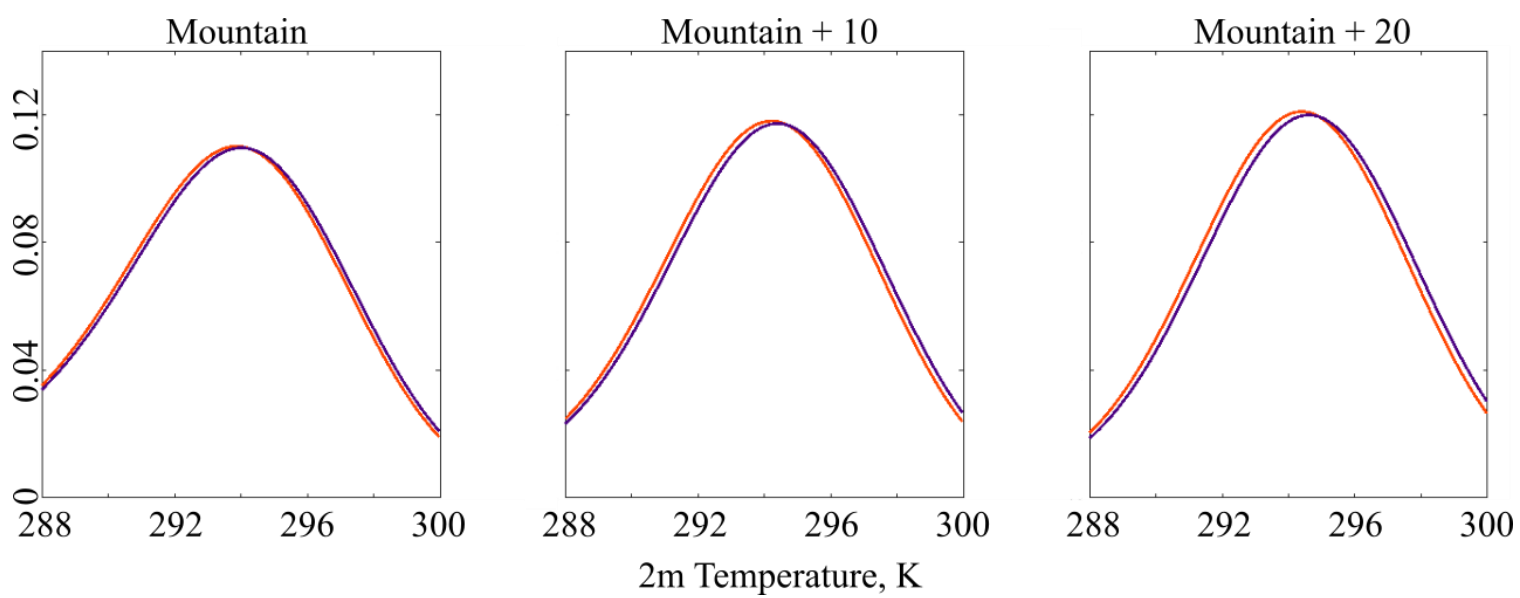

Figure 32. Probability density functions for $2 \mathrm{~m}$ Temperature. Control case in orange and modified case in indigo. $\tau$ values from left to right: $0.96,0.94,0.93$. All have a p-value of $<0.01$.

\subsubsection{Accumulated Rainfall}

In Figure 33, overall there is much less rainfall in the modified scenario, and the empirical probability distribution does not change significantly as we investigate larger regions. There is a small peak of $30 \mathrm{~mm}$ right near the mountain location, which may indicate a small increase in rainfall due to orographic lift. However, overall, the control case receives more rainfall overall. 

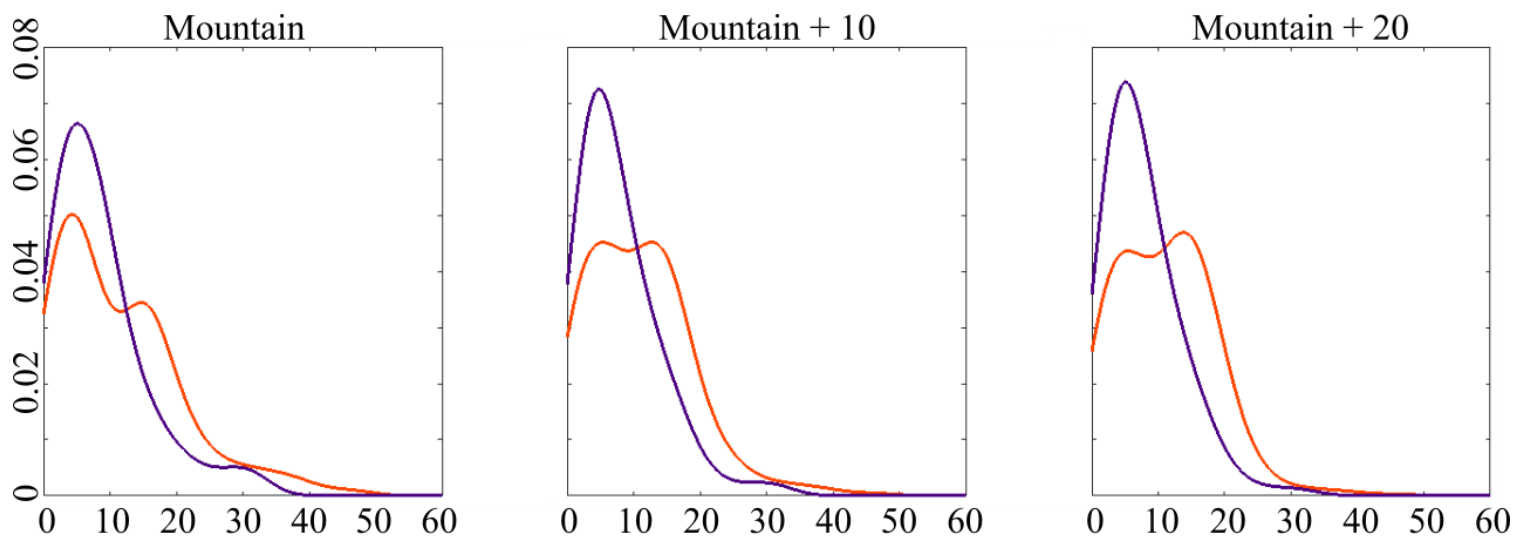

Accumulated Rainfall, mm

Figure 33. Probability density functions for accumulated rainfall. Control case in orange and modified case in indigo. $\tau$ values from left to right: $0.97,0.97,0.97$. All have a p-value of $<0.01$. 


\section{CHAPTER FIVE: DISCUSSION}

In the first portion of our study, we show a novel method for representing deforestation in a regional climate model. Though there is some underestimation of tree cover loss, especially in the savanna areas, this methodology represents a simplified way to fuse a dataset in the WRF model and the Hansen Global Forest Cover dataset together. One of the most difficult problems to overcome with comparing global land cover datasets is to find a way to translate one data type to another. We implemented a heuristic approach to determine an approximate level of change with correct spatial patterns at the spatial scale of the regional climate model. Our model was simplistic enough that it can be applied at larger scales and in a broad variety of environments. By relating loss amounts from the Hansen dataset to existing categorical land cover datasets, this methodology is applicable to all land cover types, though special care should be taken in each region to create rules of change based on the local history of deforestation and afforestation. Though our quasi-STM method showed promising results, adjustments should be made to better include forest cover loss in categories that already contain a small percentage of canopy cover. For example, we could incorporate the 2000 tree cover dataset to split our loss into percent loss per coverage amount. We could also split our thresholding into a finer resolution so that we can more effectively split the categories between those not experiencing loss (such as water) and those experiencing a small amount of loss. This will capture more of the deforestation that is occurring in land cover classes that do not have much canopy cover to begin with, such as savanna. 
We show that with this level of deforestation, some parameters exhibit effects at the location of the deforestation, while others are more likely to have farther reaching effects. This location in central Mozambique is particularly sensitive to alterations in latent heat flux, as the recycling rate in this area is relatively high. Therefore, a decrease in evapotranspiration leads to a decrease in rainfall amounts. As we have shown, this effect becomes less exaggerated in drier seasons, leading to a decrease in the net effect of deforestation during the drier periods. As latent heat and sensible heat are more likely to be perturbed by fluctuations in turbulent mixing, changes in circulation patterns combined with topographic uplift can change the distribution of these parameters. In agreement with other studies in the tropics, latent heat flux changes are the main driver in temperature change, with increases in temperature occurring at the location of LCC.

The net effect of alterations to net radiation are less widespread, especially when averaging over the whole time period for the whole domain, which smooths out any of the variation that is seen. Particularly in the case of outgoing shortwave radiation, the effects are very localized to the microclimate as albedo increase is the main driver of change. Again, distribution of moisture in the atmosphere is the most important factor for regional changes in the net radiation balance, as cloud cover impacts both incoming longwave and shortwave radiation. This is also highly dependent on storm track patterns along with uplift due to orography.

With this analysis, it becomes apparent that not only deforestation, but the spatial patterns of deforestation coupled with local atmospheric and topographic patterns are important in determining the biophysical effects of deforestation. This analysis was performed on $1 \mathrm{~km}$ grid cell spacing with a model that represents the full dynamics of the 
coupled land-atmosphere system. While modeling the Earth system at this spatial resolution is still too expensive to perform in global scale climate modeling, it is important to note that while we can determine aggregate net impacts of deforestation, linking deforestation with global rainfall patterns through teleconnections will remain difficult until we can more explicitly represent topography and spatial patterns of deforestation in global climate models. 


\section{CHAPTER SIX: CONCLUSIONS}

With this work, we have shown that regional climate, including energy and water cycling, could potentially be significantly altered by deforestation. In particular, we show that for our study area, the net impact of deforestation from the years $2000-2016$ is generally an increase in temperature and a decrease in rainfall amounts, with some variability due to moisture availability and weather patterns for the month in question. We have also shown that the magnitude and sign of these alterations depend on local weather patterns, topography, and spatial patterns of deforestation. This further supports the information gathered in the review of tropical deforestation by Lawrence and Vandecar (2014), who examined studies of deforestation which incorporated a variety of methods to represent land cover change. They show that modeled results of rainfall change depend on a critical thresholds of deforestation amounts, and that deforestation patterns (such as concentrated vs. dispersed deforestation) can determine whether there is an increase in rainfall or a decrease (Lawrence and Vandecar, 2014). While both review papers from Perugini et al. (2017) and Lawrence and Vandecar (2014) describe a variety of deforestation simulations in both GCMs and RCMs, the majority of these model simulations rely on complete deforestation. While our results are consistent with the broader impacts of these continental scale deforestation simulations (i.e. a decrease in rainfall and an increase in temperature at the locations of deforestation), our results capture the variability that a more realistic representation of deforestation brings. As regional and global climate models become increasingly more complex and are able to 
resolve finer resolutions, it is imperative that we incorporate these land-atmosphere interactions due to realistic deforestation on a more localized scale to determine how they will eventually impact (and be impacted by) larger areas of the globe.

There have been some studies that attempt to incorporate more realistic land cover change scenarios. Feddema et al. (2005) and Lejeune et al. (2015), incorporate land cover change from the Integrated Model to Assess the Global Environment (IMAGE) 2.2 from the Intergovernmental Panel on Climate Change Special Report on Emissions Scenarios (Alcamo et al., 1998 and IMAGE team 2001). The IMAGE land cover change scenarios show modeled land cover change for the years 2050 and 2100 for global climate models (IMAGE team 2001). Other methodologies include using vegetation models to deforest only areas suitable for bioenergy potential (Dass et al., 2014), and deforestation of timber concession areas (Roy et al., 2005). Here we offer the first methodology incorporating a global forest cover change dataset with a categorical land cover dataset to further improve our understanding of the impacts of land cover change on the hydroclimate. 


\section{REFERENCES}

Alcamo, J., Leemans, R., \& Kreileman, E. (Eds.). (1998). Global Change Scenarios of the $21^{\text {st }}$ Century. Results from the IMAGE 2.1 Model. London, UK: Pergamon Elsevier Science.

Alkama, R., \& Cescatti, A. (2016). Biophysical climate impacts of recent changes in global forest cover. Science, 351(6273), 600-604.

Australian Geenhouse Office (2002) National Carbon Accounting System Technical Report No. 42. Australian Greenhouse Office and New South Wales Department of Infrastructure, Planning and Natural Resources, Australia.

Beilfuss, R., F. Steinbruch, and R. Owen. (2007). Report prepared for Gorongosa Research Center.

Bestelmeyer, B. T., Ash, A., Brown, J. R., Densambuu, B., Fernández-Giménez, M., Johanson, J., ... Shaver, P. (2017). State and Transition Models: Theory, Applications, and Challenges. In D. D. Briske (Ed.), Rangeland Systems: Processes, Management and Challenges. Cham: Springer International Publishing: 303 - 345.

Betts, A. K. (1986). A new convective adjustment scheme. Part I: Observational and theoretical basis. Quarterly Journal of the Royal Meteorological Society, 112 (473). John Wiley \& Sons, Ltd: 677-91.

Betts, A. K., and M. J. Miller. (1986). A new convective adjustment scheme. Part II: Single column tests using GATE Wave, BOMEX, ATEX and Arctic Air-Mass data sets. Quarterly Journal of the Royal Meteorological Society, 112 (473). John Wiley \& Sons, Ltd: 693-709.

Bonan, G. B. (2008). Forests and climate change: forcings, feedbacks, and the climate benefits of forests. Science, 320(5882), 1444-1449. 
Bowman, A. W., and A. Azzalini. (1997). Applied smoothing techniques for data analysis. New York: Oxford University Press Inc.

Broxton, P. D., Zeng, X., Sulla-Menashe, D., \& Troch, P. A. (2014). A Global Land Cover Climatology Using MODIS Data. Journal of Applied Meteorology and Climatology, 53(6), 1593-1605.

Dass, P., Müller, C., Brovkin, V., \& Cramer, W. (2013). Can bioenergy cropping compensate high carbon emissions from large-scale deforestation of high latitudes? Earth System Dynamics, 4(2), 409-424.

Feddema, J. J., Oleson, K. W., Bonan, G. B., Mearns, L. O., Buja, L. E., Meehl, G. A., \& Washington, W. M. (2005). The importance of land-cover change in simulating future climates. Science, 310(5754), 1674-1678.

Friedl, M. A., Sulla-Menashe, D., Tan, B., Schneider, A., Ramankutty, N., Sibley, A., \& Huang, X. (2010). MODIS Collection 5 global land cover: Algorithm refinements and characterization of new datasets. Remote Sensing of Environment, 114(1), $168-182$.

Galvin, J. F. P. (2008). The weather and climate of the tropics: Part 6 - Monsoons. Weather, 63(5), 129-137.

Getis, A., \& Ord, J. K. (1992). The analysis of spatial association by use of distance statistics. Geographical Analysis, 24(3), 189-206.

Giri, C., Zhu, Z., \& Reed, B. (2005). A comparative analysis of the Global Land Cover 2000 and MODIS land cover data sets. Remote Sensing of Environment, 94(1), $123-132$.

Hanlon, J. (2011). Understanding land investment deals in Africa: Country report, Mozambique. Oakland, CA: The Oakland Institute.

Hansen, M. C., Potapov, P. V., Moore, R., Hancher, M., Turubanova, S. A., Tyukavina, A., ... Townshend, J. R. G. (2013). High-resolution global maps of 21st-century forest cover change. Science, 342(6160), 850-853.

Herold, M., Mayaux, P., Woodcock, C. E., Baccini, A., \& Schmullius, C. (2008). Some challenges in global land cover mapping: An assessment of agreement and 
accuracy in existing $1 \mathrm{~km}$ datasets. Remote Sensing of Environment, 112(5), $2538-2556$.

Hill, P. D. (1985). Kernel estimation of a distribution function. Communications in Statistics - Theory and Methods, 14(3), 605-620.

Hong, S.-Y., Lim, K.-S. S., Lee, Y.-H., Ha, J.-C., Kim, H.-W., Ham, S.-J., \& Dudhia, J. (2010). Evaluation of the WRF double-moment 6-class microphysics scheme for precipitating convection. Advances in Meteorology, 2010. https://doi.org/10.1155/2010/707253

IMAGE team (2001) The IMAGE 2.2 implementation of the SRES scenarios: a comprehensive analysis of emissions, climae change and impacts in the $21^{\text {st }}$ century. RIVM CD_ROM Publication 4810508019, National Institute of Public health and the Environment, Bilthoven

Janjic, Zavisa I. (1994). The step-mountain eta coordinate model: Further developments of the convection, viscous sublayer, and turbulence closure schemes. American Meteorological Society, 122 (May): 927-44.

Jones, M. C. (1993). Simple boundary correction for kernel density estimation. Statistics and Computing, 3(3), 135-146.

Kendall, M. G. (1938). A new measure of rank correlation. Biometrika, 30(1-2), 81-93.

Keys, P. W., Ent, R. J. van der, Gordon, L. J., Hoff, H., Nikoli, R., \& Savenije, H. H. G. (2012). Analyzing precipitationsheds to understand the vulnerability of rainfall dependent regions. Biogeosciences , 9(2), 733-746.

Latifovic, R., \& Olthof, I. (2004). Accuracy assessment using sub-pixel fractional error matrices of global land cover products derived from satellite data. Remote Sensing of Environment, 90(2), 153-165.

Lawrence, D., \& Vandecar, K. (2014). Effects of tropical deforestation on climate and agriculture. Nature Climate Change, 5, 27. 
Lee, X., Goulden, M. L., Hollinger, D. Y., Barr, A., Black, T. A., Bohrer, G., ... Zhao, L. (2011). Observed increase in local cooling effect of deforestation at higher latitudes. Nature, 479(7373), 384-387.

Lejeune, Q., Davin, E. L., Guillod, B. P., \& Seneviratne, S. I. (2015). Influence of Amazonian deforestation on the future evolution of regional surface fluxes, circulation, surface temperature and precipitation. Climate Dynamics, 44(9), 2769-2786.

Loveland, T. R., Reed, B. C., Brown, J. F., Ohlen, D. O., Zhu, Z., Yang, L., \& Merchant, J. W. (2000). Development of a global land cover characteristics database and IGBP DISCover from $1 \mathrm{~km}$ AVHRR data. International Journal of Remote Sensing, 21(6), 1303-1330.

Mahmood, R., Quintanar, A. I., Conner, G., Leeper, R., Dobler, S., Pielke, R. A., ... Syktus, J. (2010). Impacts of land use/land cover change on climate and future research priorities. Bulletin of the American Meteorological Society, 91(1), 37-46.

National Research Council, Division on Earth and Life Studies, Board on Atmospheric Sciences and Climate, Climate Research Committee, \& Committee on Radiative Forcing Effects on Climate. (2005). Radiative Forcing of Climate Change: Expanding the Concept and Addressing Uncertainties. National Academies Press. Niu, G.-Y., Yang, Z.-L., Mitchell, K. E., Chen, F., Ek, M. B., Barlage, M., ... Xia, Y. (2011). The community Noah land surface model with multiparameterization options (Noah-MP): 1. Model description and evaluation with local-scale measurements. Journal of Geophysical Research, 116(D12), D12109.

Perugini, L., Caporaso, L., Marconi, S., Cescatti, A., Quesada, B., de Noblet-Ducoudré, N., ... Arneth, A. (2017). Biophysical effects on temperature and precipitation due to land cover change. Environmental Research Letters: ERL [Web Site], $12(5), 053002$. 
Pielke, R. A., Sr. (2005). Atmospheric science, land use and climate change. Science, 310(5754), 1625-1626.

Pulsford, S. A., Lindenmayer, D. B., \& Driscoll, D. A. (2016). A succession of theories: purging redundancy from disturbance theory. Biological Reviews of the Cambridge Philosophical Society, 91(1), 148-167.

Roy, S. B., Walsh, P. D., \& Lichstein, J. W. (2005). Can logging in equatorial Africa affect adjacent parks? Ecology and Society, 10(1). Retrieved from http://www.jstor.org/stable/26267734

Sheffield, J., Wood, E. F., Chaney, N., Guan, K., Sadri, S., Yuan, X., ... Ogallo, L. (2013). A drought monitoring and forecasting system for Sub-Sahara African water resources and food security. Bulletin of the American Meteorological Society, 95(6), 861-882.

Siam, M. S., Demory, M. E., \& Eltahir, E. A. B. (2013). Hydrological cycles over the Congo and Upper Blue Nile Basins: Evaluation of general circulation model simulations and reanalysis products. Journal of Climate, 26(22), 8881-8894.

Silverman, B. W. (1986). Density estimation for statistics and data analysis. Chapman \& Hall/CRC.

Skamarock, W. C., Klemp, J. B., Dudhia, J., Gill, D. O., Barker, D. M., Duda, Huang, X., Wang, W., and Powers, J. G. (2008). A Description of the Advanced Research WRF Version 3. No. TN-475+STR. Boulder, CO: National Center for Atmospheric Research.

Smith, J. H., Wickham, J. D., Stehman, S. V., \& Yang, L. (2002). Impacts of patch size and land-cover heterogeneity on thematic image classification accuracy. Photogrammetric Engineering and Remote Sensing, 68(1), 65-70.

Smith, J. H., Stehman, S. V., Wickham, J. D., \& Yang, L. (2003). Effects of landscape characteristics on land-cover class accuracy. Remote Sensing of Environment, 84(3), 342-349. 
Steinbruch, F. (2010). Geology and geomorphology of the Urema Graben with emphasis on the evolution of Lake Urema. Journal of African Earth Sciences, 58(2), 272284.

Surussavadee, C., \& Aonchart, P. (2013). Evaluation of WRF physics options for highresolution weather forecasting in tropics using satellite passive millimeter-wave observations. In Geoscience and Remote Sensing Symposium (IGARSS), 2013 IEEE International (pp. 2262-2265).

The NCAR Command Language (Version 6.4.0) [Software]. (2017). Boulder, Colorado: UCAR/NCAR/CISL/TDD. http://dx.doi.org/10.5065/D6WD3XH5

Tinley, K. L. (1977). Framework of the Gorongosa ecosystem. Unpublished DSc Thesis. University of Pretoria.

Trenberth, K. E. (1999). Atmospheric Moisture Recycling: Role of Advection and Local Evaporation. Journal of Climate, 12(5), 1368-1381.

Westoby, M., Walker, B., \& Noy-Meir, I. (1989). Opportunistic management for rangelands not at equilibrium. Rangeland Ecology \& Management / Journal of Range Management Archives, 42(4), 266-274. 
APPENDIX A: LOCATIONS OF MODEL OUTPUT AND PROCESSING SCRIPTS 
For future studies, the model output and processing scripts used for this project are located in the following locations:

\section{Model Output}

Two analyses were performed: a small sensitivity analysis with randomized vegetation (results shown in Appendix C), as well as the full model runs used in the majority of this study. As of May 2018, model output from the sensitivity analysis is located on the Payette server in the Department of Geosciences. The full model run output is located on the BroncoNet01 server at Boise State University, at /research/wrf_mz.

\section{Script Archive}

All scripts are archived on Github at: https://github.com/LEAF-BoiseState/WRFMZ. A repository describing the methodology for the data fusion process is also located here. 
APPENDIX B: SUPPLEMENTAL FIGURES 
The following figures are the same as those shown in Section 4.1, Regional Analysis, but for the year 2015 .
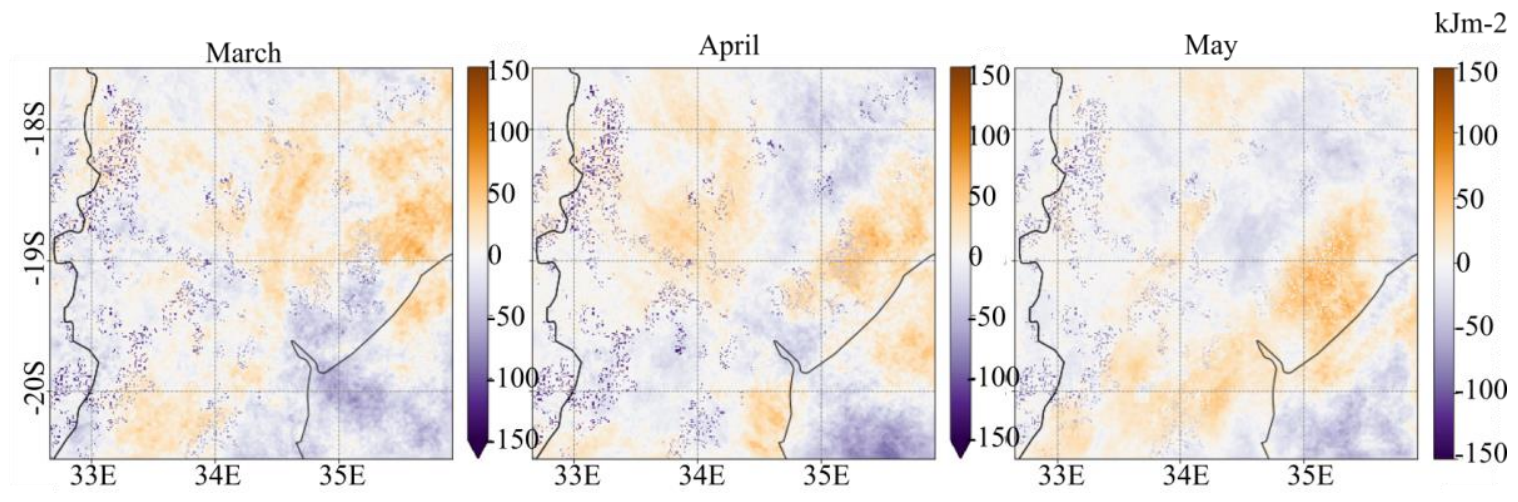

Figure 34. Monthly change in modeled net radiation due to LCC, 2015.
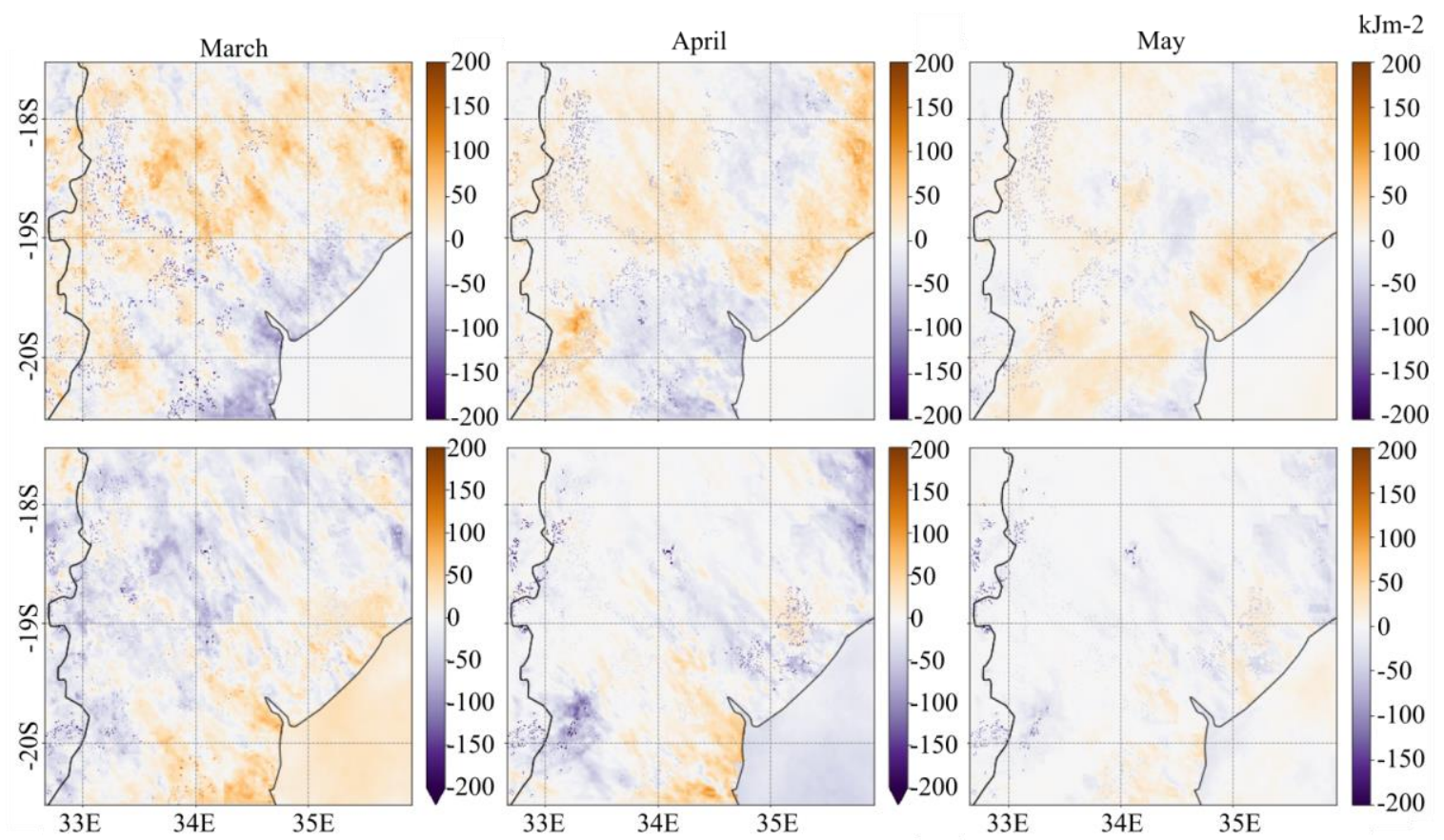

Figure 35. Monthly change in modeled upward sensible heat flux at the surface (top panel) and upward latent heat flux at the surface (bottom panel), 2015, due to LCC. 

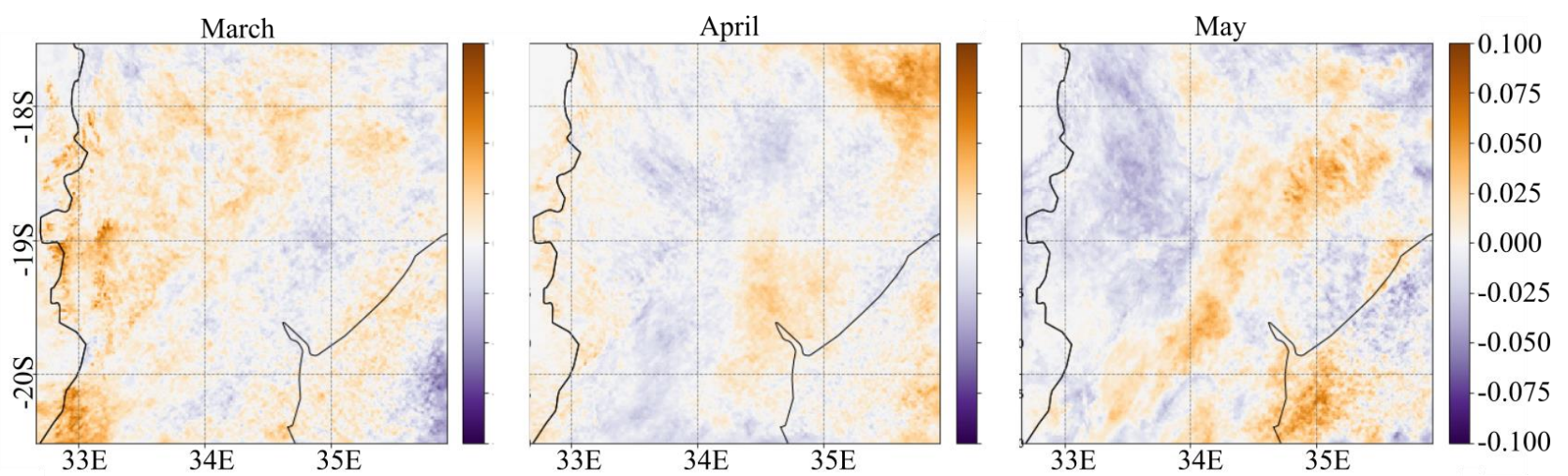

Figure 36. Monthly change in modeled cloud cover fraction due to LCC, 2015.

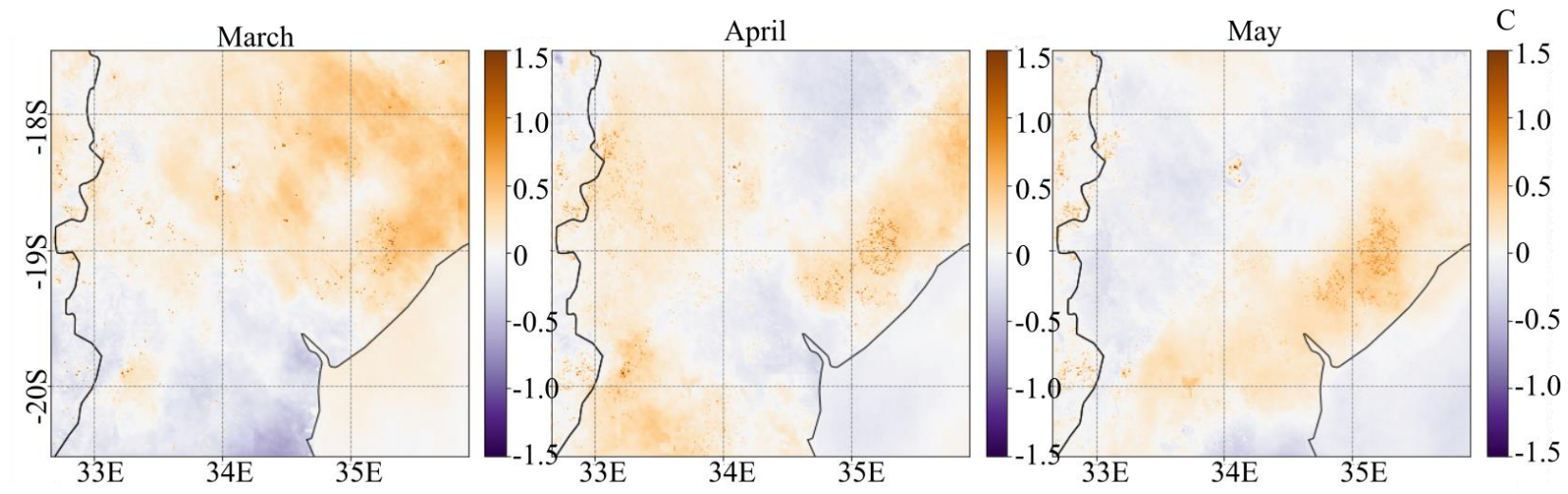

Figure 37. Monthly change in modeled temperature at 2 meters due to LCC, 2015.
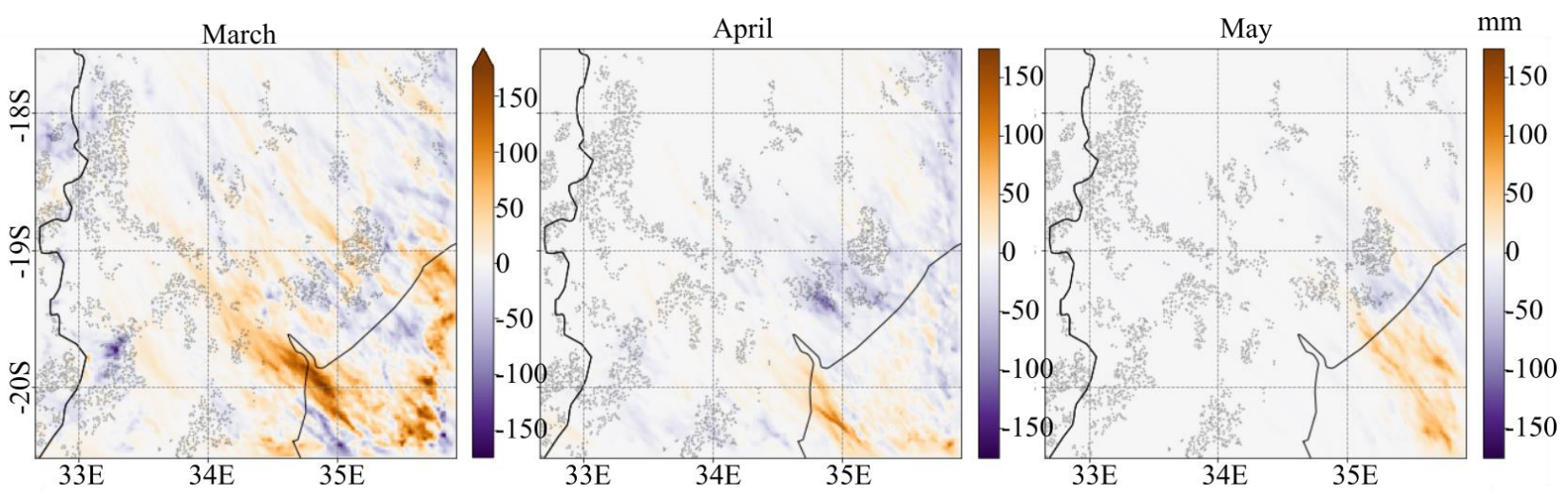

Figure 38. Monthly change in modeled accumulated rainfall, 2001, with LCC pixels shown in black. 
APPENDIX C: SENSITIVITY ANALYSIS 


\section{Background}

To plan for the final runs, we first completed a small sensitivity analysis for the same domain. Within this study, the same WRF model parameterization was implemented as the final runs. The time period in this sensitivity analysis was for the month of July 2013 (the dry season), with a one month spin-up. For these modeling scenarios, we used the same control run, but implemented a randomized land cover set up, shown in Figure 35. In this randomized scenario, each pixel of land cover from the WRF model (excluding water pixels) was randomly moved. In this way we could examine the role of spatial patterns in deforestation.

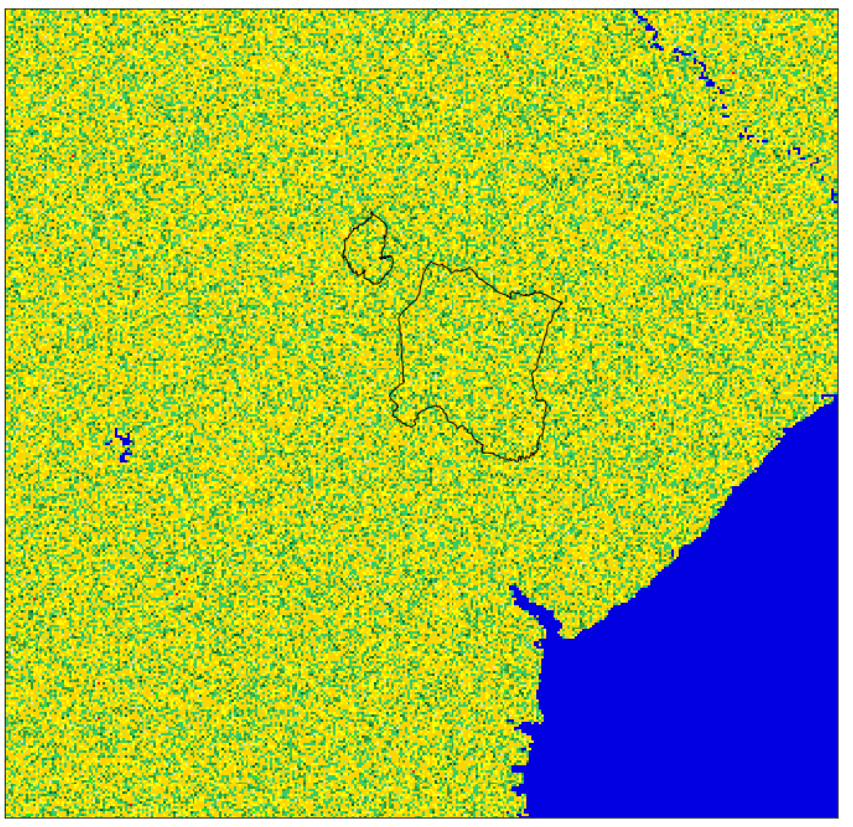

Barren or Sparsely Vegetated
Water Bodies
Mixed Forest
Evergreen Broadleaf
Deciduous Broadleaf Forest
Savanna
Grassland
Cropland/Woodland Mosaic
Cropland/Grassland Mosaic
Dryland Cropland and Pasture
Urban and Built-up Land

Figure 39. Randomized land cover used in modified scenario for the sensitity analysis.

\section{Results}

To analyze this data, we averaged the domain-wide variables and plotted the time series for both the control ("standardized") run and the randomized run. 


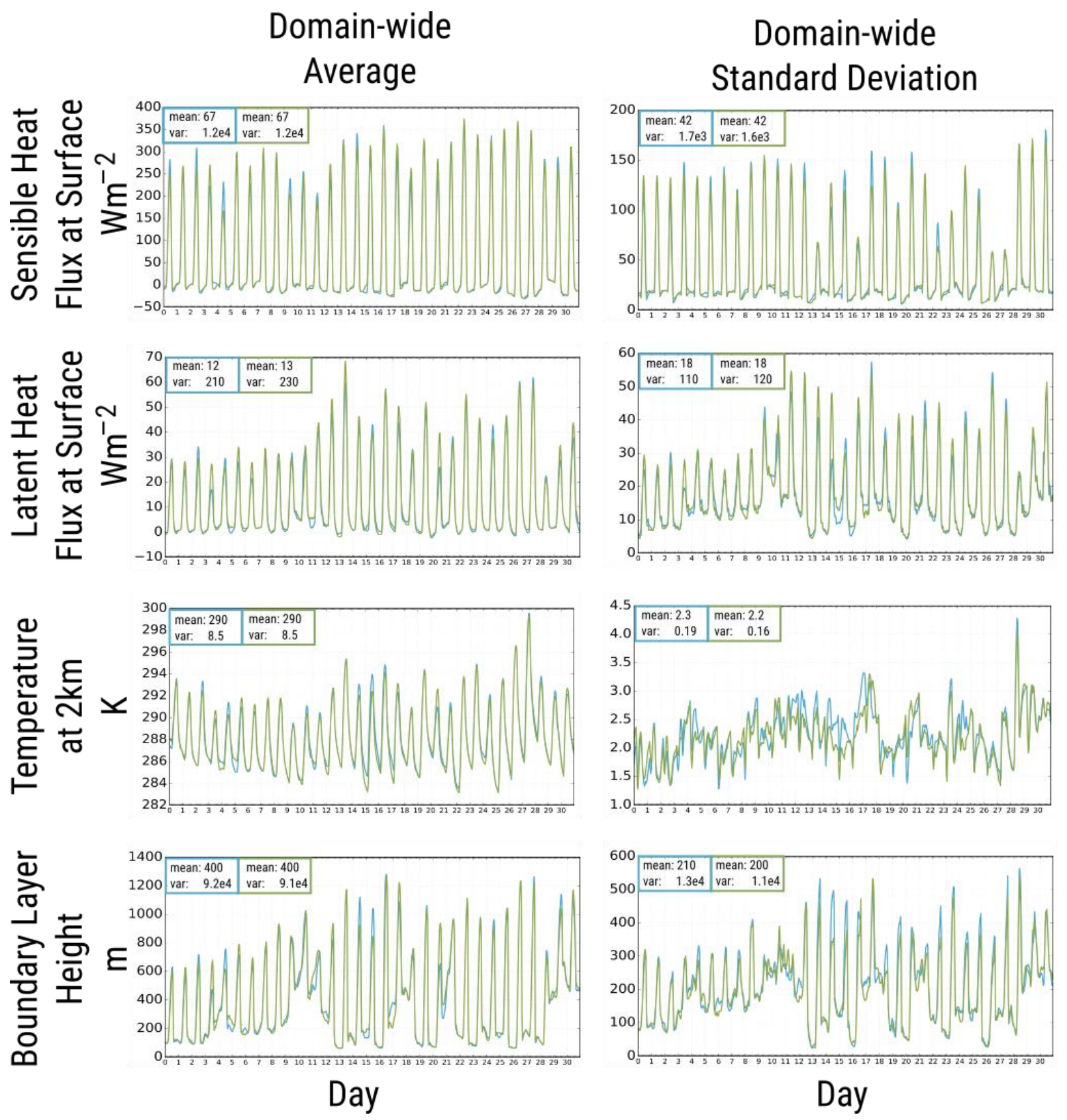

Figure 40. Time series data for specified variables for the whole domain. Control run in blue and randomized land cover run in green. 


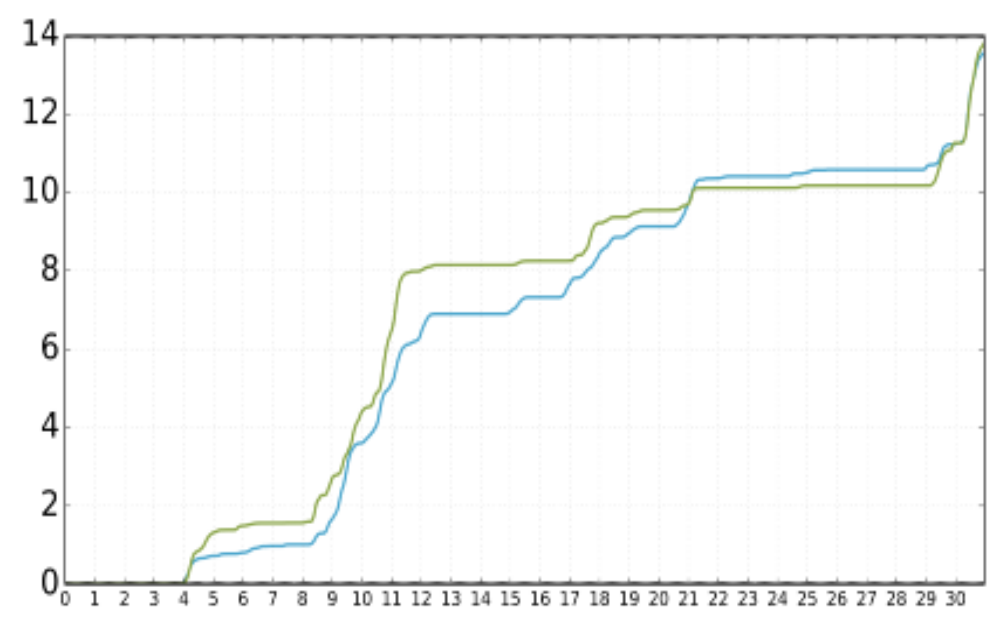

\section{Figure 41. Domain-wide acumulated rainfall in $\mathrm{mm}$. Control run in blue and randomized land cover run in green.}

\section{Conclusions}

From this analysis, we saw very little difference when we look at the time series of each data. It was also a relatively dry month. We used these results to inform the setup of our final run and analyses methods. From this, we decided to look more at spatial patterns of deforestation and the resultant energy and water balance changes, as well as both wetter and drier time periods. 